Portland State University

PDXScholar

Spring 6-3-2013

\title{
Nursing Student Anxiety in Simulation Settings: A Mixed Methods Study
}

Mary Louise Cato

Portland State University

Follow this and additional works at: https://pdxscholar.library.pdx.edu/open_access_etds

Part of the Educational Leadership Commons

Let us know how access to this document benefits you.

\section{Recommended Citation}

Cato, Mary Louise, "Nursing Student Anxiety in Simulation Settings: A Mixed Methods Study" (2013). Dissertations and Theses. Paper 1035.

https://doi.org/10.15760/etd.1035

This Dissertation is brought to you for free and open access. It has been accepted for inclusion in Dissertations and Theses by an authorized administrator of PDXScholar. Please contact us if we can make this document more accessible: pdxscholar@pdx.edu. 
Nursing Student Anxiety in Simulation Settings:

A Mixed Methods Study

\author{
by \\ Mary Louise Cato
}

A dissertation submitted in partial fulfillment of the requirements for the degree of

\title{
Doctor of Education
}

in

Educational Leadership: Postsecondary Education

\author{
Dissertation Committee: \\ Candyce Reynolds, Chair \\ Andrew Job \\ Dannelle Stevens \\ Leslie McBride
}

Portland State University

2013 
(C) 2013 Mary Louise Cato 


\title{
NURSING STUDENT ANXIETY IN SIMULATION SETTINGS
}

\begin{abstract}
The use of simulation as a clinical learning activity is growing in nursing programs across the country. Using simulation, educators can provide students with a realistic patient situation using mannequins or actors as patients in a simulated environment. Students can practice multiple aspects of patient care without the risk of making mistakes with real patients, and faculty can reinforce course objectives and evaluate student learning. Because of the technology, the environment, and the methods by which simulation is implemented, it may cause anxiety in learners, which may interfere with the learning process. Anxious students may miss an opportunity for learning valuable aspects of nursing care that are reinforced in simulation.

This paper will describe a study of the student perspective on simulation, particularly related to the anxiety experienced by many learners. Nursing students in a baccalaureate program who participate in simulation in their clinical courses were recruited for the study, which consisted of a survey and a focus group. Participants were asked to rate nineteen aspects of simulation in regards to the feelings they elicit, from confidence to anxiety. The survey, completed by 73 of the 178 eligible participants, also included open-ended questions in which students could elaborate on their responses. A focus group was held after the survey, during which nine volunteer participants were asked further questions about their feelings and reactions in simulation, specifically as related to their effect on learning. During a facilitated discussion, they also offered
\end{abstract}




\section{NURSING STUDENT ANXIETY IN SIMULATION SETTINGS}

suggestions for interventions that they believed would decrease their anxiety and improve the learning environment in simulation.

After an analysis of the data, a “comfort-stretch-panic” model (Palethorpe \& Wilson, 2011) emerged as a useful framework for understanding the student perspective. Students in the "stretch” zone, in which they perceived a manageable amount of stress, were motivated to perform and experienced optimal learning from the simulation session. The student suggestions for interventions which would aid their learning may be useful for transitioning them into the "stretch" zone, and should be considered as potential tools in simulation practice. 
NURSING STUDENT ANXIETY IN SIMULATION SETTINGS

\section{Acknowledgements}

I am indebted to a number of people for their assistance and support during my dissertation work. The faculty in the Graduate School of Education were inspirational from the first course through the last. The colleagues in my cohort impressed me with their knowledge and skills, and I feel privileged to have been on this journey with them. My advisor and dissertation chair, Dr. Candyce Reynolds, continuously challenged me and encouraged me to think more deeply, and my committee provided me with helpful ideas for my research. My colleagues at OHSU were supportive and understanding of the energy and effort needed to pursue my interests in student perspectives on learning. The students I work with every day continue to motivate me to be a better teacher, and I appreciate their willingness to share their thoughts and ideas for this study. And, last but not least, I am grateful to my friends and family for sustaining me through this process. 


\section{NURSING STUDENT ANXIETY IN SIMULATION SETTINGS}

\section{Table of Contents}

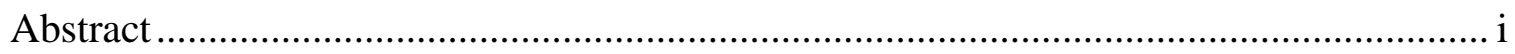

Acknowledgements.............................................................................................. iii

List of Tables …................................................................................................ vii

Chapter 1 - Overview and Conceptualization of the Research ....................................... 1

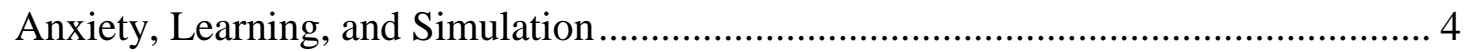

Background of the Problem in Practice......................................... 8

The Research Problem......................................................... 9

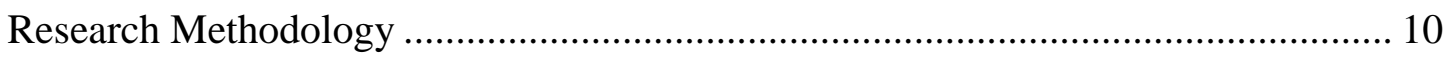

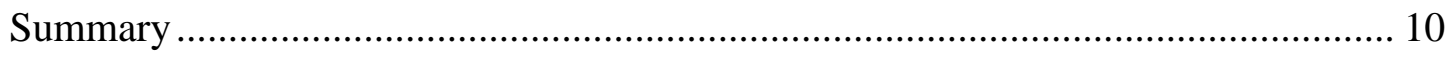

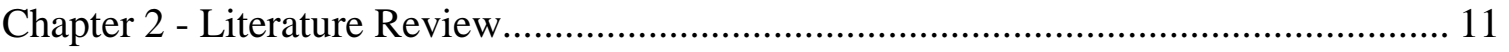

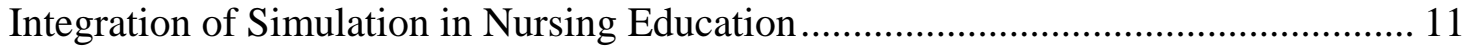

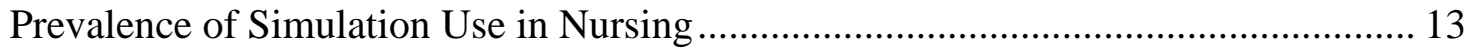

Rationale and Evidence for Effectiveness of Simulation ........................................ 15

Evidence for Effectiveness of Simulation............................................................. 26

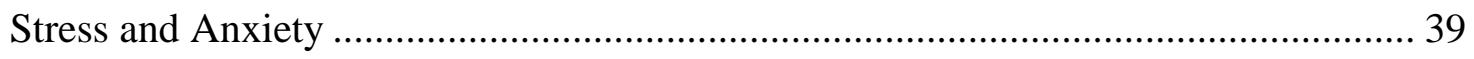

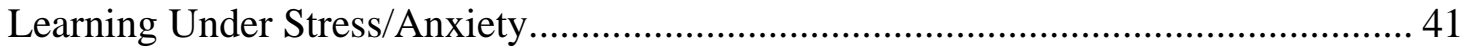

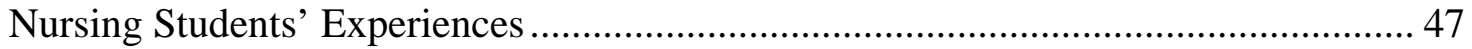

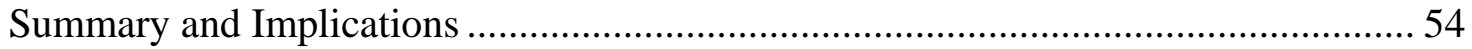

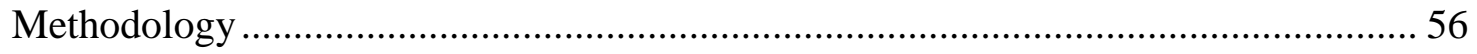

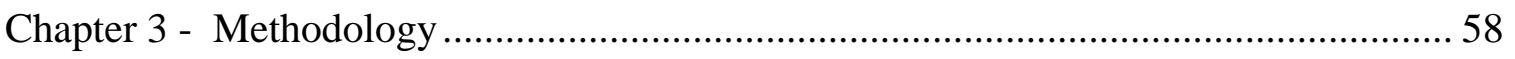

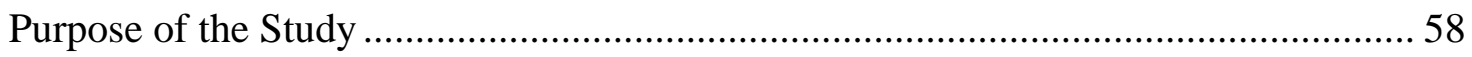

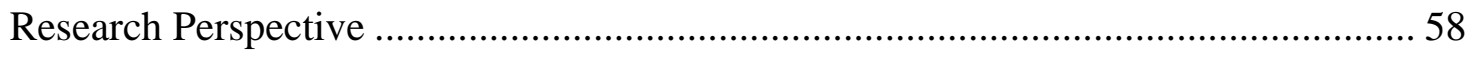

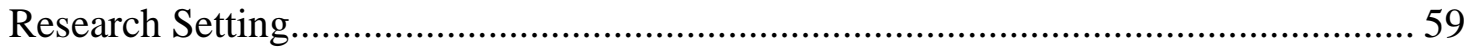

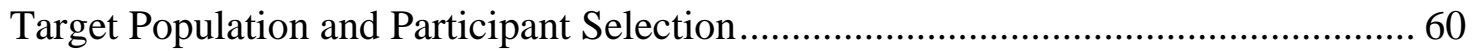

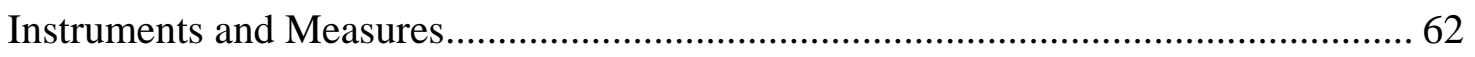

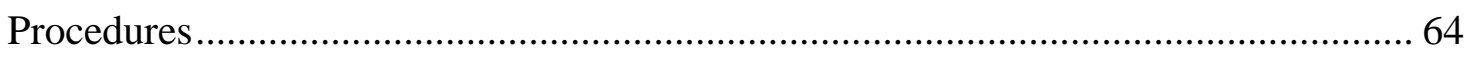

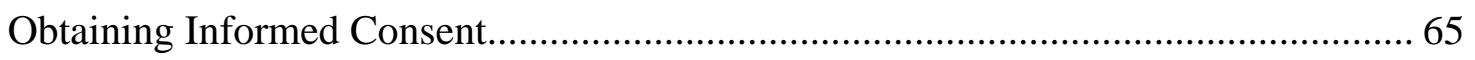

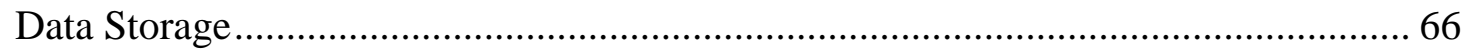




\section{NURSING STUDENT ANXIETY IN SIMULATION SETTINGS}

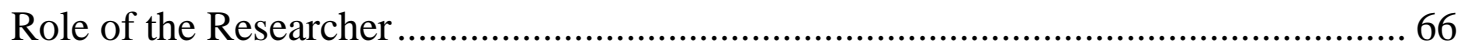

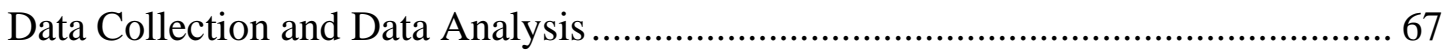

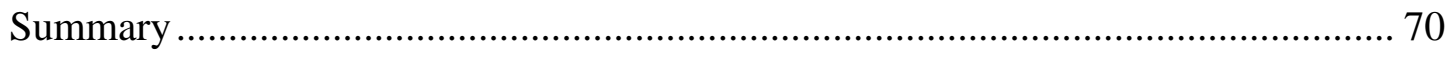

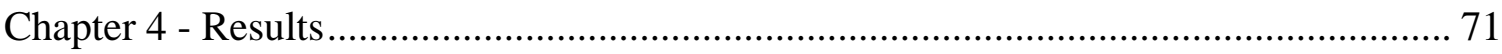

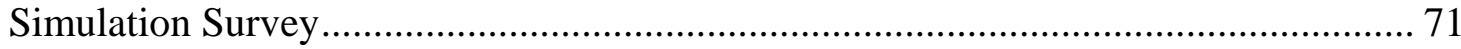

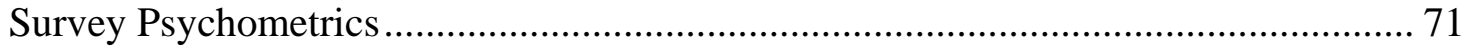

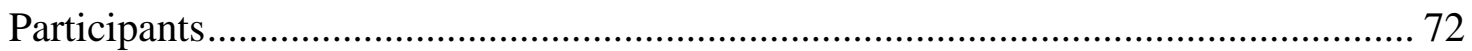

Relationship of Responses to Student Characteristics ........................................... 75

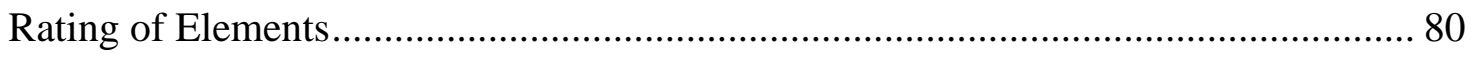

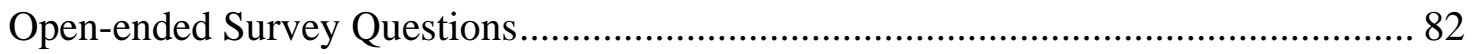

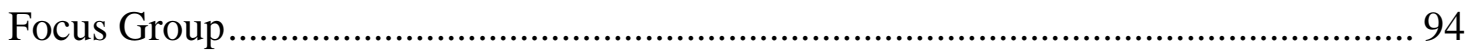

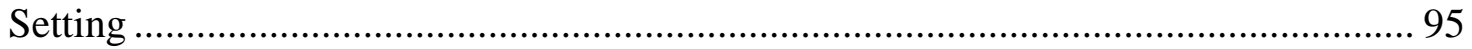

“Draw Yourself in Simulation” Activity ............................................................... 95

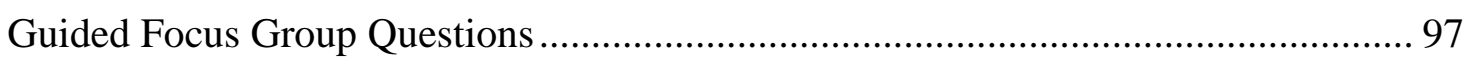

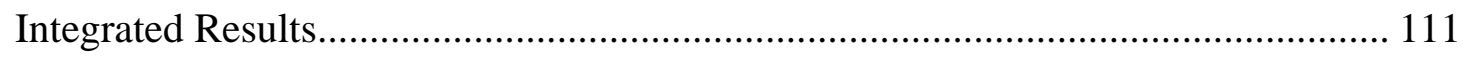

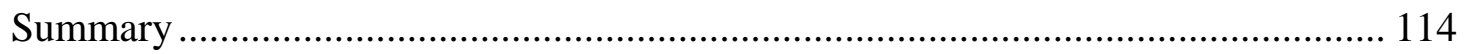

Chapter 5 - Summary, Conclusions, Implications …................................................. 115

Themes Derived From Data .................................................................................. 116

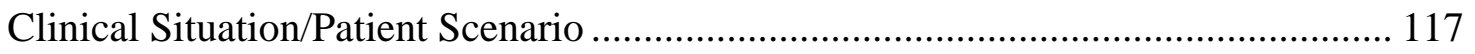

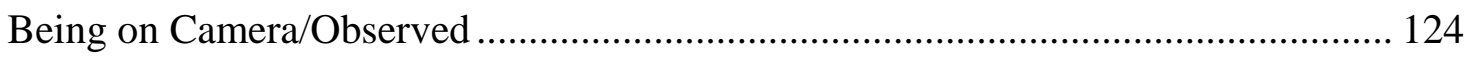

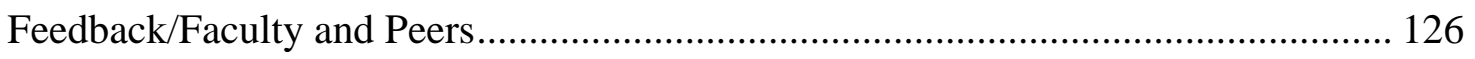

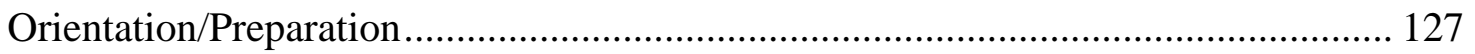

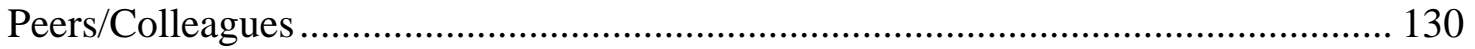

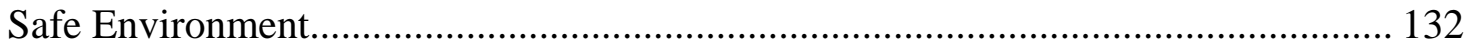

Challenges/Prepares for Real Life ................................................................. 134

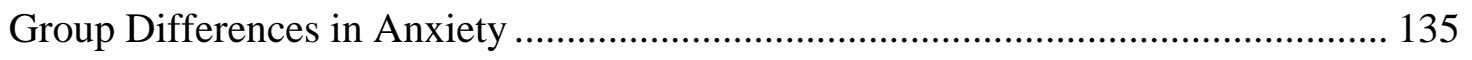

Working with Medical Equipment-Gender ........................................................ 136

The Preparation Beforehand - Late in Program Vs. Early in.................................. 136

Working with Medical Equipment - Accelerated Program Vs. 3-year Program........ 137

Working with Mannequin - Accelerated Vs. 3-year Program ................................. 137 


\section{NURSING STUDENT ANXIETY IN SIMULATION SETTINGS}

Administering Medications - Accelerated Vs. 3-year Program.................................. 138

Differences in Accelerated Vs. 3-year Program Students ...................................... 139

Research Aims.......................................................... 141

Implementing the Findings: A Broad Perspective ............................................. 141

Implementing the Findings: Student Suggestions .............................................. 144

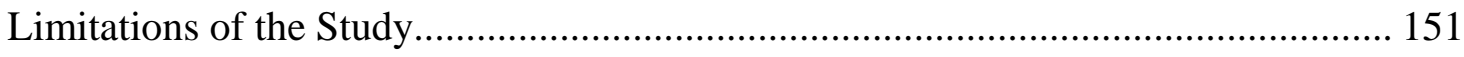

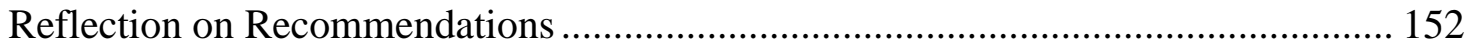

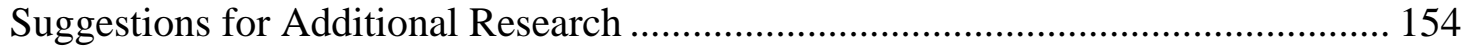

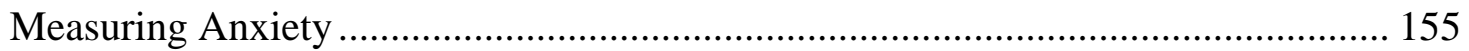

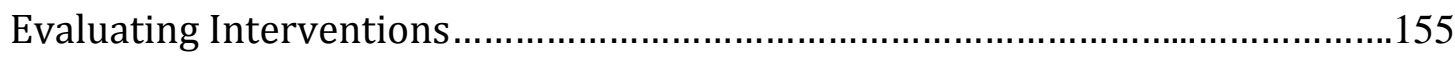

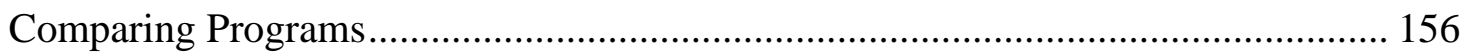

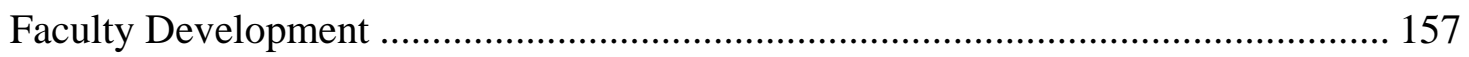

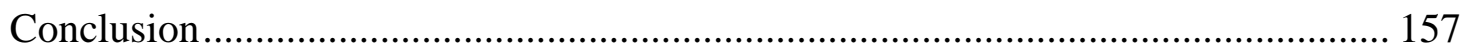

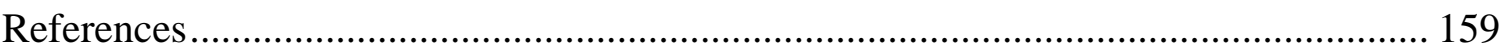

Appendix A - Informed Consent for Research Study, Survey...................................... 170

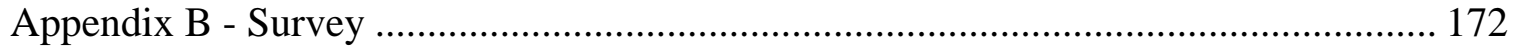

Appendix C - Informed Consent for Research Study, Focus Group ........................... 175 


\section{NURSING STUDENT ANXIETY IN SIMULATION SETTINGS}

\section{List of Tables}

3.1 Students Eligible for Simulation Study............................. 61

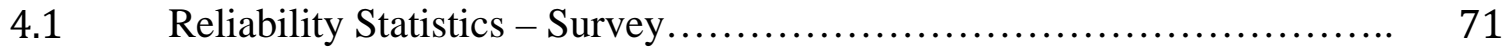

4.2 Numbers of Nursing Students Completing Survey..................... 72

$4.3 \quad$ Number of Survey Respondents with Previous Degree................... 73

4.4 Prior Work Experience of Survey Respondents........................ 74

$4.5 \quad$ Age Ranges of Survey Respondents................................ 74

4.6 Differences in Survey Responses Based on Program /Time in Program.... 76

$4.7 \quad$ Anxiety Scores - Elements of Simulation............................ 81

4.8 Themes for Confidence-building Elements / Respondents Mentioning..... 84

4.9 Themes for Anxiety-Related Elements and Respondents Mentioning..... 89

4.10 Frequency of Feelings Identified by Participants........................ 98

$4.11 \quad$ Causes of Anxiety and Times Mentioned.............................. 99

4.12 Causes of Calm/Relaxed/Confident Feelings and Times Mentioned........ 99

4.13 Themes/Helps Anxiety or Increases Confidence.......................... 102

4.14 Student Recommendations to Improve Learning in Simulation............ 106

5.1 Themes-Sources of Anxiety and Confidence........................... 117

5.2 Comfort-Stretch-Panic Model in Simulation............................. 142 


\section{NURSING STUDENT ANXIETY IN SIMULATION SETTINGS}

\section{Chapter 1 - Overview and Conceptualization of the Research}

Technology is allowing nurse educators to develop creative techniques to teach students the knowledge and skills they will need to practice their profession. Due to a national nursing shortage, an increase in the number of nursing education programs, and a shortage of clinical learning sites, many nursing programs are utilizing simulation to help students learn the roles and responsibilities of the nurse. These teaching tools include the use of a simulated clinical environment in which students practice with mannequins or actors as patients and may include being observed via cameras by faculty and colleagues. The equipment and methodology support learning, but may also cause stress and anxiety for some students, which may in turn impact their ability to learn.

Simulation, as utilized in nursing education, is defined as an "attempt to replicate some or nearly all of the essential aspects of a clinical situation so that the situation may be more readily understood and managed when it occurs for real in clinical practice” (Morton, 1995, p. 76). The term "simulation" is often used to describe learning activities that are based on use of a high-fidelity mannequin designed to respond physiologically in ways similar to a human. Faculty in both nursing and medical schools, however, may also use other types of simulation, including role-playing, standardized patients or actors, and lower fidelity (or less realistic) mannequins intended for training of a specific skill. Typically, a simulation consists of a student or group of students providing care for a simulated patient, who is represented by a mannequin or an actor, depending on the clinical situation. Often, simulation is an activity in which students participate in groups in a planned patient care scenario and are observed by faculty and colleagues. The patient 


\section{NURSING STUDENT ANXIETY IN SIMULATION SETTINGS}

care scenario is followed by a reflection, or debriefing period, during which the case is deconstructed and analyzed and feedback is given to the participants by faculty and other students. Simulation is usually used to complement clinical learning that is done in patient care environments such as hospitals, clinics, long-term care centers and community settings.

Nursing education literature substantiates the fact that simulation is becoming increasingly common as a clinical learning tool (Jeffries, 2007; Kaakinen \& Arwood, 2009; Sinclair \& Ferguson, 2009). The National Council of State Boards of Nursing did a national survey of the use of simulation in nursing education in 2010. The results from 1,060 pre-licensure nursing programs revealed that $87 \%$ used simulation, and most respondents reported integrating simulation into five or more courses. The majority of respondents (81\%) also thought they should be using more simulation but faced barriers such as lack of faculty training and cost (Hayden, 2010).

There is increasing evidence in the literature that simulation can be an effective means to promote learning in nursing and other healthcare professions. Simulation has been demonstrated to be effective in improving student cognitive skills and critical thinking (Elfrink, Kirkpatrick, Nininger, \& Schubert, 2010; Kaddoura, 2010), selfconfidence and self-efficacy, (Blum, Borglund, \& Parcells, 2010; Wagner, Bear, \& Sander, 2009; Schoening, Sittner, \& Todd, 2006; Sinclair \& Ferguson, 2009), clinical skills and clinical performance (Alinier, Hunt, Gordon, \& Harwood, 2006; Anderson \& Warren, 2011; Meyer, Connors, Hou, \& Gajewski, 2011), safe medication administration (Sears, Goldsworthy, \& Goodman, 2010), and leadership skills (Reed, Lancaster, 


\section{NURSING STUDENT ANXIETY IN SIMULATION SETTINGS}

\&Musser, 2009). As students graduate and enter the practice arena, simulation has been used to help them transition into professional practice (Chappy, 2010; Stefanski \& Rossler, 2009). Also, in the interest of patient safety, simulation is used to facilitate teamwork and communication both inter- and intra-professionally (Kuehster \& Hall, 2010). Focusing on the affective domain, others have used simulation to promote learning in the areas of cultural diversity and caring (Haas, Seckman, \& Rea, 2010; Eggenberger, Keller, \& Locsin, 2010; Storr, 2010), nursing care at end-of-life (Hamilton, 2010; SmithStoner, 2009), and ethical decision-making (Gropelli, 2010).

Because it is a practice discipline, nursing must be taught not only in the classroom, but in clinical areas as well. Students need to apply the knowledge learned, practice the necessary skills, and incorporate the behaviors needed to practice nursing in a real environment. Simulation has been incorporated into nursing education because it allows students to “engage in the same critical thinking and clinical decision-making skills required in actual clinical practice” (Sinclair \& Ferguson, 2009, p. 1). When utilized as a clinical learning activity, simulation builds upon what students know and allows them to demonstrate their knowledge and skills in a safe learning environment by providing "a wide range of experiences that are either too rare or too risky for novices to engage in using actual patients” (Hovancsek, 2007, p. 3). With deliberate planning, thoughtful curricular integration, and support from faculty, simulation can help bridge the gap between the classroom and the patient care environment.

Some students report anxiety in simulation that may affect learning. Cordeau (2010) examined the experience of novice nursing students who were involved in a 


\section{NURSING STUDENT ANXIETY IN SIMULATION SETTINGS}

graded clinical simulation activity. Several themes were identified by the students, including perceived anxiety that occurred "during all levels of the process” (Cordeau, p. 14.) Walton, Chute, and Ball (2011) examined the student perspective of simulation in a grounded theory study. Students reported high levels of anxiety with all simulations, though this reportedly decreased with continued practice. Lasater (2007) reported that students experienced heightened anxiety levels while in simulation, particularly related to the anticipation of an unexpected event.

There is evidence that the stress of simulation may be problematic for those learning to become nurses. Simulation (or practicing clinical nursing in a simulated environment) has been integrated into many nursing curricula, and has been proven to be an effective learning activity. Yet, some students experience such high stress levels in a simulation environment that their learning is compromised. Unless they receive support, students may not obtain the maximum learning benefits possible in the simulation component of their curriculum.

\section{Anxiety, Learning, and Simulation}

In order to understand the problems of stress and anxiety related to simulation, several definitions and explanations will be useful. The relationship between stress and anxiety is important to understand. Stress is "a physical, chemical, or emotional factor that causes bodily or mental tension and may be a factor in disease causation," or "a state resulting from a stress; especially: one of bodily or mental tension resulting from factors that tend to alter an existent equilibrium” (Merriam-Webster.com, 2011). 


\section{NURSING STUDENT ANXIETY IN SIMULATION SETTINGS}

Anxiety is "painful or apprehensive uneasiness of mind usually over an impending or anticipated ill," "fearful concern or interest,” and “an abnormal and overwhelming sense of apprehension and fear often marked by physiological signs (as sweating, tension, and increased pulse), by doubt concerning the reality and nature of the threat, and by self-doubt about one's capacity to cope with it” (Merriam-Webster.com, 2011). Stress and anxiety are related. Stress can come from any situation or thought that makes a person frustrated or angry, and stress responses can differ from person to person. Anxiety is a feeling of apprehension or fear; it is the psychophysiologic signal that the stress response has been initiated (Robinson, 1990). Stress is normal, and can have the positive effect of motivating an individual to action. An excess of stress, however, is harmful, and can cause physical symptoms such as pain, dizziness, headaches, muscle tension, sweating, decreased concentration, and trembling (MedLine Plus, 2011).

Learning to manage their anxiety in simulation may help students in areas beyond the simulation environment. The practice of nursing exposes students to a number of stressors, including patient situations, critical events, and communication challenges. Many of these situations cause anxiety, particularly for new practitioners. By helping students manage anxiety in simulation, faculty may be helping them learn to provide better patient care by dealing with the stress of a "real" patient care environment. Showing concern for students experiencing anxiety also reinforces the caring nature of nursing, as modeled by faculty.

Faculty may have other reasons for helping anxious students. In nursing programs where simulation has been integrated into the curriculum, all students are expected to 


\section{NURSING STUDENT ANXIETY IN SIMULATION SETTINGS}

participate. One of the benefits of simulation is that all students can be exposed to the same clinical event, with the intention of integrating what they have learned into practice. Simulation activities may be integral to meeting course objectives. If a student experiences too much anxiety, faculty may need to spend individual time with that student to help them not only manage the anxiety, but attain the learning objectives of the simulation. Clinical hours for pre-licensure nursing education are mandated by state boards of nursing, and many programs use simulation as a portion of students' clinical hours. This means that all students must participate in order to meet clinical hour requirements. It is within the role of faculty to ensure that students meet these requirements.

Stress may not be a completely negative experience in a learning environment. Joëls et al (2006) propose that the timing of a stressor has an impact on whether or not it facilitates learning. They found that there is improved learning when the stress is experienced during the learning activity, and that stress may help students remember what is learned. In other words, stress can be associated with either impaired cognitive performance or “good learning and memory performance” (p. 152). Zoladz and Diamond (2009) suggest that the stress may impair or facilitate learning and memory in a doseresponse manner. They explain that "the magnitude of the stress-induced enhancement of a simple learning experience increases linearly as the stressor intensity and corticosteroid levels increase. For more complex learning tasks, especially those that involve great cognitive demands which require prefrontal cortex activity, high levels of stress would interfere with performance" (p. 136). They describe this as a "true hormetic relationship 


\section{NURSING STUDENT ANXIETY IN SIMULATION SETTINGS}

between stress and learning," "where low levels of stress stimulate and high levels of stress impair cognitive processes.” In other words, “subjects under a minimal amount of stress (or motivation) would exhibit relatively weak levels of performance. From this low motivational level, increasing levels of stress would facilitate performance, and importantly, high levels of stress would actually produce performance that is significantly impaired” (p. 136). This concept is important for nursing faculty who need to create an environment for using simulations in which students experience an optimal level of stress for effective learning.

Sappington (1984) addressed the responsibility of educators to create emotionally safe learning environments for students. Sappington interviewed teachers about what caused fears for their adult students, and what could be done to alleviate them. The teachers identified areas they believed affected students, including fear of failure and embarrassment, and being incompetent. Sappington made recommendations to respect students as adults and give them control in the learning environment. This type of safe environment may facilitate student learning in simulation, and in fact, simulation is frequently identified as a "safe" learning environment. What that means to students and faculty is not well understood.

Some studies have explored nursing programs and nursing students in general, and identified stressors reported by students. These stressors include heavy workloads, family responsibilities, and writing assignments (Weitzel \& McCahon, 2008). Gibbons, Dempster, and Moutray (2007) also explored eustress, or positive stress leading to improved learning. They found that experiential learning and providing patient care were 


\section{NURSING STUDENT ANXIETY IN SIMULATION SETTINGS}

sources of eustress for students, although this experience referred to time on clinical units and not in a simulation lab. For some students, the environment in simulation may be more stressful than a real clinical unit. Students identified faculty as sources of support to help cope with stress. Strategies to help students cope should be identified in simulation as well as other learning environments.

\section{Background of the Problem in Practice}

Because of the intensity of the realistic activity and the public nature of simulation, many students report being stressed in the simulation setting. Some have commented that simulation can be more stressful than clinical learning with "real" patients. For example, the following statements were made by nursing students in evaluations at the end of a clinical course:

My IQ drops twenty-five points just walking through the door of the sim room. I just get so nervous.

The scenario inside the sim lab is always a little bit stressful and tense because I know they are watched, scrutinized, and judged, though well-intentioned. But the debriefing session is always great. I learned a lot from everybody’s comments.

I am not comfortable in practicing at simulation because I fear that I do something completely wrong AND EVERYONE IS WATCHING! (Student evaluations, personal communication, 2008).

Although several studies found that simulation may cause some participants to be anxious, there is little documentation of what aspects of the simulation experience cause that anxiety. There are likely environmental, technological, and human factors that cause discomfort for learners in simulation, but those specific factors have not been studied from a student or learner perspective. In addition to the specific anxiety-producing elements of simulation, it is important to identify ways to help students manage their 


\section{NURSING STUDENT ANXIETY IN SIMULATION SETTINGS}

anxiety. These management techniques should also be examined from a student, or learner, perspective.

\section{The Research Problem}

While stress may facilitate learning, faculty need to determine how much stress is helpful, when it becomes detrimental, and how to create an environment that is optimal for student well-being and learning. Clearly, simulation has become a widely utilized clinical learning activity in nursing education. Simulation may take place in a stressful environment, and can cause anxiety, which may deter student learning. In order to help students learn, we need to understand what is causing their anxiety and help them discover and use strategies to manage it.

While there are studies providing evidence that students are stressed in simulation and in clinical learning environments, few have looked at student experiences and explored what might help. This study will further the knowledge about stress and anxiety in simulation by examining specific elements of the experience and asking students to provide information about what might help them to learn. Specifically, the student experience in simulation will be explored by asking what aspects of simulation are causing anxiety, and what would help them manage their anxiety. We know that simulation can improve learning, and that nursing programs may be able to expand clinical experiences for students by using a simulated environment. What is learned from this study may be used beyond the simulation environment, as students may benefit from the implementation of strategies to help them manage their anxiety in real clinical environments as well as in simulation. 


\section{NURSING STUDENT ANXIETY IN SIMULATION SETTINGS}

\section{Research Methodology}

In order to understand the problem of simulation anxiety, the student perspective of the experience must be explored. This study began with a survey in which students were asked to rate a list of potential stressors present in the simulation environment. Stressors included the technical aspects of simulation, such as video equipment and mannequins, as well as the human aspects, such as being observed by faculty and student colleagues. Participants had an opportunity to respond to an open-ended question and list other self-identified stressors in the simulation experience. The survey was piloted in summer 2012, and was revised according to student input for additional data collection in fall 2012. A focus group was held after the results of the surveys had been reviewed. The most frequently identified stressors were discussed in the group and student suggestions for interventions to help them manage their anxiety were elicited.

\section{Summary}

To review, this exploratory study examined anxiety in simulation from a student perspective. Students who participated in simulation as a component of their prelicensure nursing curriculum were asked about their experience. A survey was given which asked students to identify which specific components of simulation caused anxiety. The most stressful components identified by the students were determined and used as a framework for discussion in a focus group. The focus group also addressed student suggestions of what might be helpful for them in managing their anxiety. 


\section{NURSING STUDENT ANXIETY IN SIMULATION SETTINGS}

\section{Chapter 2 - Literature Review}

In this chapter, three areas of literature will be discussed: integration of simulation in nursing education, rationale and evidence for effectiveness of simulation as a teaching strategy, and stress and anxiety as they relate to learning and to simulation. The methodology of this study will be introduced. As stated in Chapter 1, simulation has been integrated into many nursing curricula, and evidence exists that it is an effective learning activity. Simulation can also cause students to feel stressed and anxious, and in some instances this anxiety may compromise their learning. It is important that educators using simulation understand this anxiety and provide some type of support or tool to help students manage their anxiety so they obtain the maximum learning benefits possible in the simulation component of their curriculum.

\section{Integration of Simulation in Nursing Education}

In nursing and healthcare, both in educational programs and in practice, simulation is used in a multitude of ways. Simulation has been defined as "techniques used to represent nursing processes and actions in an educational context” (Schiavenato, 2009, p. 389). This broad definition includes the practice of many aspects of the nursing role. On a basic skill level, this could include the simulation of skills such as intramuscular injection on a plastic body part model, and the teaching of intravenous fluid pump operation in a skills lab. On a more complex level, simulation may include practicing the nurse role in a patient care situation involving not only technical skills, but also cognitive skills such as patient assessment and teaching, critical thinking, teamwork, and communication. 


\section{NURSING STUDENT ANXIETY IN SIMULATION SETTINGS}

For some authors, the term "simulation” is used more specifically to describe learning activities that are based on the use of a high-fidelity mannequin designed to respond physiologically in ways similar to a human. Note that both "manikin” and “mannequin” are considered acceptable spellings in the healthcare simulation literature. In this paper, I will use “mannequin,” but “manikin” will be cited in several articles. Defining simulation by the type of mannequin is unfortunate, as it doesn't do justice to the capability and range of experiences possible for the use of simulation as a teaching/learning strategy. For the purposes of this literature review, the definition of simulation will not be limited by the type of equipment used, and will include learning activities using not only mannequins but other types of "live” participants as well. From this broader perspective, there are two aspects of a simulation activity. One of these is the nursing situation being represented, from the performance of a simple technical skill to a complex patient situation. The other is related to how the patient is portrayed, which might take the form of a simple body part or “task trainer," a mannequin of varying fidelity, or a human actor or standardized patient (SP) as a patient. Rather than limit this discussion to literature describing simulation in terms of equipment used, the literature about other types of simulation will be examined as well, particularly as experiences that may be stressful for students. As Schiavenato (2009) explains, "the challenge in nursing education is not the integration of the human patient simulator in nursing curriculum but rather the reconceptualization of simulation as a teaching tool encompassing varied methods and a wealth of applications throughout the prenursing and nursing curricula” (p. 392). If we are to examine how simulation is being utilized, and also look towards the 


\section{NURSING STUDENT ANXIETY IN SIMULATION SETTINGS}

future and find ways to improve learning through the use of simulation, the broader definition is one that should be used.

\section{Prevalence of Simulation Use in Nursing}

The National Council of State Boards of Nursing (NCSBN) study was initiated in 2010 for the purpose of assessing the use of simulation in pre-licensure nursing programs in the United States. This large-scale study began with the mailing of 1729 surveys to programs for registered nurse (RN) education, including associate, baccalaureate, and master’s degree programs. The 62\% response rate (1060 surveys) included data from every state in the country. Colleges, universities, and technical schools from both urban and rural areas were represented.

Three types of simulation, as determined by fidelity, were defined for the NCSBN survey, and these included not only the use of a mannequin, but a "standardized patient" as well. Standardized patients are "people who may or may not be professional actors who are instructed on how to act as if they have a particular disease or condition in a given patient situation in a given healthcare setting” (Nehring \& Lashley, 2010, p. 14). In

this study, high-fidelity simulation referred to a "patient-care scenario that uses a standardized patient or a full-body patient simulator that can be programmed to respond to affective and psychomotor changes, such as breathing chest action” (Hayden, 2010, p. 52). Medium-fidelity simulation involves a "patient-care scenario that uses a full-body simulator with installed human qualities such as breath sounds without chest rise” (Hayden, 2010, p. 52). The third type of simulation used "task trainers," or "part of a 


\section{NURSING STUDENT ANXIETY IN SIMULATION SETTINGS}

manikin designed for a specific psychomotor skill, for example, an arm for iv insertion practice” (Hayden, 2010, p. 52).

Eighty-seven percent of the respondents in the NCSBN study reported using high-

or medium- fidelity simulation experiences in their programs, with 54\% using simulation in five or more nursing courses. Simulation was used most frequently in courses teaching foundations of nursing and care of medical and surgical patients. Although assessment and psychomotor skills were listed as the focus of most simulations, faculty also reported using simulation for teaching behavioral skills such as communication, clinical decisionmaking, and interdisciplinary team training.

The results of this large study provide evidence that instructors utilize and value simulation as a desired teaching strategy. This is evident in the responses to a question about how much simulation should be used in nursing programs. Respondents were asked whether they believed their nursing education programs should be using more or less simulation. Eighty-one percent thought that using more simulation would be preferred, $18 \%$ believed they were using the right amount, and only three respondents believed they were using too much (Hayden, 2010). Although authors often lamented the fact that there is little evidence supporting the use of simulation as a teaching strategy, there are many articles in which the benefits of simulation are discussed, though not all are researchbased. The definitions of simulation vary within the literature, complicating the attempt to summarize the findings. The literature regarding this topic will be explored in the following section. 


\section{NURSING STUDENT ANXIETY IN SIMULATION SETTINGS}

\section{Rationale and Evidence for Effectiveness of Simulation}

Learning theory has been used as rationale for simulation in multiple studies. In an article about simulation in healthcare, Clapper (2010) cites several learning theories and discusses how they might be applied to simulation learning experiences. At the forefront in the simulation literature is Malcolm Knowles' theory of andragogy, though Clapper encourages educators to also consider other theories as frameworks for simulation. These include Brookfield's use of critical reflection, which Clapper believes is a useful experience not only for learners, but for instructors as well, who should "receive regular feedback from students on what is working in the classroom and what is not” (p. e8). In a discussion of learning Clapper alludes to the effect of stress on learning as "an emotional thing” and states, "being that the brain is very susceptible to emotion, positive emotion can pave the way for memory and higher-order thought” (p.ell). Fear and intimidation, however can have negative effects on learning, and the question arises how much stress is too much? Some participants in simulation may be worried about being “unveiled as a fraud” (p. e12), which could be extremely stressful. Clapper suggests that although the experience in simulation might evoke negative emotions, discussing those emotions is an important part of the debriefing process after a simulation, and may help learners make meaning of the experience. (Clapper, 2010).

In an extensive review of 120 articles on nursing simulation, Kaakinen and Arwood (2009) found that the majority of articles (104) discussed the use of simulation as a teaching strategy, and did not address learning theory in the simulation design. Sixteen articles discussed learning as a purpose for simulation and utilized a specific 


\section{NURSING STUDENT ANXIETY IN SIMULATION SETTINGS}

learning theory as an important element. Bandura was the learning theorist identified most frequently by Kaakinen and Arwood in the nursing simulation articles they reviewed. The authors believe that "using Bandura as a foundational theorist for planning and designing simulation focuses the effort on tenets of behaviorism and operant conditioning” (p. 12), and might not be encouraging students to focus on higher cognitive levels such as critical thinking. Bandura’s theory therefore, may not be ideally suited to simulations, especially those designed for learning higher order thinking rather than simply practice of skills and tasks.

Kaakinen and Arwood (2009) also found that Kolb’s theory on experiential learning has been applied to simulation. In order for Kolb’s theory to be useful, Kaakinen and Arwood state that a pretest would need to be done to determine students' learning styles, a practice which is time-consuming and not often done. They also state that teaching in a manner preferred by students "provides for a positive social learning environment and a positive student experience, but it does not necessarily challenge the student’s thinking” (p. 14). Other theories discussed include Knowles’ Adult Learning Theory, social construct theory or constructivism, reflective practice, and novice to expert theory. Kaakinen and Arwood conclude that faculty designing simulations must first determine the purpose: teaching or learning. If the purpose is viewed from a learning paradigm, they propose that social construct theories are most beneficial as a framework for the design.

Although there is little direct reference to stress in the learning theories addressed, they each contain ideas that could be applied to stress and its effect on learning, and 


\section{NURSING STUDENT ANXIETY IN SIMULATION SETTINGS}

specifically the learning that occurs in simulation. Clapper (2010) cited multiple learning theories and discussed how each could be applied to simulation, including addressing the emotional aspect of learning. It is interesting to note that the early simulation literature (late 1990's to 2004), is primarily focused on equipment and techniques, but more recent articles are based on learning theories, student perspectives, and research. As simulation has become an accepted, widely used learning strategy, faculty are making increased efforts to ground it in research and make connections to accepted theories of learning, with an ultimate goal of that learning being transferred to real environments and the safe provision of patient care.

Knowles and the adult learner. Malcolm Knowles first introduced his idea of adult learning, or andragogy, in the early 1970's. The concept that children and adults learn differently was the basis for Knowles’ work. In the sixth edition of The Adult Learner (2005), Holton and Swanson add to the content and address some of the critique and debate that occurred in response to Knowles’ original work. They assert that “andragogy presents core principles of adult learning that in turn enable those designing and conducting adult learning to build more effective learning processes for adults” and that andragogy "is a transactional model in that it speaks to the characteristics of the learning transaction, not to the goals and aims of that transaction” (Knowles, Holton, \& Swanson, 2005, p. 2).

Knowles believes that, in the education of children, the child plays a submissive role and the teacher has full responsibility for the learning. The andragogical model, however, places more responsibility on the learner, using the following precepts: 


\section{NURSING STUDENT ANXIETY IN SIMULATION SETTINGS}

- Adults need to know why they need to learn something;

- Adults maintain the concept of responsibility for their own decisions, their own lives;

- Adults enter the educational activity with a greater volume and more varied experiences than do children;

- Adults have a readiness to learn those things that they need to know in order to cope effectively with real-life situations;

- Adults are life-centered in their orientation to learning; and

- Adults are more responsive to internal motivators than external motivators (p. 73).

These precepts certainly apply to students in a nursing program who have chosen the nursing field as one of interest, and intend to use what they are learning in a professional role.

Although Knowles (2005) does not specifically mention the relationship between stress and learning, he does discuss some conditions that support learning, and the role of the andragogical teacher in helping to create those conditions. Stress is least likely to occur when, “The learning environment is characterized by physical comfort, mutual trust and respect, mutual helpfulness, freedom of expression, and acceptance of differences” (p. 93). Knowles lists some principles of teaching which address the learning environment, which include: the teacher "accepts each student as a person of worth and respects his feelings and ideas,” and "seeks to build relationships of mutual trust and helpfulness among the students by encouraging cooperative activities and refraining from inducing competitiveness and judgmentalness” (p. 93). The fear of being watched, being 


\section{NURSING STUDENT ANXIETY IN SIMULATION SETTINGS}

judged, and possibly of not being as competent as others can be a contributing factor to the stress of learning situations that use simulation. A teacher who created the accepting environment described above, especially in the reflection or debriefing component of simulation, could presumably alleviate some of the stress for students. As Sappington (1984) suggests, a facilitator must manage “a variety of learning styles, levels of experience, and individual concerns and anxieties” in order to build “an environment where fear/safety motivates individuals to ever deeper levels of learning” (p. 28).

Another concept discussed by Knowles (2005) is “learning-how-to-learn,” which he believes "holds great promise for helping adults to expand their learning effectiveness” (p. 217). Citing a model designed by Gibbons in 1990, Knowles discusses three aspects of learning pertinent to learning how to learn: reason, emotion, and action. Of these, emotion is most applicable to the idea of stress and learning. The elements of emotion described by Gibbons are “experiencing feelings, clarity, developing confidence, developing determination, and trusting intuition” (Knowles, p. 218). Helping a learner manage these elements may help bring the stress of a learning situation to a manageable level.

How People Learn. Two committees of the National Research Council, the Committee on Developments in the Science of Learning and the Committee on Learning Research and Educational Practice, explored the linking of research findings to classroom practice and learning, and these findings were summarized in How People Learn. In this book, Bransford, Brown, and Cocking, Eds, (2000) reported on many of these research studies as they examined scientific literature on cognition, learning, and development, 


\section{NURSING STUDENT ANXIETY IN SIMULATION SETTINGS}

and explored multiple ideas about ways to facilitate learning. Although much of their work investigates learning as applied to children, they also discuss learning at the college level. The importance of a learner's pre-existing knowledge is foundational in adult education, and Bransford, Brown, and Cocking state that the "logical extension of the view that new knowledge must be constructed from existing knowledge is that teachers need to pay attention to the incomplete understandings, the false beliefs, and the naïve renditions of concepts that learners bring with them to a given subject” (p. 10). Since fear of being observed, being critiqued, or appearing incompetent may increase students’ stress during a learning activity, the teacher needs to decrease the stress enough that students are willing to admit to their incomplete understandings and express their beliefs. Without an open and accepting learning environment, the teacher may never know what pre-existing knowledge and beliefs students are using as foundations for their new knowledge. As Bransford, Brown and Cocking (2000) explain, “students who think that intelligence is a fixed entity are more likely to be performance oriented than learning oriented- they want to look good rather than risk making mistakes while learning” (p. 23). In simulation, being learning oriented is crucial. It is important that students accept the fact that mistakes may be made, and that mistakes are opportunities for further learning.

Transfer of learning is another important concept explored by the committees.

Transfer of learning applies directly to simulation in nursing education, since the goal of simulation is not only to help students learn in a simulated environment, but for them to transfer what they have learned to help them practice safely and competently with "real" patients. Some of the elements that influence the transfer of learning are learning for 


\section{NURSING STUDENT ANXIETY IN SIMULATION SETTINGS}

understanding as opposed to memorization, pattern recognition, and the use of feedback. Bransford, Brown and Cocking (2000) cite studies on the importance of transfer and state that "students need feedback about the degree to which they know when, where, and how to use the knowledge they are learning” (p. 59). Making this a focus of simulation may help students who are feeling stressed or threatened by helping them focus on the fact that what's happening is not about them, but rather about the patients they will care for in the future. Designing the simulations at a level appropriate for the students will also facilitate learning. It is possible to create a high level of stress by presenting students with a challenge that is too great for their level of knowledge and skill. Bransford, Brown, and Cocking believe that challenges should be "at the proper level of difficulty in order to be and to remain motivating: tasks that are too easy become boring; tasks that are too difficult cause frustration” (p. 61).

Bransford and Schwartz (1999) believe that educators value learning activities that affect a learner after the activity is done. Certainly, nurse educators hope that students carry what they have learned in simulation to their "real” patients. Educators, Bransford and Schwarz claim, "are hopeful that students will show evidence of transfer in a variety of situations: from one problem to another within a course, from one course to another, from one school year to the next, and from their years in school to their years in the workplace” (p. 61). The transfer of learning from the simulation environment to the real world is difficult to prove, since students learn in multiple venues such as lectures, labs, and clinical sites, often experiencing all within a short period of time. However, since "effective transfer requires a sufficient degree of original learning” (p. 63), the 


\section{NURSING STUDENT ANXIETY IN SIMULATION SETTINGS}

reinforcement of didactic and skill-based learning in simulation is likely supportive of transfer of knowledge to the real world.

A final idea from How People Learn relates to the use of technology. Bransford, Brown and Cocking (2000) recommend using tools of technology such as videos, simulations, and internet connections to help create effective learning environments and opportunities for transfer of learning. Technology, however, cannot be helpful as a learning tool without the involvement of a teacher, who plans and facilitates the learning. The use of technology in learning is "never solely a technical matter, concerned only with properties of educational hardware and software,” but must function “in a social environment, mediated by learning conversations with peers and teachers” (p. 230).

Constructivism and social constructivism. Constructivism is a learning theory based on the idea that learners construct understanding for themselves. Hmelo-Silver, Duncan, and Chinn (2007) believe that all learning is a constructivist process because knowledge construction is the goal. The constructivist view includes the ideas that learning occurs when multiple perspectives are incorporated into the learner's previous knowledge, and that the teacher's role is to facilitate and guide learning, and to create environments conducive to learning. The role of the student is to engage in exploring, questioning, and interpreting knowledge. The following are some of the principles of constructivism which are applicable to simulation: the use of real-world settings or casebased learning, the encouragement of thoughtful reflection on experience, collaboration among learners, integration of prior knowledge, and hands-on activities (Jonnasen, 1994). 


\section{NURSING STUDENT ANXIETY IN SIMULATION SETTINGS}

The social constructivist view is particularly applicable to simulation, because it contends that learning is a social process that occurs when individuals interact with one another, or are engaged in social activities. In a constructivist view, "the potential for learning at different levels is thought to grow as the environment becomes richer and more engaging for the learner” (Rieber, 1992, p. 94). Rieber writes from an instructional technology viewpoint and discusses the creation of computer "microworlds," defined as “a small but complete subset of reality in which one can go to learn about a specific domain through personal discovery and exploration” (p. 94). Rieber explains that microworlds differ from simulations in several ways, but focuses on what is similar in their design. He lists the following principles for incorporating constructivist goals into the design of learning activities, all of which apply to the use of simulation in nursing education:

- Provide a meaningful learning context that supports intrinsically motivating and self-regulated learning.

- Establish a pattern whereby the learner goes from the "known to the unknown."

- Provide a balance between deductive and inductive learning.

- Emphasize the usefulness of errors.

- Anticipate and nurture incidental learning (p. 98).

Detractors of social constructivism contend that constructivist teaching, along with strategies like problem-based learning and discovery learning is based on minimal guidance and is therefore not likely to be effective (Kirschner, Sweller, \& Clark, 2006). These authors state, “empirical research on this issue has provided overwhelming and unambiguous evidence that minimal guidance during instruction is significantly less effective and efficient than guidance specifically designed to support the cognitive 


\section{NURSING STUDENT ANXIETY IN SIMULATION SETTINGS}

processing necessary for learning” (p. 76). The learning that takes place in simulation, however, is not without the guidance of an instructor. Proponents of constructivism claim that in problem-based learning, "students learn content, strategies, and self-directed learning skills through collaboratively solving problems, reflecting on their experiences, and engaging in self-directed inquiry” (Hmelo-Silver, Duncan, \& Chinn, 2007, p. 100), which is exactly what happens in simulation. In simulation, as in problem-based learning, scaffolding is provided by instructors who coach, structure tasks, and provide opportunities to solve problems. Simulation requires much more than minimal guidance in order to provide students with optimal opportunities for learning.

The importance of the teacher or facilitator is addressed more directly in Vygotsky’s theory of social constructivism. Two important concepts in Vygotsky’s theory are the More Knowledgeable Other (MKO) and the Zone of Proximal Development (ZPD). The MKO is a person who has more knowledge about or experience with a specific topic than the learner and who may or may not be the teacher. The ZPD is an individual's potential for learning, or the point in cognitive development between requiring the assistance of the MKO to perform a task and being able to perform a task independently. As Lutz and Huitt (2004) explain, “This zone indicates that at any point in development, there are three levels of ability that are possible: That which a person can do without guidance or help, that which a person cannot do even if helped, and that which a person can do with help” (p. 72). Vygotsky believes that "when a student is at the ZPD for a particular task, providing the appropriate assistance (scaffolding) will give the student enough of a 'boost' to achieve the task. Once the student, with the benefit of 


\section{NURSING STUDENT ANXIETY IN SIMULATION SETTINGS}

scaffolding, masters the task, the scaffolding can then be removed and the student will then be able to complete the task again on his own” (Galloway, 2001).

Brandon and All (2010) call for a restructuring of nursing education based on a constructivist model, citing the importance of a student-centered, interactive curriculum as critical to this restructuring. They propose minimizing the use of lecture and memorization of facts and increasing the use of concept-based learning activities, believing that engaging active learners and helping them build on their knowledge together will help nursing students during their education and as they become expert practitioners. As Brandon and All explain, "Nurses are far more than beings of memorization. They must be lifelong, adult learners who engage in reflective practice, self-critique, and self-direction, and they must be able to synthesize information, link concepts, and think critically. Therefore, it is imperative to evaluate the use of constructivism in nursing education curricula” (p. 89).

The use of simulation aligns well with Vygotsky’s theory of social constructivism and Brandon and All's promotion of constructivist curricula. Although faculty create and implement the simulation cases, and facilitate the learning that occurs in a simulated environment, it is the students who are responsible for actively engaging in the nursing scenario. Much of simulation is team-based, and students must work together to plan and perform the needed nursing care. After the simulation, during a debriefing period, the team has an opportunity to discuss the case and reflect on their own interventions as well as those of others in the group. In this way, simulation can be used to help them create more knowledge and understanding together. 


\section{NURSING STUDENT ANXIETY IN SIMULATION SETTINGS}

\section{Evidence for Effectiveness of Simulation}

Although it is difficult to prove that simulation or any teaching strategy is solely responsible for effective learning of clinical skills, multiple researchers have made connections between simulation and learning. Large-scale reviews as well as selected simulation studies will be described.

Large-scale reviews. Several large-scale review articles have provided information on simulation and its outcomes and effectiveness as a teaching strategy. A consistent definition for simulation has not been utilized; therefore the results have varied usefulness. A review by Weaver (2011), for instance, searched multiple databases and literature for evidence supporting the use of simulation as an alternative clinical experience. The search included articles from 1998-2008, and yielded 24 articles addressing nursing education and patient simulation.

The articles examined by Weaver used several terms for simulation, including patient simulation, high-fidelity patient simulation, and human patient simulation. The latter term, human patient simulation, is interesting, since nurses and other healthcare providers are not likely practicing on any patients who are not human. The term human patient simulation may be based on a specific model of mannequin termed an "HPS" or “Human Patient Simulator” by its manufacturer. There are now several manufacturers designing and producing mannequins, and they are referred to by multiple names other than HPS.

Weaver states that for this review, "patient simulation refers to high-fidelity patient simulation conducted using realistic scenarios with a high-fidelity manikin” 


\section{NURSING STUDENT ANXIETY IN SIMULATION SETTINGS}

(Weaver, 2011, p. 38). Therefore, although twenty-four articles were examined, they all relied on the use of a mannequin as a teaching tool, eliminating other types of simulation using actors or SP's. The findings revealed that high-fidelity patient simulation "benefits nursing students in terms of knowledge, value, realism, and learner satisfaction,” but that "findings were mixed in the areas of student confidence, knowledge transfer, and stress" (Weaver, p. 37). Knowledge transfer is an important aspect of simulation because it addresses the reason for using the strategy in educational programs, which ultimately is improved patient care. If students cannot apply what they have learned in simulation to real situations in real environments, then it is of questionable use.

Brewer (2011) performed an integrative review of literature to explore techniques that contributed to successful simulation practice. Brewer used the term human patient simulation (HPS) in the review, and defined it as "the use of life-size full-body mannequins capable of electronically interacting with humans” (p. 311). This definition limits the investigation to studies in which a mannequin was used, and excludes any simulation done with actors or SP's. Thirty-seven studies were reviewed and all but 10 were excluded due to not meeting the author's criteria. The 10 included studies took place between 2005 and 2010, reflecting current practice in nursing education and in simulation. The studies all used simulated hospital rooms for the activity, and in all studies the students prepared in advance for the simulation. All ten of the studies described the research design along with reporting and analyzing of data.

Based on the review, Brewer concluded that while simulation use is increasing, “HPS use has not developed to its fullest potential” (p. 317). This author would have 


\section{NURSING STUDENT ANXIETY IN SIMULATION SETTINGS}

found more literature on the use of simulation if studies utilizing actors or SP's were included. By limiting the review to mannequin-based simulation, the richness of learning experiences provided by the addition of actors and SP's was missing. Faculty, simulation planners, and simulation facilitators contribute far more to the learning than does the technology or the equipment. Brewer's conclusion that more research is needed to prove the value of simulation in nursing education is important, however, and broadening the definition of simulation would definitely yield more data.

In a review of simulation in nursing over the past 40 years, Nehring and Lashley (2009) examined the nursing research on the topic and labeled it inconclusive. They stated that it is "hampered by low sample sizes, different samples, different constructs, and instruments with questionable validity” (p. 538). They identified a general attitude among faculty and students towards simulation that deemed it useful as a teaching tool in addition to real clinical experiences, but stated "the statistical measurement of its efficacy is hard to measure, especially its application to performance in the actual clinical setting” (p. 538). In spite of this difficulty in measuring the value of simulation, Nehring and Lashley cite the 2002 recommendations of the National Advisory Council on Nurse Education and Practice that all faculty be oriented on the use of simulation, and the National Council of State Boards of Nursing that simulation be included as a teaching strategy in nursing (p. 540).

Leigh (2008) explained that nursing students need confidence in their own knowledge and abilities before they can attend to the needs of their patients. Identifying that the terms self-efficacy, confidence, and self-confidence are often used 


\section{NURSING STUDENT ANXIETY IN SIMULATION SETTINGS}

interchangeably, Leigh reviewed the literature examining these constructs and the usefulness of simulation in their attainment. The review included 62 quantitative and qualitative studies, with the majority using qualitative methods. Studies were limited to those using a high-fidelity mannequin in patient scenarios taking place in clinical settings (thus excluding actors or SP's and environments such as community settings.) Many positive outcomes of simulation were identified in the studies, including improvement in critical thinking and leadership skills, practicing in a non-threatening environment, applying knowledge to practice, learning from mistakes, identifying gaps in knowledge, decreasing stress in a clinical environment, and providing valuable feedback. In discussing the effects of simulation on self-efficacy, Leigh cites 15 studies in which an increase in confidence or self-efficacy was found. Specific benefits listed were confidence in technical skills, increased motivation to learn, learning to control feelings of panic and fear, and ability to handle the unexpected. In spite of these findings, Leigh identifies a number of areas in which more research is needed. Questions such as how much simulation practice is needed, and whether the self-efficacy continues when students become nurses has not been studied. Understanding that the ultimate goal of simulation training is improved patient care, research on self-efficacy as it relates to patient outcomes is also needed.

In an effort to gather and analyze the research that has been done on simulation, the International Society for Simulation in Healthcare held a Research Summit at their annual meeting in January 2011. As part of this summit, Nestel, Groom, EikelandHusebo, and O’Donnell, (2011) were asked to summarize the best evidence and answer 


\section{NURSING STUDENT ANXIETY IN SIMULATION SETTINGS}

the question: “To what extent does simulation support learning and teaching in procedural skills?” Their search of literature from 2000-2010 yielded 81 abstracts that met their criteria. Fifty different journals were represented in the panel's literature search, and most papers cited were empirical. The simulation participants, or learners, included a variety of levels of students and practitioners. Simulated patients included not only mannequins or task trainers, but live patients or actors as well. Learning outcomes were described as changes in knowledge, skills, and attitudes, and all but 7 of the 81 studies reported an increase in at least one of these areas based on simulation. From their review, the panel concluded that simulation not only increases participants’ knowledge and skills, but also that participants are highly satisfied with the use of simulation as an educational method. Most studies focused on short-term rather than long-term gains from the simulation activities, however, and while there were some studies providing evidence of the transfer of what has been learned in simulation to the real clinical setting, these studies were limited. The panel also recommended further study to "optimize the alignment of learner, instructor, simulator, setting, and simulation for learning and teaching procedural skills” (Nestal et al, p. S12).

Selected studies. In addition to the review articles, other studies will be identified which provide specific evidence about simulation's effect on learning. These studies address different approaches to simulation and describe multiple types of methodology employed to provide students with a specific learning experience. They were selected to illustrate the wide range of learning experiences that simulation can provide. 


\section{NURSING STUDENT ANXIETY IN SIMULATION SETTINGS}

Crider and McNiesh (2011) explain how they applied a professional apprenticeship model and integrated a psychiatric-mental health (PMH) scenario into a nursing education program. The professional apprenticeships to which they refer were described by Benner, Sutphen, Leonard, and Day (2010) in their work “Educating Nurses: A Call for Radical Transformation,” a volume in the Carnegie Foundation’s “Preparation for the Professions” series. In this work, Benner, Sutphen, Leonard and Day describe what they term the three apprenticeships, which are part of professional practice: “(1) an apprenticeship to learn nursing knowledge and science, (2) a practical apprenticeship to learn skilled know-how and clinical reasoning, and (3) an apprenticeship of ethical comportment and formation” (p. 25). Crider and McNiesh (2011) used this framework as they created a scenario to help students practice the professional role of the nurse in caring for a psychiatric patient. Recognizing that “clinical encounters are often fraught with ambiguity and uncertainty,” and that “educating for a practice discipline requires experiential and situated learning” (p. 42), the authors describe how they implemented a scenario in which students care for a schizophrenic patient. They identified that their students had expressed fear and anxiety about caring for a patient with a mental illness. Providing evidence that simulation should not be defined strictly by experiences with a mannequin, the authors created a simulation scenario about a patient who was experiencing paranoia and hallucinations, and utilized an actor as the patient. Students were provided an opportunity to practice establishing a therapeutic relationship with the patient. In a debriefing afterward, the authors recommend a reflection on the case, along with exploration of students' attitudes towards 


\section{NURSING STUDENT ANXIETY IN SIMULATION SETTINGS}

patients with mental illness. This type of patient encounter may happen in a real patient setting, and exposure in a structured environment with instructor support is relevant practice that addresses the three apprenticeships.

Kameg, Mitchell, Clochesy, Howard, and Suresky (2009) also advocated for the use of simulation for teaching communication in psychiatric nursing. They cite the anxiety and lack of confidence expressed by students in caring for psychiatric patients and the need to practice communication in a supportive environment. Patient safety in many areas is dependent upon the healthcare providers' ability to communicate not only with patients and families, but with one another as well. Simulation is identified as an area in which students can not only practice, but also receive immediate feedback on how they used communication in a clinical situation. The authors conclude that although there are studies on the use of simulation to teach technical and psychomotor skills, there is little literature or student outcome data on simulation's value in teaching nursing students to communicate.

A qualitative research study by Eggenberger, Keller, and Locsin (2010) examined the caring behaviors of nursing students in a scenario using a high-fidelity patient simulator. Seventy-seven nursing students in an adult acute care nursing course participated in a simulation with a high-fidelity mannequin. The scenario depicted a male patient, his wife (an actor) at his bedside, experiencing chest pain progressing to a need for cardiopulmonary resuscitation (CPR). Students were prepared in advance by reviewing CPR guidelines along with equipment and medications. They participated in the simulation scenario and a group debriefing afterward. Data regarding their experience 


\section{NURSING STUDENT ANXIETY IN SIMULATION SETTINGS}

was obtained through focus groups along with anonymous program evaluations. The students were asked questions about how they came to know the patient and how they experienced and practiced caring behaviors. The themes that emerged from the focus groups are evidence that the study participants were able to identify and appreciate caring behaviors in the patient care situation. These thematic categories included "knowing persons through descriptions from significant others, utilizing ways of knowing in nursing, and identifying nursing calls and responses” (p. 26). Although a high-fidelity mannequin was needed to create a realistic situational context, participants mentioned multiple examples of caring, including knowing the patient through the interaction with his wife, treating the patient and not just his monitor, and caring for their own colleagues as they dealt with the patient. Recognizing the value of simulation as more than the practice of technical skills, the authors conclude, "it is gratifying to see that students have absorbed this way of being and caring for the persons they nurse, particularly in a simulated environment” (p. 28).

Gonzales et al., (2010) questioned whether caring could be taught using simulated patient care scenarios. Their review of the literature focused on qualitative studies and concluded that positive effects of using simulation include confidence and nurse satisfaction with the teaching strategy, but that there was little evidence of the impact of simulation on the caring aspect of nursing. The research team used a meta-synthesis approach in their analysis. Their findings described the following commonalities between simulation and caring: simulation marginalizes caring; simulation positively affects nurses' self-worth and performance, which can contribute to nurses' caring. Furthermore, 


\section{NURSING STUDENT ANXIETY IN SIMULATION SETTINGS}

the educator has an impact on the use of simulation to teach caring. The authors did note that students expressed empathy while caring for simulated patients, but doubted that this was sincere. They recommend that future research be done on caring and simulation.

A greater amount of literature looks beyond the caring aspect of nursing and examines constructs such as perceived knowledge and skill attainment. Kaddoura (2010) explored new graduate nurses’ impressions of simulation, specifically its effect on critical thinking, learning, and confidence in a critical care environment. Kaddoura identified that educational programs cannot provide students with every situation they might encounter in practice and that the teaching of critical thinking enables nurses to apply what they have learned to a multitude of situations. Critical thinking is deemed necessary for nurses to make skilled assessments, interpret complex data, manage medical technology, and deal with ethical dilemmas, among other skills. Kaddoura's exploratory descriptive study collected data from a convenience sample of 10 new nursing graduates who completed demographic questionnaires and participated in interviews. The participants were engaged in a six month critical care training course that included approximately eight days of simulation-based training. The simulation training focused on situations that nurses could practice in a nonthreatening environment with support of experienced nurses.

Three themes emerged from Kaddoura’s data. The first includes cognitive and psychomotor skills such as providing holistic care, and applying what they had learned in class to a patient situation. The second theme refers to the attainment of critical thinking skills through teamwork and feedback. The third theme relates to safety and practice in a 


\section{NURSING STUDENT ANXIETY IN SIMULATION SETTINGS}

non-threatening environment, which participants identified as critical to the development of confidence. Based on the participants' overwhelmingly positive reactions to the simulation-based learning activities, the author recommends that simulation replace some of the more traditional methods of teaching nursing. The value of a safe environment for practice was stressed as beneficial to learning critical thinking skills.

Reising, Carr, Shea, and King, (2011) compared communication outcomes in traditional and simulation strategies with an interprofessional group of participants. Using a prospective, descriptive survey design, data were collected on 41 nursing students and 19 medical students. The patient scenario was a "mock code," or a critical event in which a patient deteriorates and requires Advanced Cardiac Life Support (ACLS), a situation that in real practice requires a multi-disciplinary team management approach. Students were divided into interprofessional teams, each containing both nursing and medical students. The teams were assigned to either a simulation-based strategy using a highfidelity mannequin or a traditional presentation of an unfolding case in which the scenario was presented by a facilitator and discussed by the team.

In both strategies, students reported appreciation for an opportunity to interact with another discipline, a better sense of their role on the team, and the importance of teamwork in attaining a positive patient outcome. The greatest difference in comments between the simulation group and the traditional group was that the simulation group gained an increased awareness of the timing needed to manage the patient situation, as well as the need for practitioners to assume a variety of roles. This timing can be critical to patient outcomes in an ACLS situation. The only quantitative difference between the 


\section{NURSING STUDENT ANXIETY IN SIMULATION SETTINGS}

groups was a reported increase in stress level in the simulation groups. It is likely that this stress is also present in real ACLS activities. The authors plan to use the results of this study to create a communication rubric to evaluate team members in both traditional and simulation activities.

Schoening, Sittner, and Todd (2006) designed an evaluation study to explore the student perspective on working with a preterm labor scenario in an obstetric setting. They identified the fact that nursing students are not often given the responsibility of caring for high-risk patients and wanted to provide them this opportunity. The researchers used the term "simulated clinical experience" (SCE) and defined this as "a realistic reenactment of a clinical situation in which the student is able to step into the role of the nurse.” In the SCE, "students are allowed to make independent decisions and experience the consequences of their actions as the SCE unfolds” (p. 253). This definition is very useful, and explains the role of the student as care provider and decision-maker in the scenario.

The researchers used a convenience sample of 60 baccalaureate nursing students enrolled in a clinical course, and the SCE was a required part of the clinical course content. Student activities included readings on the preterm labor content, an orientation to the mannequin and the simulation environment, their actual participation in the scenario, and a debriefing afterward. Because the research question was about student perceptions, the students were asked to complete a survey to evaluate their own attainment of the learning objectives related to nursing skills in preterm labor, and identify whether they gained confidence, were satisfied with the experience, and felt it would help them in the real world of patient care. The quantitative data revealed that 


\section{NURSING STUDENT ANXIETY IN SIMULATION SETTINGS}

students valued the SCE and felt that it provided an effective learning experience. A qualitative component included reflecting on the experience in a journal, in which students revealed that their confidence was increased as a "result of hands-on practice, teamwork, communication, and the decision-making skills that they were able to acquire in the nonthreatening environment of the simulation laboratory” (Schoening et al, p. 257).

Nurses are often the providers assisting patients and families at the time of death. Smith-Stoner (2009) has provided students with an opportunity to be exposed to an endof-life (EOL) situation using simulation. Smith-Stoner created a conceptual model that is the foundation for the learning activity labeled the "Silver Hour," which is focused on the 30 minutes prior to the patient's death, along with the events following death. Scenarios were created which involve a patient dying after a traumatic incident and patients dying from advanced stages of illnesses. The EOL simulations are thoughtfully and deliberately integrated into a course and curricular plan, and students are provided with materials to prepare in advance for the activity. These include select readings on EOL care and activities designed to help students reflect on their own attitudes towards death.

The simulations include use of a mannequin as the dying patient and use of actors as the family members in attendance. Some students are actively involved in the patient care; others are observing the EOL case and completing a written observation guide analyzing the scenario. The authors, utilizing several widely used tools, are conducting an evaluation of the EOL scenarios. Based on experience with students and the author's own experience as a nursing expert in care of the dying patient, the simulations are considered valuable tools for teaching EOL care. In spite of student reactions of being overwhelmed 


\section{NURSING STUDENT ANXIETY IN SIMULATION SETTINGS}

with the content, Smith-Stoner contends that the simulations provide them with an opportunity to use what they have learned in a low-stress environment such as a classroom, and apply it in a patient care scenario.

In a collaboration between a college of nursing and local hospitals, a course was developed to facilitate the transition of nursing students into a critical care environment. Titled, “Preparing the Critical Care Nurse,” the five-day course included didactic content on care of patients in an intensive care environment, followed by simulations in which participants could apply what they had learned (Stefanski \& Rossler, 2009). Stefanski and Rossler explained how new nurses often become dissatisfied and stressed when confronted with the realities of the critical care environment, and that retention of nurses is often difficult. They sought an innovative approach to orient new nurses that utilized mannequins as patients and offered the opportunity to integrate concepts into patient care in a simulated critical care environment. Each simulation and subsequent debriefing focused on content that had been presented that day. Course evaluations revealed that $96 \%$ of participants felt the simulations were effective teaching methods, and $88 \%$ felt they were more prepared after the simulations to care for patients in the critical care setting.

Because it is a practice discipline, nursing must be taught not only in the classroom, but in clinical areas as well. Students need to practice the necessary skills, apply the knowledge learned, and incorporate the behaviors needed to practice nursing in a real environment. Simulation has been incorporated into nursing education because it allows students to "engage in the same critical thinking and clinical decision-making 


\section{NURSING STUDENT ANXIETY IN SIMULATION SETTINGS}

skills required in actual clinical practice” (Sinclair \& Ferguson, 2009, p. 1.) When used as a clinical learning activity, simulation builds upon what students know and allows them to demonstrate their knowledge and skills in a safe learning environment by providing "a wide range of experiences that are either too rare or too risky for novices to engage in using actual patients” (Hovancsek, 2007, p. 3). With support from faculty, simulation can help bridge the gap between the classroom and the patient care environment.

As noted in some of the literature, the use of simulation can cause anxiety for the participants. The next section will address the relationship between stress, fear, anxiety, and learning, and explore nursing students' experiences with these emotions in simulation.

\section{Stress and Anxiety}

In his 1956 work on stress and illness, Hans Selye explained that stress is unavoidable and "is not necessarily bad for you; it is also the spice of life, for any emotion, any activity causes stress” (Selye, 1950, p. vii). People respond to stress in different ways, adapting as well as they can to "the circumstances in which we exist" (Selye, p. vii). Selye's study of how the human body responds to stress led him to the definition of stress as "essentially the rate of all the wear and tear caused by life" (Selye, p. viii).

Joëls, Pu, Wieger, Oitzl, and Krugers, (2006) describe a multitude of life events that can cause stress, stating that "our daily lives are full of emotionally arousing experiences, ranging from small annoyances to major life events like the loss of a spouse” (Joëls et al. p.152). Joëls explains that stressful events “can be tangible or 


\section{NURSING STUDENT ANXIETY IN SIMULATION SETTINGS}

mentally evoked, and of a physical or psychological nature” (p 152). More specific than stress, anxiety is a response of an individual to a stressor involving “a feeling of apprehension and dread” (Palethorpe \& Wilson, 2011, p. 423). Palethorpe and Wilson specify "state anxiety” as "a temporary cognitive, behavioral and physiological reaction to a threatening situation” (p.423). They identify a relationship between anxiety and learning, and believe that an optimal level of stress promotes learning, but that "too much stress may push course participants over the edge into a state of temporary anxiety where learning is severely impaired” (p. 421). Not all learners respond to anxiety in the same way, which complicates the issue for teachers attempting to create optimal learning environments. Sogunro (1998) explored evaluation anxiety in adult learners, describing anxiety as having "an elusive bothersome quality," and "being associated with feelings of inadequacy and inferiority” (p. 110). Eysenck, Derekshan, Santos, and Calvo (2007) further described the negative effects of anxiety, labeling it "an aversive emotional and motivational state occurring in threatening circumstances” (p. 236). Fear is also described in the literature as related to anxiety and is defined as a reaction to a more specific danger.

As opposed to anxiety, the desired state in a learning environment has been defined as "psychological safety," which occurs "when an individual is able to behave or perform without fear of negative consequences to self-image, social standing, or career trajectory” (Ganley \& Linnard-Palmer, 2010, p. e2). Characteristics of an environment that is psychologically safe include respect, faculty and peer support, and provision of constructive feedback (Ganley \& Linnard-Palmer, 2010). 


\section{NURSING STUDENT ANXIETY IN SIMULATION SETTINGS}

\section{Learning Under Stress/Anxiety}

Anxieties experienced by a learner that impact the learning process may be concrete, "such as the lack of academic skills," or more abstract, "such as a sense of vulnerability” (Askham, 2008, p. 92). The relationship between stress, anxiety, and learning will be explored in this section.

Joëls et al (2006) propose that stress, when experienced at an opportune time, can facilitate learning. They define stress as “emotionally arousing experiences” that cause potential threats to our bodily homeostasis. Stress can be associated with either impaired cognitive performance or "good learning and memory performance” (p. 152). The authors explore two physiological systems that are activated by stress: the autonomic nervous system and the hypothalamo-pituitary-adrenal system. The biological details will not be explained in this paper, but the authors' conclusions are relevant. They examined several studies related to the importance of context, and state that "these studies underline an important principle regarding stress and memory: increases in stress hormone levels, particularly of corticosteroid hormones, within the context (and around the time) of the learning situation help to remember that particular event” (p. 154). Stress that is experienced by a learner "within the context of a learning experience" has the benefit of causing “focused attention” and improved memory of relevant information (p. 157). As noted by student comments regarding simulation, stress is experienced during the time of the learning activity and thus may facilitate the learning that is intended in that experience. 


\section{NURSING STUDENT ANXIETY IN SIMULATION SETTINGS}

The responsibility of educators to create emotionally safe learning environments, described as environments "where the desire to learn outweighs the fears surrounding the learning process” (p. 25) was addressed by Sappington (1984). Sappington interviewed 10 teachers about what caused fears for their adult students, and what could be done to alleviate them. Since stress is closely related to fear, Sappington's conclusions about emotionally safe environments could help bring learner stress to a manageable level. He identified the following areas as significant fears of learners: outcome fears (insufficient time for learning), evaluation fears (fear of failure), interpersonal fears (fear of embarrassment), and internal fears (incompetency or inadequacy). To manage these fears, Sappington recommends creating "an environment of respect or adultness in which the control of the learning process is placed in the hands of the student," and giving "students a sense of respect or safety where they can then move deeper in the learning process” (p. 28). Although the interviews were conducted with the teachers and not the learners, the responses seem to incorporate a learner-focused perspective.

Indirectly, practices that promote self-confidence in students would seem to decrease their stress levels. Lundberg (2008) examined research on student confidence and clinical teaching. Bandura’s Social Cognitive Theory was used as a framework for describing "interconnections between the constructs of confidence, motivation, and success” (p. 86). Within a clinical learning environment, Lundberg does not seem to recognize any beneficial aspects of stress, stating that "instructors who are mindful of Bandura's theoretical constructs can develop and implement teaching principles that provide opportunities for repeated successes and observation of confident peers and offer 


\section{NURSING STUDENT ANXIETY IN SIMULATION SETTINGS}

ample encouragement-all within a nurturing, stress-free environment” (p. 87). This is at odds with the idea that there is an optimal level of stress that may promote learning. Lundberg specifically mentions the use of simulation as an activity through which students can apply theory to a controlled clinical learning environment, and proposes that nurse educators can help build confidence by utilizing "immediate feedback, peer modeling, and opportunities to practice newly acquired skills” (p. 87). As evidenced by student comments, it is difficult and probably not optimal to completely remove all stress in a clinical learning environment, whether that environment is simulation or an authentic patient care area.

One study was found which used physiological measures of the stress response to determine whether high-fidelity patient simulation produces significant stress. Muller et al. (2009), recognizing that “stress modifies human performance,” and "can influence the management of crises” (p. 919), measured salivary alpha-amylase and cortisol levels in critical care physicians participating in simulation training. Their data suggests that "a 1day simulator training course improves clinical and non-technical performance of ICU physicians in simulated crisis scenarios” (p. 923), which is an important conclusion, given the fact that simulator training is becoming increasingly popular as a teaching tool. More important is the finding that a high-fidelity simulation scenario produces a significant stress response in the participants, which did not prevent the improvement of performance in the participants. This stress response is most likely similar to the stress experienced by physicians and nurses in a real clinical environment with real patients. 


\section{NURSING STUDENT ANXIETY IN SIMULATION SETTINGS}

Palethorpe and Wilson (2011) used a qualitative research strategy to investigate how challenging learning environments can enhance learning. Palethorpe and Wilson believe that a helpful approach is based on a "Comfort-Stretch-Panic" model, in which the degree of learning is related to the degree of challenge presented to the learner. When there is little challenge present, the learner is in the comfort zone and any learning that happens is mainly considered to be by chance. In the stretch zone, learners are presented with some stress, and are motivated to optimal performance. When the challenge, or stress becomes too great, “individuals enter the 'panic zone' in which learning is severely impaired” (p. 422). When learners are in the panic zone they may lose memory and be less effective at processing the material presented to them.

Palethorpe and Wilson (2011) developed a survey in which they asked trainers to list approaches they utilize to help learners manage anxiety. Common approaches cited included providing learners with extra coaching, working with learners individually to identify causes of anxiety, and encouraging the group to support each other (p. 429). Although the participants in the study were involved in indoor-based management training programs, outdoor experiential training programs, and social work programs, the recommended teaching approaches may apply to a professional educational program such as nursing. In fact, some of the anxious behaviors identified in the learning environment are seen in simulation activities with nursing students, including melting "into the background in group work,” "becomes upset or needs constant approval,” and complaining about the course (p. 432). 


\section{NURSING STUDENT ANXIETY IN SIMULATION SETTINGS}

Sogunro (1998) wrote specifically about evaluation anxiety in adults. In nursing education, simulation is often not used as a graded or evaluative activity, but rather as an opportunity for students to practice patient care in a simulated environment. It is often included in clinical practice hours, similar to clinical activities on a hospital unit.

Nevertheless, there is a formative evaluation component in that faculty are observing the activities and facilitating a feedback, or debriefing session, after the simulation.

Therefore, the anxiety felt by students may be likened to evaluation anxiety. Sogunro believes that educators ought to "adopt some teaching strategies to disabuse the minds of the learners from the traditional belief that evaluation is the pinnacle of the teachinglearning transaction” (p. 118). In nursing simulation programs, this might mean convincing students of the value of the practice situation, even when mistakes are made or the activity does not unfold as planned. Similar to other authors, Sogunro believes that "while a moderate amount of anxiety can enhance adult motivation toward learning, too much anxiety can be devastating” (p. 109). Some of the specific factors identified by Sogunro as causing anxiety for learners include negative feedback, memory deficits, inadequate preparation, unfriendly environment and impromptu assessments, all of which could exist in a nursing education program. Practices which may help learners manage anxiety were discussed, including acknowledging that students may experience anxiety and that it is normal, relaxation and meditation, study skills, counseling, and regular and constructive feedback.

In an exploration of the causes and consequences of academic anxiety, Levine (2008) used the work of Michel Foucault and others to understand the anxiety related to 


\section{NURSING STUDENT ANXIETY IN SIMULATION SETTINGS}

performance and achievement among children and adults. In a thorough description of

learning that relates particularly well to simulation, Levine explains:

Learning can be understood as an encounter with unknown or unfamiliar material. The challenge of this encounter is to master new material. However, in a sense, at the beginning of the learning experience, everyone is in a state of failure - not knowing the new material. Consequently, when an individual experiences failure as a threatening situation that prevents that person from proceeding forward (in this case, learning new material), then anxiety becomes an obstacle that may prevent that person from successfully approaching and mastering new material. Thus, learning may be perceived as a continuous process in which an individual encounters material that is not known, with the intention of organizing and integrating that material into an already-developed base of knowledge. Students for whom anxiety prevents ongoing engagement in this process do not succeed in learning (Levine, 2008, p. 63).

Levine contends that students who do not understand the material being taught or cannot apply it in context, may focus on memorizing small details and facts instead of stepping back and understanding where the details and facts fit into the bigger picture. Some of the consequences of anxiety reported by Levine are rigid thinking, inability to solve problems, and focusing on one's self instead of what is happening in the larger environment. An anxious student in simulation may demonstrate this by spending an inordinate amount of time watching a monitor or preparing a medication correctly while a patient is "going downhill" and needs immediate attention. As Levine states, "because the learning process requires reorganization of one's disciplinary knowledge to accommodate new information, limitations on cognitive or complex intellectual processing and increased rigid thinking diminish learning directly” (Levine, 2008, p. 65). Levine’s work reinforces the need to examine how anxiety in simulation affects the learning of the nursing student. Learning under stress and the anxiety experienced by students are issues 


\section{NURSING STUDENT ANXIETY IN SIMULATION SETTINGS}

worth investigating. The following section explores selected literature on stress and anxiety as perceived by nursing students in simulation, and includes some of their recommendations to help manage anxiety.

\section{Nursing Students’ Experiences}

Cordeau (2010) used a phenomenological approach to help understand the experience of the learners in simulation. The research sample consisted of 19 junior level baccalaureate students who participated in a graded simulation activity. The students received preparatory materials prior to the simulation and were offered orientation to the simulation mannequin as well as practice sessions prior to the graded activity. This was a high stakes endeavor because the students needed a "Pass" grade in order to progress in the program. Students were allowed to repeat the simulation as many times as necessary to pass the course, and three of the 19 required a second attempt, which they did pass.

Students who participated were asked to write a reflection on the following: “Please describe your experience of living through your high-fidelity simulated learning experience focusing on your thoughts and feelings before the simulation, during the simulation, and during the debriefing period. Describe your state of mind, your mood, your emotions. Try to focus on an example of the experience which stands out for its vividness, or as well as the first time” (Cordeau, 2010, p. 10). Five themes were identified in the student reflections, and the first one identified was perceived anxiety. The anxiety was present at multiple times throughout the simulation experience, beginning with confronting the unknown in the scenario, and continuing through the debriefing experience, which the author terms “critiquing-the-performance” (Cordeau, 2010, p. 13). 


\section{NURSING STUDENT ANXIETY IN SIMULATION SETTINGS}

Most of the students also discussed how they valued the simulation for the learning it provided, which included understanding patient cues and responses and the opportunity to analyze their own thoughts and actions. Cordeau concluded that faculty responses to the students' anxiety could have an impact on their learning, and that if anxiety is managed effectively, "the student can focus on the cognitive, affective, and psychomotor skills needed for the scenario and critiquing, rather than on the physical and emotional sensations that accompany the anxiety” (Cordeau p. 14). Although the sample was small, Cordeau's work contributes to the rationale for studying anxiety, simulation, and learning.

Elfrink, Nininger, Rohig, and Lee, (2009) obtained data from 114 senior nursing students to determine how simulation could be adapted to decrease apprehension and promote collaborative learning. Utilizing surveys and focus groups, the researchers asked questions at midterm, made changes to the course, and again surveyed the students at the end of the term. Questions addressed what students found helpful and not helpful in simulation, and what they would like changed.

Students identified that during simulation, they "felt unfairly 'singled out'... and perceived that their apprehension interfered with their learning” (Elfrink et al., 2009, p. 83). They were concerned about not knowing what to do in the scenario, and having difficulty approaching the patient and beginning to provide care. Students particularly opposed watching their videotaped scenario in the debriefing, and having to repeat the scenario a second time, reporting that they would benefit instead from more time discussing the case in debriefing. 


\section{NURSING STUDENT ANXIETY IN SIMULATION SETTINGS}

As part of this formative evaluation research, the faculty addressed the student concerns and made changes mid-course, including refraining from playing the videotaped scenarios and adding a group planning time prior to the scenario. The students were surveyed again at the completion of the course and asked again about their learning in simulation. They reported less anxiety and "greater ownership of the entire simulation plan” (Elfrink et al., p. 86) along with a better learning experience. The authors conclude that "the case can be made that there is a link between what information or meaning the student takes from a simulation and emotions and self-awareness that are experienced during the simulation” (Elfrink et al., p.84). The practices incorporated into the learning activity at mid-term may have brought students’ anxiety from a panic level to a manageable level, allowing them to experience greater learning.

Recognizing the importance of a safe learning environment, Ganley and LinnardPalmer (2010) used a descriptive online survey design to examine student and faculty perceptions of academic safety. They cited multiple sources describing student apprehension and anxiety in a simulation environment, including reports of nervousness, humiliation, and intimidation, and gathered data regarding what is needed to provide an academically safe learning environment in which anxiety was manageable. Students described the preferred environment as "one in which they were not ridiculed, or embarrassed by their mistakes, where they were able to function without debilitating anxiety, and where they were not afraid to fail” (p. e4). Students also reported wanting to be exposed to challenges and wanting to ask questions of supportive faculty, along with being "given an opportunity to increase confidence, to experience healthy anxiety, and to 


\section{NURSING STUDENT ANXIETY IN SIMULATION SETTINGS}

excel in a positive environment” (p. e4). The students seemed to have some appreciation for the role anxiety plays in their learning.

Faculty perceived safe learning environments differently, and were much broader in their descriptions. They described an academically safe environment as one "with psychologically and emotionally balanced conditions; it should be a positive experience for everyone and non-threatening for the students” (Ganley \& Linnard-Palmer, 2010, p. e8). Based on the descriptions of students and faculty, Ganley and Linnard-Palmer made recommendations for creating a safe environment in simulation, including orienting students to the environment, ensuring that they were prepared to perform necessary skills prior to the simulation, encouraging critical thinking, and creating a nurturing environment where students are expected to succeed. Although the sample size was small, (101 students and 24 faculty), the results were important because they included a student perspective.

Gore, Hunt, Parker, and Raines, (2011) performed a study to determine the effect of a mock hospital simulation experience on students' anxiety levels prior to caring for patients in a real clinical environment. The sample consisted of 70 junior level nursing students who were enrolled in their first nursing clinical course. The simulation experience was unique in that it was a four hour activity and included students' review of patient charts, a discussion of nursing diagnoses led by faculty, bedside care, medication administration, and charting, closely resembling a student's clinical day on a hospital unit. In this experimental study, 47 students participated in this simulation activity prior to clinical, and a control group of 23 did not. The Spielberger State-Trait Anxiety 


\section{NURSING STUDENT ANXIETY IN SIMULATION SETTINGS}

Inventory (STAI) was used as a measurement tool, and results support the use of simulation to decrease student anxiety prior to their first clinical experience. The anxiety scores of students who participated in the four-hour simulation were significantly lower than those who did not. Although this study did not explore the students' anxiety experience during the simulations, the authors report that their findings "demonstrate the value of reducing one critical barrier to learning: anxiety level” (Gore et al., p. e179). The authors, however, did not address the fact that some degree of anxiety may actually facilitate learning.

In another study examining the use of simulation to decrease student anxiety in clinical, Megel et al., (2011) examined the effects of a pediatric assessment simulation session prior to students' assessment of a hospitalized child. The researcher identified that nursing students have particularly high anxiety levels when caring for hospitalized children and attempted to prepare them by using a high-fidelity infant mannequin in a controlled learning environment. The STAI was used in this study, which included 52 baccalaureate nursing students in a pediatric course. Twenty-seven of the students participated in the pre-clinical simulation with a child mannequin, and 25 participated in a preparation session that consisted primarily of skills practice, without a mannequin. The authors found that anxiety scores as measured prior to patient care on the pediatric unit were significantly lower for the students who, prior to clinical, participated in the simulated patient assessment. Although the study did not investigate the impact of anxiety on learning, it did make some connections between anxiety, patient care, and the use of simulation as a tool. 


\section{NURSING STUDENT ANXIETY IN SIMULATION SETTINGS}

Szpak and Kameg (2011) performed a similar study, using simulation to decrease nursing students' anxiety prior to care of mentally ill patients. The authors identified a lack of research on the use of simulation in psychiatric nursing courses. Like pediatrics, psychiatric nursing has also been identified as a clinical area in which students exhibit “anxiety, fear, and negative attitudes” (p. e1) and the authors wished to prepare them to communicate more effectively with psychiatric patients. The participants, undergraduate nursing students in a psychiatric nursing course, listened to a two-hour lecture and participated in a simulation of a mental health patient prior to clinical. The authors used a quantitative, quasi-experimental study design, and measurement tools included the STAI, a visual analogue scale on anxiety, and a student satisfaction scale. Their findings revealed that the students' anxiety levels, as measured by the STAI, decreased after their participation in the simulation. They also reported that the simulation would help them be less nervous working with patients on the clinical unit. Similar to other studies, there is no examination of the impact of anxiety in simulation on learning, but a connection is made between simulation and anxiety reduction.

Lasater (2007) described the student experience in simulation, particularly as it related to their development of clinical judgment. Defining clinical judgment as "those thinking and evaluative processes that focus on a nurse's response to a patient's illstructured and multilayered problems” (p. 269), the author stated that high-fidelity simulation was one of the ways in which faculty could create a realistic context in which to engage students in complex patient situations. Lasater's subjects were from a cohort of 48 nursing students, 47 of whom signed consent forms to participate. Of the 47 who 


\section{NURSING STUDENT ANXIETY IN SIMULATION SETTINGS}

signed consents, 39 of them were observed by the researcher. Of these 39, 8 volunteered to participate in focus groups. In the focus groups, Lasater discussed with students how simulation helped them develop clinical judgment. The groups were asked questions about the helpfulness of the debriefing, their thoughts during the simulation, and how the scenarios helped them learn the most about clinical judgment.

A main theme in the focus groups was anxiety, or, what Lasater terms "the paradox of anxious and stupid feelings yet increased awareness” (p. 273). Students described a sense of foreboding in the scenarios, along with feeling "like an idiot" and knowing they “could really mess up” (p. 273). In spite of this discomfort, students reported that they did learn from the simulations, and in fact, learned most when a mistake had been made. They also verbalized a need for feedback, particularly feedback about what they might have done better. For Lasater's students, there may have been an optimal level of anxiety that facilitated, rather than deterred learning (Lasater, 2007).

Walton, Chute, and Ball, (2011) conducted a grounded theory qualitative study in which they asked students about how simulation helped them learn, and how the faculty in simulation facilitated their learning. Data were collected using "in-depth audio-taped interviews lasting 16-60 minutes, theoretical memos, field notes, and focus group interviews” (p. 300). The participants were 26 baccalaureate nursing students who had completed two semesters of clinical courses involving simulation.

From the student responses, the researchers identified a primary theme that they labeled "Negotiating the Role of the Professional Nurse” (p. 301). The students' comments fell into five phases of role attainment, beginning with "feeling like an 


\section{NURSING STUDENT ANXIETY IN SIMULATION SETTINGS}

imposter” and ending with "professionalization” (p. 301). Interestingly, anxiety was reported as a predominant theme in all phases, and students also expressed fear, awkwardness, and insecurity as they learned the professional nurse role in a simulation environment. Although a high level of anxiety was reported initially, this anxiety decreased as students became more experienced in simulation, and they were able to comfort and support other students. In fact, during the third phase, "taking the role seriously,” students related that they had studied and practiced for their simulations, and "felt anxious and ready to meet the challenge of the simulation experience” (p. 305). Again, it may be that they were nearing a helpful level of anxiety in which their learning could be optimized. An important outcome of the study was that "students verbalized that they were able to transfer their skills and knowledge to clinical practice while gaining confidence” (p. 309). This transference of learning to the clinical setting is the ultimate goal of simulation, and this study demonstrates that, even though anxiety is present, it does not prevent learning for nursing students in simulation.

There is evidence in the literature that anxiety is commonly seen in nursing students engaged in simulation activities. There is also evidence that anxiety can facilitate learning, and, if we examine the students’ perspective, we may learn more about how to use this anxiety to help them gain the most benefit from their simulation activities.

\section{Summary and Implications}

The literature on the use of and rationale for using simulation in nursing education programs was reviewed. Learning theory supporting the use of simulation was summarized, and stress and anxiety and their effect on learning were identified as both 


\section{NURSING STUDENT ANXIETY IN SIMULATION SETTINGS}

detrimental and beneficial aspects of simulation. Several studies examining both faculty and student perspectives of simulation were explained, specifically as they explored the anxiety elicited by a simulation experience.

Several educators called for further research on the issue of student anxiety and its effect on learning in a simulated clinical environment, especially from the student perspective. Ganley and Linnard-Palmer (2012) suggested investigating "how to make nursing students feel academically safe in high-fidelity simulation situations” (p. e8). Cordeau (2010) recommends that nursing faculty “consider students’ perception and meaning of the experience when designing, implementing, and evaluating individual graded clinical simulations” (p. 10). Elfrink et al. (2009) suggest “further study is also needed to determine the influence of differing variables on the degree of learning achieved through simulation” (p. 86). Gore et al. (2010) identified a need to evaluate student anxiety and elicit student suggestions for how to improve the simulation experience. Further study of "the effects of simulated learning experiences on student affective, cognitive, and psychomotor outcomes” was recommended by Megel et al. (2011).

This literature review supports the further investigation of student anxiety in simulation. Evidence was found that simulation does indeed cause anxiety, and that anxiety effects student learning. There was mention of the idea that anxiety may be beneficial to student learning, but little evidence of how much anxiety is needed, and how faculty can help students manage their anxiety and use it to help them learn. The student 


\section{NURSING STUDENT ANXIETY IN SIMULATION SETTINGS}

perspective is explored in some literature, but studies investigating what specifically causes anxiety and what might be helpful are rare.

The intention of this study was to explore the student perspective on learning in simulation, specifically to answer the questions of what is causing anxiety for nursing students in simulation, how anxiety affects their learning, and what can be done to decrease anxiety and maximize learning.

\section{Methodology}

This exploratory study used a mixed methods approach to identify the specific anxiety-producing elements of simulation from a student perspective, along with student ideas of what helps them manage anxiety. Marshall and Rossman (2011) define the purpose of exploratory studies as investigating issues that are poorly understood. General research questions relate to what is happening, and what are the themes or "categories of meaning” for the participants (p. 69). Johnson and Onwuegbuzie (2004) promote the use of mixed methods in educational research, explaining that mixed research "can provide stronger evidence for a conclusion through convergence and corroboration of findings,” and, can "produce more complete knowledge necessary to inform theory and practice”(p. 21). Use of both quantitative and qualitative methods in this study expanded the understanding of the students’ perspectives, and provided the best data to answer the research questions.

When the survey results were compiled and analyzed, students were invited to participate in focus groups. The questions for the focus group were designed to elicit further information about anxiety and learning in simulation. Students were asked about 


\section{NURSING STUDENT ANXIETY IN SIMULATION SETTINGS}

their feelings in simulation, which elements of simulation gave them confidence and caused anxiety, how anxiety affects their learning, and what helps their learning in simulation. Chapter 3 will discuss the methodology in greater depth. 


\section{NURSING STUDENT ANXIETY IN SIMULATION SETTINGS}

\section{Chapter 3 - Methodology}

\section{Purpose of the Study}

The purpose of this study was to explore the student experience in simulation. Simulation is used in nursing education programs to provide an environment for students to practice the nurse role in a simulated patient care setting. The use of simulation in multiple formats is increasing in nursing education programs across the country. Studies have been done in nursing education programs and in other healthcare environments demonstrating that simulation can be effectively used as a teaching strategy, and also that simulation can cause anxiety for the learner. The anxiety may be related to multiple aspects of simulation, including the technology of the mannequins, the cameras and audio-visual equipment, and the fact that students are often observed by colleagues and faculty. While some anxiety may be motivating to the learners, it also may have negative effects. In order to maximize student learning, it is important that educators understand the student experience in simulation, specifically related to the stress and anxiety that simulation produces. The data obtained may be helpful in designing simulation activities and providing support to learners.

\section{Research Perspective}

This exploratory study used a mixed methods approach to answer the questions of what is causing anxiety in nursing simulation, how anxiety affects this learning, and what can be done to decrease anxiety and maximize learning in simulation. A survey was administered as the first step of the study in order to obtain quantifiable data on what specifically is causing student anxiety. The survey was followed by a focus group 


\section{NURSING STUDENT ANXIETY IN SIMULATION SETTINGS}

interview, in which students were led in a discussion of their perspectives of learning in simulation. Data from both stages of the study were examined and incorporated in the results. Use of both quantitative and qualitative methods in this study expanded the understanding of the students' perspectives, and provided the best data to answer the research questions.

\section{Research Setting}

Two baccalaureate degree programs in the same academic health center in the Pacific Northwest were used for the study. These included an accelerated 15-month (five 10-week terms, or quarters) nursing program, in which students must have a previous degree and complete pre-requisites prior to beginning the nursing courses, and a more traditional baccalaureate approach, which requires completion of pre-requisites followed by three years (nine 10-week terms, or quarters) of nursing courses. Students in both programs participate in simulation in clinical courses each term, beginning their first term in both programs. The students in the accelerated program are enrolled in a condensed version of the traditional baccalaureate curriculum, and they attend the program yearround with no breaks. The traditional program students begin in fall quarter, and the students enroll in courses fall, winter, and spring quarters, with a break during the summers. Because of the different approaches to presenting the nursing curriculum, it was thought that students in each program would describe different stressors, and that they may have differing ideas about what would facilitate their learning in simulation.

Simulation is implemented in the same way for the accelerated students and the traditional three-year program students. In groups of eight to twelve students, they attend 


\section{NURSING STUDENT ANXIETY IN SIMULATION SETTINGS}

a four-hour simulation session, during which four cases, or clinical situations, are depicted. The simulation facilitators are School of Nursing faculty members, and they guide the simulated clinical situations from a control room, from which they are able to view the participants through a one-way viewing window. Typically, during each case, a team of two or three students participates in the clinical situation. The remaining students in the group observe the case from the observation, or "debriefing” room. All students, including participants in the case and observers, are led in a debriefing session facilitated by the simulation faculty immediately following each case. These debriefing sessions are carefully led with attention to case objectives and known best practices in debriefing. For some sessions, the students’ clinical instructors are present and observe the simulations from the observation room along with the rest of the student observers. These instructors also accompany the students when they practice clinical nursing activities on patient care units.

\section{Target Population and Participant Selection}

All nursing students in both programs who had taken part in simulation were solicited for the study. This sample of undergraduate nursing students is representative of nursing students across the country, in terms of their involvement in simulation as a clinical learning activity. As noted in a large study on simulation conducted by the National Council of State Boards of Nursing (NCSBN), fifty-four percent of nursing programs used simulation in five or more nursing courses (Hayden, 2010). The students in this study participated in simulation in either five courses (the accelerated students), or eight courses (the traditional program students), demonstrating consistency with the 


\section{NURSING STUDENT ANXIETY IN SIMULATION SETTINGS}

national trend. Also, as a member of the nursing faculty in simulation, I am familiar with their curriculum and simulation activities, and I will have access to their email addresses in order to contact them regarding the research.

Table 3.1 below provides details about the students and their eligibility to participate in the research. In fall 2012, four cohorts of nursing students were eligible for the research study. The following table lists the programs, levels, and numbers of students whose participation was enlisted.

Table 3.1: Students Eligible for Simulation Study

\begin{tabular}{|l|l|l|l|}
\hline Program & Cohort Enrollment & $\begin{array}{l}\text { Number of Quarters } \\
\text { of Simulation } \\
\text { Completed }\end{array}$ & $\begin{array}{l}\text { Number of Students } \\
\text { in Cohort }\end{array}$ \\
\hline $\begin{array}{l}\text { 15-month } \\
\text { Accelerated } \\
\text { Baccalaureate }\end{array}$ & Summer 2012 & 1 & 64 \\
\hline $\begin{array}{l}\text { 15-month } \\
\text { Accelerated } \\
\text { Baccalaureate }\end{array}$ & Fall 2011 & 4 & 28 \\
\hline $\begin{array}{l}\text { 3-Year Traditional } \\
\text { Baccalaureate }\end{array}$ & Fall 2011 & 3 & 24 \\
\hline $\begin{array}{l}\text { 3-Year Traditional } \\
\text { Baccalaureate } \\
\text { (includes 30 } \\
\text { community college } \\
\text { transfer students, } \\
\text { who joined cohort in } \\
\text { spring 2012) }\end{array}$ & Fall 2010 & 6 & 62 \\
\hline & Total \# eligible \\
\hline
\end{tabular}




\section{NURSING STUDENT ANXIETY IN SIMULATION SETTINGS}

\section{Instruments and Measures}

In this section, the survey and the focus group will be explained. The procedures used to enlist participants and collect the data will be described.

Survey. The first step of the study involved a survey that was administered electronically using Qualtrics software. Qualtrics is an online survey platform used to collect and perform preliminary analysis of data. The survey consisted of a list of aspects of simulation that have been identified, either in the literature or personal conversation with students, as causing anxiety. Survey respondents were asked to rate the individual items on a 5-point scale according to their response to each item. The scale responses were 1 . Very confident, 2. Moderately confident, 3. Neutral, 4., Slightly anxious, and 5. Very Anxious. The survey contained two open-ended questions: "Please describe anything else about simulation that has helped you feel confident in your learning, and “Please describe anything else about simulation that has caused anxiety for you.” Basic demographic information was also included.

Johnson and Christensen (2012) state that a questionnaire, or survey, must be pilot tested "to determine whether it operates properly," and that this must be done "before using it in a research study (p. 183). The simulation survey was first piloted with faculty and staff colleagues, who provided feedback on the questions and ease of administration. The survey was then given to a group of 46 volunteer students near the completion of their nursing program who had participated in multiple simulation activities, and who were asked not only the survey questions, but also for feedback on the tool itself. Because they were about to graduate, none of the students completing the pilot 


\section{NURSING STUDENT ANXIETY IN SIMULATION SETTINGS}

survey were eligible for inclusion in the actual data collection. Based on their comments, two changes were made to the final survey. One change involved rewording of a question, and the other resulted in the inclusion of an additional potential stressor that had not been considered in the original list (“observing others in simulation”).

After the survey was reviewed and revised for final data collection, the final survey, (Appendix A), was administered to nursing students in fall of 2012. Survey results were analyzed, and the results were used to guide a focus group discussion, which took place in late fall of 2012. The intention of the focus group was to confirm and expand upon the survey data.

Focus Group. Focus groups are one of the most commonly used methods of data collection in education research (Johnson \& Christensen, 2012). Their purpose is to provide "in-depth and rich information about participants; worldviews and their personal perspectives and subjective meanings” (Johnson and Christensen, 2012, p. 429). The focus group explored more holistically what students feel and believe about simulation, anxiety, and learning. Using results from the survey identifying major stressors, questions were intended to obtain information from the students' perspectives. One of the benefits of using focus groups is the "explicit use of group interaction to produce data and insights that would be less accessible without the interaction found in a group” (Morgan, 1997, p. 2). The intention of the group was that, by hearing from others about their anxiety, students would be encouraged to be honest and participate in an open dialogue about the topic and their personal experience. Rather than being too directive, “the focus group 


\section{NURSING STUDENT ANXIETY IN SIMULATION SETTINGS}

interview allows the participants in the group to comment, explain, disagree, and share attitudes and experiences” (Curtis \& Redmond, 2007, p. 25).

Cazzell and Rodriguez (2011) used focus groups in a study exploring nursing students’ feelings, beliefs, and attitudes about completing an Objective Structured Clinical Evaluation (OSCE). The OSCE was similar to a simulation experience in that students were performing medication administration with a simulated patient while being videotaped. For this OSCE experience students performed the patient care alone rather than as part of a team, and the purpose of the OSCE was evaluation (pass/remediate) rather than practice. Cazzell and Rodriguez state that the cognitive or knowledge domain and psychomotor skills are frequently addressed in the evaluation of nursing students. The authors claim that "the affective domain is the most neglected domain in higher education” (p. 711) and that behavior is associated with emotions, an aspect of the affective domain. While paper and pencil tests and skills check-offs can be used to test knowledge and skills, focus groups can elicit comments from students in their own words and provide a more accurate portrayal of their feelings, beliefs, and attitudes towards a topic. In a focus group setting, participants can "engage in communication which highlights their perspective, appraisal, and even suggested solutions to a specific problem” (Serrant-Green, 2007, p. 3). It was with this intent that a focus group was used in the study.

\section{Procedures}

The research was explained to all eligible nursing students in an email in which the study was described. Students were assured of the anonymity of their responses, the 


\section{NURSING STUDENT ANXIETY IN SIMULATION SETTINGS}

pooling of the data, and the promise that their involvement in the study would not affect their grades or standing in the program in any way. As a faculty member in the simulation center who teaches in many courses, neither I nor other simulation faculty members administer grades to students in any courses, which hopefully reassured students of safe participation. Students who expressed interest in the survey needed only to click on a link in the email to be connected to the consent and survey.

The survey was administered using Qualtrics software. There was no assignment to groups for the study, other than the groups the participants are already part of related to their program. Focus group participants were also solicited via an email invitation sent to all students in eligible cohorts. The focus group took place within two weeks after the survey on the school campus.

\section{Obtaining Informed Consent}

The nursing students who expressed interest in participating in the study completed a Portland State University Institutional Review Board approved consent form. Because there were two parts of the study, two consent forms were used. One was sent by email to students who volunteered to complete the survey, and the second consent was completed by participants prior to participation in the focus group. Both consent forms included my name as the researcher, the purpose of the study, risks and safeguards for the participants, reassurance that participation was voluntary, a statement that the participant could withdraw at any time, the extent to which confidentiality would be maintained, contact information for the researcher and the IRB, and indication that the participant would receive a copy of the form for his/her own records. The consent form 


\section{NURSING STUDENT ANXIETY IN SIMULATION SETTINGS}

for focus group participants contained the above information along with a statement that confidentiality cannot be guaranteed in the focus group setting, as the researcher has no control over the information that may be discussed by participants after the focus group has concluded. Participants were asked to respect each other's privacy by not discussing the conversation of those who attended the group.

\section{Data Storage}

Completed surveys were identified by responses only; no name was required on the survey form. Data from the surveys was transferred to IBM Statistical Package for the Social Sciences software (SPSS) for analysis. Completed surveys were identified by responses only; no name was required on the survey form. The surveys will be kept in an electronic file for a minimum of three years. The audio-tapes and transcriptions of the focus group will also be kept for a minimum of three years.

\section{Role of the Researcher}

Due to the sensitive nature of the information requested of the participants and the researcher's role in the nursing program (I am a faculty member who teaches in the simulation center), care was taken to protect students who elected to participate. Inclusion in the study, particularly in the focus group portion, required that students be willing to share personal experiences in simulation. Orb, Eisenhauer, and Wynaden (2000) explain that "embedded in qualitative research are the concepts of relationships and power between researchers and participants” (p. 93). Although students are likely to perceive a faculty/student power differential, they were reassured of the following: that I will not, at any time during their nursing program, be administering a grade in any nursing courses; 


\section{NURSING STUDENT ANXIETY IN SIMULATION SETTINGS}

that I will not be leading the focus group; and, that the results of the study will be used for the intended purpose of maximizing student learning by considering their recommendations for supportive measures to help learners manage anxiety. As Orb, Eisenhauer, and Wynaden (2000) explain, “the intention of the researcher is to listen to the voice of participants” (p. 94).

\section{Data Collection and Data Analysis}

The following chart depicts the methods used to analyze the data.
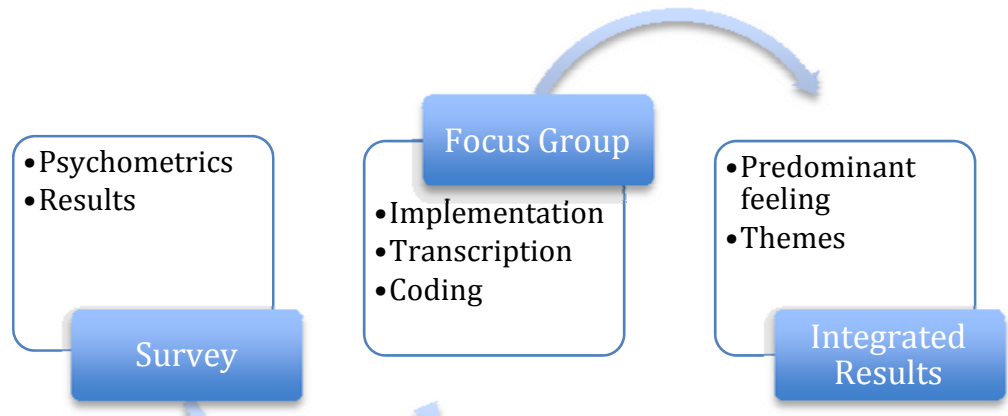

Surveys. The email invitation to participate was sent to 176 eligible undergraduate nursing students. Seventy-three students, or $40 \%$ of those eligible, completed the survey. This included 66 students identified as female, and 7 students identified as male. The majority of respondents (35 students) were in the 20 to 29 year old age range. Twenty-nine respondents were between 30 and 39, eight were between 40 and 49, and one was between 50 and 59. Statistical analysis of the demographic data and responses to the survey items was completed using SPSS software.

Focus group. After the survey, students were invited to participate in focus groups to further explore the notion of simulation anxiety. Morgan (1997) stated that 


\section{NURSING STUDENT ANXIETY IN SIMULATION SETTINGS}

focus groups can add to the data obtained by using qualitative methods, and that "issues of depth can sometimes favor focus groups” (p. 11). Since discussing their anxiety may itself cause students to be anxious, it was thought that a group setting would offer collegial support and students may elicit comments within a conversational context.

Marshall and Rossman (2011) express concern over the role of power dynamics in a focus group setting. Creswell (2012) also questions whether data collection in one’s own organization may "introduce a power imbalance between the researcher and the individuals being studied” (p. 151). For this reason, simulation faculty did not conduct the focus group for this study. A graduate student who was trained as a social worker and was an experienced moderator was enlisted to conduct the group, encouraging participants to be forthright in their responses.

The original research plan included two focus groups consisting of 6 to 12 participants each, with one group for each program. Because homogeneous groups are reportedly more likely to promote discussion (Johnson \& Christensen, 2012), the accelerated program students were invited to participate in one group, and the traditional program students in another. Sim (1998) believes that "the more homogeneous the membership of the group, in terms of social background, level of education, knowledge, and experience, the more confident individual group members are likely to be in voicing their views” (p. 348). At the time of the focus groups however, there were not enough students volunteers to convene two separate groups. Ten students volunteered, including both accelerated and traditional program students. One student was ill the evening of the focus group, leaving the combined final focus group with nine participants. Volunteers 


\section{NURSING STUDENT ANXIETY IN SIMULATION SETTINGS}

were provided with a light meal and given a gift card to a local coffee shop for their participation.

Two activities took place during the focus group. Because the students were from different cohorts and did not necessarily know one another, the facilitator spent approximately 45 minutes with them prior to starting the audio-recorded dialogue. Snacks and beverages were provided to help increase participant comfort and familiarity with one another. As an icebreaker at the beginning of the session, the participants were provided with paper, pens, and colored markers, and asked to “draw yourself in simulation.” Each of the nine participants drew a picture, and these were submitted after the focus group. Themes similar to those identified in the survey could be found in the pictures, and these will be discussed in Chapter 4. The facilitator then directed a conversation with the use of the following probing questions:

"What feelings do you experience around simulation, before, during and after?

“How is your anxiety manifested?”

"What helps, what makes you feel more confident?”

“How does being anxious affect your learning?

"What would help lower anxiety levels and raise your confidence?”

The focus group, which lasted 63 minutes, was audio-recorded. The recording was saved as a digital file and sent electronically to an outside company for transcription. The transcribed data was then analyzed for further investigation. Participants were reassured that they would not be identified by name, and that the tapes would be used only for data analysis and not presented in any way to the public, as recommended by 


\section{NURSING STUDENT ANXIETY IN SIMULATION SETTINGS}

Morgan (1997). The transcribed documents were coded and categories of responses were identified. According to Creswell (2013), triangulation involves the use of multiple sources of data and "corroborating evidence from different sources to shed light on a theme or perspective” (p. 251). Triangulation of data was achieved by use of defined survey items, two open-ended survey questions to which students could reply with their own comments, and the responses in the focus group.

\section{Summary}

Chapter 3 explained the methodology and purpose of this study, which is to explore the student experience in simulation. The potential participants and their programs of study were defined, as well as how students were solicited for participation. The survey instrument and data collection was discussed. The focus group technique was described, along with the specific role of the researcher and protection of the student participants. 


\section{NURSING STUDENT ANXIETY IN SIMULATION SETTINGS}

\section{Chapter 4 - Results}

This study examined the anxiety experienced by nursing students as they participate in simulation activities, particularly as anxiety relates to their learning. Data collection began with a pilot survey, which was followed by a final survey incorporating feedback and additional information obtained from the pilot. Survey results were used to create discussion questions for a focus group of volunteer nursing students whose clinical courses included simulation. A nursing graduate student who had participated in simulation in her undergraduate program, and was therefore familiar with the simulation process facilitated this focus group. The results are presented in two categories: results of the online survey and results of the focus group.

\section{Simulation Survey}

\section{Survey Psychometrics}

A Cronbach's alpha test was run on the survey results, to determine measure of reliability of the survey, which should indicate that a measure (the survey), consistently reflects the construct, anxiety (Field, 2009). Cronbach’s alpha is considered the “appropriate choice for measuring internal consistency in scales where items have more than two responses” (Adamson \& Prion, p. e1); in this case the scale includes five possible responses.

Table 4.1: Reliability Statistics - Survey

\begin{tabular}{|l|l|l|}
\hline Cronbach's & $\begin{array}{l}\text { Cronbach's } \\
\text { Alpha based on } \\
\text { Alpha }\end{array}$ & $\begin{array}{l}\text { N of } \\
\text { Items } \\
\text { Itandardized } \\
\text { Items }\end{array}$ \\
\hline
\end{tabular}


NURSING STUDENT ANXIETY IN SIMULATION SETTINGS

\begin{tabular}{|l|l|l|}
\hline .922 & .923 & 19 \\
\hline
\end{tabular}

The Cronbach’s alpha for the survey is .923. In general, a value of .7 to .8 is considered acceptable, with lower scores suggestive of unreliability of the scale, or survey instrument. The value of .923 indicates a high Cronbach’s alpha, therefore the survey is likely reliable (Field, 2009).

\section{Participants}

The survey (Appendix B) was distributed via email to students who were on the enrolled class lists for eligible participants, including all undergraduate nursing students who had completed at least one term in the nursing program and participated in simulation in at least two courses. The eligible students had all experienced simulation in the two months preceding the survey; therefore they had recent experience in simulation upon which to consider their responses. There were 178 nursing students eligible, and 73 students, or $40 \%$ of those eligible completed the survey.

\section{Demographics of participants}

The students who completed the survey represent the following cohorts:

Table 4.2: Numbers of Nursing Students Completing Survey

\begin{tabular}{|l|l|l|l|}
\hline $\begin{array}{l}\text { Nursing Student } \\
\text { Cohort } \\
\text { (Program/Time in } \\
\text { Program) }\end{array}$ & $\begin{array}{l}\text { Number of } \\
\text { surveys } \\
\text { completed }\end{array}$ & $\begin{array}{l}\text { Number of } \\
\text { eligible students }\end{array}$ & $\begin{array}{l}\text { Percentage of } \\
\text { cohort } \\
\text { completing } \\
\text { survey }\end{array}$ \\
\hline $\begin{array}{l}\text { Accelerated } \\
\text { Baccalaureate, } 2^{\text {nd }} \\
\text { quarter/5 quarters }\end{array}$ & 28 & 64 & $44 \%$ \\
\hline $\begin{array}{l}\text { Accelerated } \\
\text { Baccalaureate, } 5^{\text {th }}\end{array}$ & 12 & 28 & $43 \%$ \\
\hline
\end{tabular}


NURSING STUDENT ANXIETY IN SIMULATION SETTINGS

\begin{tabular}{|l|l|l|l|}
\hline quarter/5 quarters & & & \\
\hline $\begin{array}{l}\text { 3-year program, } \\
\text { junior, } 4^{\text {th }} \text { quarter/9 } \\
\text { quarters }\end{array}$ & 11 & 24 & $46 \%$ \\
\hline $\begin{array}{l}\text { 3-year program, } \\
\text { senior, 6 } \\
\text { quarters }\end{array}$ & 22 & 62 & $35 \%$ \\
\hline
\end{tabular}

The reason for the lower response rate of the 3-year program seniors is unknown. Approximately half of this cohort began the nursing program at the university and were beginning their third year on the campus. Thirty of the 62 students, however, were community college transfer students who, as part of a statewide curricular initiative, had joined the cohort the prior spring and were therefore relatively new to the campus and the type of simulation being done in their courses. Due to the anonymity of the survey responses, it is unknown which students in this cohort elected to complete the survey. Although a previous degree is required only for the students in the accelerated program (40/73, or $55 \%$ of the participants were in the accelerated program,) most of the students who completed the survey had a previous degree of some type.

Table 4.3: Number of Survey Respondents with Previous Degree

\begin{tabular}{|l|l|}
\hline Previous degree & Number of respondents \\
\hline No previous degree & 7 \\
\hline Associate degree & 8 \\
\hline Bachelors degree & 56 \\
\hline Masters degree & 9 \\
\hline Other advanced degree & 2 \\
\hline
\end{tabular}




\section{NURSING STUDENT ANXIETY IN SIMULATION SETTINGS}

Nearly all of the respondents reported having previous work experience, many in healthcare and customer service fields.

Table 4.4: Prior Work Experience of Survey Respondents

\begin{tabular}{|l|l|}
\hline Prior work experience & $\begin{array}{l}\text { Number of } \\
\text { respondents }\end{array}$ \\
\hline In healthcare & 32 \\
\hline In customer service & 48 \\
\hline In public speaking or performing & 25 \\
\hline Other work experience & 52 \\
\hline No previous work experience & 1 \\
\hline
\end{tabular}

As seen in most undergraduate nursing programs across the country, the majority of nursing students enrolled at the university are female, which is represented in the survey response rate. Seven males and 66 female students completed the survey. Many of the students in the undergraduate nursing program have a previous degree and some type of work experience prior to entering the nursing program. This is reflected in their age, which is higher than traditional college students who matriculate after high school graduation. Although thirty-five respondents were between 20 and twenty-nine, more than half were over thirty years old.

Table 4.5: Age Ranges of Survey Respondents

\begin{tabular}{|l|l|}
\hline Age Range & Number of Respondents \\
\hline
\end{tabular}


NURSING STUDENT ANXIETY IN SIMULATION SETTINGS

\begin{tabular}{|l|l|}
\hline $20-29$ & 35 \\
\hline $30-39$ & 29 \\
\hline $40-49$ & 8 \\
\hline $50-59$ & 1 \\
\hline
\end{tabular}

\section{Relationship of Responses to Student Characteristics}

Respondent demographics were examined to determine whether any group of students experienced similar reactions in the simulation activities and how demographics might account for the findings as a whole. The variables of program and time in program are discussed first, since they are the most relevant variables when examining student perspectives in simulation. These variables are known to faculty who are teaching the students, and separate interventions to assist students’ learning could theoretically be offered to students at various times in the individual programs. Cross-tabs and Pearson's chi-square tests were done for each of the nineteen elements on the survey to determine relationship between accelerated program students and three-year program students and their survey responses. Field (2009) recommends using Pearson’s chi-square, which is "based on the simple idea of comparing the frequencies you observe in certain categories to the frequencies you might expect to get in those categories by chance” (p. 688). The following table lists the nineteen elements on the survey, and examines differences between programs (accelerated, or AB, vs. three-year) and time in program (with late in program being $5^{\text {th }}$ quarter/5 quarters for the accelerated program, and $7^{\text {th }}$ quarter/9 quarters for the three-year program.) There was little difference among the groups in the 


\section{NURSING STUDENT ANXIETY IN SIMULATION SETTINGS}

amount of confidence or anxiety reported. The significant results will be discussed after the table.

Table 4.6: Differences in Survey Responses Based on Program and Time in Program

\begin{tabular}{|c|c|c|}
\hline $\begin{array}{l}\text { Element of } \\
\text { Simulation }\end{array}$ & AB vs. 3-year & $\begin{array}{l}\text { Late in program } \\
\text { vs. early }\end{array}$ \\
\hline & p-value & p-value \\
\hline $\begin{array}{l}\text { Possibility of } \\
\text { making a mistake }\end{array}$ & .496 & .338 \\
\hline Being “on camera” & .517 & .286 \\
\hline $\begin{array}{l}\text { Performing in front } \\
\text { of faculty }\end{array}$ & .214 & .354 \\
\hline $\begin{array}{l}\text { Performing in front } \\
\text { of peers }\end{array}$ & .765 & .825 \\
\hline $\begin{array}{l}\text { Distinguishing } \\
\text { between what is real } \\
\text { and what is } \\
\text { simulated }\end{array}$ & .142 & .762 \\
\hline $\begin{array}{l}\text { Working with } \\
\text { medical equipment }\end{array}$ & $.015^{*}$ & .681 \\
\hline $\begin{array}{l}\text { Calling a physician } \\
\text { or provider }\end{array}$ & .103 & .154 \\
\hline $\begin{array}{l}\text { General feeling } \\
\text { during simulation }\end{array}$ & .735 & .073 \\
\hline $\begin{array}{l}\text { Making decisions } \\
\text { for a patient }\end{array}$ & .623 & .708 \\
\hline $\begin{array}{l}\text { Making a decision } \\
\text { about a patient }\end{array}$ & .664 & .564 \\
\hline $\begin{array}{l}\text { Caring for a patient } \\
\text { in the simulation } \\
\text { room }\end{array}$ & .696 & .971 \\
\hline $\begin{array}{l}\text { Working with the } \\
\text { mannequin }\end{array}$ & $.026 *$ & .370 \\
\hline $\begin{array}{l}\text { The preparation } \\
\text { beforehand }\end{array}$ & .307 & $.046 *$ \\
\hline $\begin{array}{l}\text { Administering } \\
\text { medications }\end{array}$ & $.017 *$ & .843 \\
\hline $\begin{array}{l}\text { Working with an } \\
\text { actor or } \\
\text { standardized patient }\end{array}$ & .267 & .850 \\
\hline When I receive & .384 & .748 \\
\hline
\end{tabular}


NURSING STUDENT ANXIETY IN SIMULATION SETTINGS

\begin{tabular}{|l|l|l|}
\hline $\begin{array}{l}\text { feedback from } \\
\text { faculty }\end{array}$ & & \\
\hline $\begin{array}{l}\text { When observing } \\
\text { other students }\end{array}$ & .347 & .563 \\
\hline $\begin{array}{l}\text { When I receive } \\
\text { feedback from other } \\
\text { students }\end{array}$ & .393 & .970 \\
\hline $\begin{array}{l}\text { Working with my } \\
\text { team }\end{array}$ & .053 & .808 \\
\hline
\end{tabular}

- $\quad$ alpha level .05

Working with medical equipment - accelerated versus 3-year program. Using

an alpha level of .05, the difference between students in the accelerated program versus those in the 3-year program was statistically significant, with a p-value of .015. The mean score for those in the accelerated program was 3.75, and for those in the 3-year program, 3.03. Working with medical equipment was related to increased anxiety for students in the accelerated program.

Working with mannequin - accelerated versus 3-year program. Using an alpha-level of .05, the difference between the anxiety of the accelerated students and the students in the 3-year program related to working with a mannequin is statistically significant. The mean score for the accelerated program students is 3.33, compared to 2.56 for those in the 3-year program. Working with the mannequin was related to increased anxiety among students in the accelerated program.

The preparation beforehand - late in program versus early in program.

The mean score for students late in the program (therefore with more time and clinical experience) was 3.15, and for those early in the program, 2.67. The p-value was .046. 


\section{NURSING STUDENT ANXIETY IN SIMULATION SETTINGS}

This indicates that, as students move closer to graduation, the preparation for simulation is related to an increase in anxiety, and the difference is statistically significant.

Administering Medications-Accelerated versus 3 - year Program. The mean score for accelerated program students was 3.56, and for 3-year program students, 2.36. This is statistically significant, with a p-value of .017. The accelerated program students reported more anxiety related to medication administration than the 3-year program students.

Other Demographics. Students were asked about gender, age, previous degree, and previous work experience primarily to obtain information about the sample population. In terms of student recommendations to improve learning, no specific interventions to decrease anxiety or improve learning would be offered based on any of these attributes. In fact, age, previous degree, and previous work experience would not necessarily be revealed to faculty during a student's nursing program. These are variables that might, however, impact the results as a whole.

Age Ranges. Age ranges were specified as 20-29, 30-39, 40-49, and 50-59. Because only one student identified as being in the 50-59 year age range, that student was included in the group from 40-49, expanding that range to include 40-59. Because three groups were being compared, a one-way ANOVA method was used. Each element on the survey was examined, revealing similar means for each age grouping. There were no statistically significant differences in survey responses based on age for any items on the survey. 


\section{NURSING STUDENT ANXIETY IN SIMULATION SETTINGS}

Gender. Consistent with nursing programs nationally, a small percentage of students in the programs in which the study took place are males. Seven of the 73 students completing the study identified as male. Pearson’s Chi-Square was done, identifying the means and the p-values of the responses. Using an alpha level of .05, there was a statistically significant difference in the element related to working with medical equipment based on gender, with a p-value of .000. The mean score for males was 2.28, and the mean score for females was 3.56. The male students appear to be more confident in working with medical equipment, which might include items such as cardio-respiratory monitors, IV pumps and tubing, and oxygen delivery devices.

Previous degree. Information on students’ previous degrees was obtained primarily to describe the sample population in the study. Faculty do not necessarily know which students have other degrees prior to entering the nursing program, other than the fact that a previous bachelor's degree is required prior to entering the accelerated program. Two-sample t-tests were used to examine the differences in responses, revealing that 10 of the 19 survey items had no significant differences. Respondents could select more than one option for previous degrees, complicating the value of this data. The most significant difference was in the item on "preparation beforehand," with students with a previous associate’s degree having a mean score of 2.38 and students with no associate’s degree having a mean score of 3.02. (with 2 being moderately confident, 3 being neutral, and 4 being slightly anxious.) The specific differences in this demographic data have little consequence to the study results, and there were no major differences noted that could affect the final results. 


\section{NURSING STUDENT ANXIETY IN SIMULATION SETTINGS}

Previous work experience. Previous work experience had little effect on student responses to the survey items. Two-sample t-test results were used to examine differences. Only one element of simulation, “observing others,” had any significant difference between groups. The mean score for students with experience in public speaking or performing was 2.96, and the mean for no experience in this area was 2.51 . The $\mathrm{t}$-value was -2.04 , and the p-values were 0.0236 and 0.9764 . Thus, previous work experience does not seem to be a mitigating factor in students' anxiety or confidence in simulation.

\section{Rating of Elements}

As there are few significant differences in response patterns based on demographics, the survey results for the whole sample will be presented. The survey included nineteen questions about aspects of simulation which students were asked to rate according to the feelings they experienced related to that aspect. The instructions to students were: “GENERAL DIRECTIONS: Think about how each of these aspects of simulation affects your feelings while you are engaged in simulation activities. Mark the response that most closely explains your reaction.” The possible responses were: Very confident, Moderately confident, Neutral, Slightly anxious, and Very anxious.

The following table lists the nineteen elements of simulation students were asked to rate in the survey questions, along with the results. Elements are listed in order from highest score (5) to lowest score (1.) The numbers correspond to the following responses: 1. Very confident, 2. Moderately confident, 3. Neutral, 4. Slightly anxious, and 5. Very anxious. 
NURSING STUDENT ANXIETY IN SIMULATION SETTINGS

Table 4.7: Anxiety Scores - Elements of Simulation

\begin{tabular}{|c|c|c|}
\hline $\begin{array}{l}\text { Element of } \\
\text { Simulation }\end{array}$ & $\begin{array}{l}\text { Mean } \\
\text { Score }\end{array}$ & $\begin{array}{l}\text { Standard } \\
\text { Deviation }\end{array}$ \\
\hline $\begin{array}{l}\text { Possibility of making } \\
\text { a mistake }\end{array}$ & 4.04 & 0.71 \\
\hline Being “on camera” & 3.95 & 0.92 \\
\hline $\begin{array}{l}\text { Performing in front of } \\
\text { faculty }\end{array}$ & 3.82 & 0.93 \\
\hline $\begin{array}{l}\text { Performing in front of } \\
\text { peers }\end{array}$ & 3.75 & 1.08 \\
\hline $\begin{array}{l}\text { Distinguishing } \\
\text { between what is real } \\
\text { and what is simulated }\end{array}$ & 3.55 & 0.93 \\
\hline $\begin{array}{l}\text { Working with medical } \\
\text { equipment }\end{array}$ & 3.38 & 1.13 \\
\hline $\begin{array}{l}\text { Calling a physician or } \\
\text { provider }\end{array}$ & 3.29 & 1.04 \\
\hline $\begin{array}{l}\text { General feeling } \\
\text { during simulation }\end{array}$ & 3.27 & 1.12 \\
\hline $\begin{array}{l}\text { Making decisions for } \\
\text { a patient }\end{array}$ & 3.14 & 0.92 \\
\hline $\begin{array}{l}\text { Making a decision } \\
\text { about a patient }\end{array}$ & 3.13 & 1.00 \\
\hline $\begin{array}{l}\text { Caring for a patient in } \\
\text { the simulation room }\end{array}$ & 3.11 & 1.14 \\
\hline $\begin{array}{l}\text { Working with the } \\
\text { mannequin }\end{array}$ & 2.95 & 1.01 \\
\hline $\begin{array}{l}\text { The preparation } \\
\text { beforehand }\end{array}$ & 2.94 & 1.07 \\
\hline $\begin{array}{l}\text { Administering } \\
\text { medications }\end{array}$ & 2.91 & 1.15 \\
\hline $\begin{array}{l}\text { Working with an } \\
\text { actor or standardized } \\
\text { patient }\end{array}$ & 2.87 & 1.16 \\
\hline $\begin{array}{l}\text { When I receive } \\
\text { feedback from faculty }\end{array}$ & 2.78 & 1.08 \\
\hline $\begin{array}{l}\text { When observing other } \\
\text { students }\end{array}$ & 2.66 & 0.89 \\
\hline $\begin{array}{l}\text { When I receive } \\
\text { feedback from other } \\
\text { students }\end{array}$ & 2.61 & 0.94 \\
\hline Working with my & 2.45 & 0.91 \\
\hline
\end{tabular}




\section{NURSING STUDENT ANXIETY IN SIMULATION SETTINGS}

\begin{tabular}{|l|l|l|}
\hline team & & \\
\hline
\end{tabular}

The possibility of making a mistake received the highest score in terms of causing anxiety for students, receiving a mean value of 4.04. The next three elements causing the most anxiety were "being on camera” (mean score 3.95), "performing in front of faculty” (mean score 3.82), and "performing in front of peers” (mean score 3.75). These three elements are conceptually similar, with all related to the idea of being observed by others while performing patient care in simulation. Receiving feedback, both from peers and faculty, was among the least anxiety-provoking elements of simulation. Observing other students also received a lower score in terms of anxiety. Working with a team received the lowest score among the elements on the scale, with responses ranging from 1 to 5 , and a mean score of 2.45 .

\section{Open-ended Survey Questions}

The survey also included two open-ended questions in which the students were asked 1) Please describe anything else about simulation that has helped you feel confident in your learning, and, 2) Please describe anything else about simulation that has caused anxiety for you. The qualitative content analysis, defined by Hsieh and Shannon (2005) as "a research method for the subjective interpretation of the content of text data through the systematic classification process of coding and identifying themes or patterns” (p. 1278), began at this point.

Of the 73 surveys that were completed, 46 students included written responses regarding what has helped them feel confident. The responses ranged from brief phrases 


\section{NURSING STUDENT ANXIETY IN SIMULATION SETTINGS}

to paragraphs consisting of several sentences. As the responses were analyzed for themes, recurrent words and ideas emerged. Although no preconceived codes were used, it was noted that several themes reiterated students' responses to the multiple-choice questions. Additionally, it was found that some of the student comments were consistent with data discussed in the simulation literature. As recommended by Marshall and Rossman (2011), patterns were noted in the responses that were "internally consistent but distinct from one another” (p. 215). From this analysis, five major themes were identified in the open-ended questions. These were feedback/debriefing, safe environment, orientation/preparation, prepares for real life, and peers. Several minor themes were mentioned and will also be discussed.

Although counting frequency of codes present in the data is a controversial practice among qualitative researchers, I did count codes as they were mentioned in the student responses to the open-ended survey questions. Creswell (2013) has addressed this practice, and states that looking "at the number of passages associated with each code" can be “an indicator of participant interest in a code” (p. 185). Because the student surveys were sent to individuals via email and completed online, it is assumed that their responses to the open-ended questions reflect their personal reactions to the survey content as described in their own words. Therefore, the number of times the themes were mentioned individually seems relevant in this study.

The table below lists the general themes identified in response to the question "Please describe anything else about simulation that has helped you feel confident in your learning," and the number of students whose comments fell into that theme on the survey. 
NURSING STUDENT ANXIETY IN SIMULATION SETTINGS

Table 4.8: Themes for Confidence-building Elements and Respondents Mentioning

\begin{tabular}{|l|l|}
\hline Theme & $\begin{array}{l}\text { Number of } \\
\text { Respondents }\end{array}$ \\
\hline Feedback/Debriefing & 14 \\
\hline Safe Environment & 10 \\
\hline Orientation/Preparation & 9 \\
\hline Challenges/Prepares for Real Life & 7 \\
\hline Peers & 7 \\
\hline
\end{tabular}

Responses to the item "Please describe anything else about simulation that has helped you feel confident in your learning” included 14 mentions of “feedback” or “debriefing.” Some of the comments were very general (“feedback from peers and faculty," "I really enjoy the feedback from the faculty after simulation," "The discussions afterward about best practice, or typical treatments for specific problems," and “The debriefing sessions generally give me a sense of reassurance”).

Some responses were more specific. Students expressed a need to hear comments affirming what they had done in a simulation, for example, "If one person, peer or faculty, calls out one thing I did well, it boosts my confidence very much. If faculty could find one positive thing to say about each person in each simulation, it would go a long way toward building everybody’s confidence.” Other students reflected a need to be informed specifically about what they may have done wrong As one participant noted, "When faculty are very clear about errors made in the debriefing, that makes me feel better (even if I'm anxious at the time because it's a mistake I made) because I feel like I 


\section{NURSING STUDENT ANXIETY IN SIMULATION SETTINGS}

am getting clear information about what is correct and incorrect that I can bring with me into future real-life situations.” Several comments indicate an appreciation for all types of feedback, such as the following: "Knowing that my peers and faculty will provide constructive and supportive feedback also reduces anxiety and allows us to be more confident.”

Relating the events of a simulation scenario to real-life events is critical to student learning. Several students indicated how feedback or debriefing a scenario helps them make these connections. Their comments included: “Talking through possibilities of other things that could have been addressed, or other ways to handle the situation are always initiated in a very positive way and it allows me to feel like there are several 'right' ways, ” “I’m always hopeful I'll do well but I like that I can receive immediate feedback and constructive criticism, so I know what to do when I'm on the floor," and “I enjoy debriefing afterwards and walking through the pathophysiology of what was happening during the simulation to assist me in gauging if I was able to understand the subtle/obvious assessment data and what that meant for the patient’s health status.”

The second theme identified, with responses provided by 10 respondents, was “safe environment.” Simple comments included: "Having the opportunity to practice in a safe environment,” “the learning environment is very safe,” and “knowing you can’t cause patient harm in simulation is slightly comforting.” Some comments were more specific and related to understandings about the meaning of safety to the student. Some discussed an appreciation for the fact that simulation cannot harm a "live" patient. Their comments included: "I get a bit anxious about making a mistake in the simulation room, 


\section{NURSING STUDENT ANXIETY IN SIMULATION SETTINGS}

but I prefer that they are committed when practicing on a dummy rather than a real patient," and "I like that it pushes us a little more...I'd rather have a new experience in SIM than on the floor at a critical moment of patient care.” One student explained that safety and the support of the group can help the learning process: "I feel comfortable being myself and I know that if I make a mistake, it is a safe space to do so, will be supportively corrected by faculty/my peers, and I will learn overall. It is a very enjoyable and valuable aspect of my nursing education.” Specific mention was made of an appreciation for the safety provided by adherence to a confidentiality agreement in simulation. Comments included: "Vegas style: what happens in sim, stays in sim, really helps create comfortable learning environment,” and “ 'What happens in sim stays in sim' is probably the only thing that allows me to survive it."

Nine respondents mentioned orientation and preparation as things that helped them feel confident. Students in each course are provided with scenario-specific patient information including medical history, relevant articles, and documents such as policies and procedures prior to their simulation session. One student mentioned that this "patient synopsis and resource information provided before Sim are really useful to gain a background understanding.” Further patient information is given immediately prior to the students' entering the simulation room, and one student commented that "Having the opportunity to ask questions right before I go in the room helps me to feel more confident about the scenario.”

Gaining comfort in the simulation environment was addressed by some students whose confidence was increased by "watching the orientation video" and "getting a tour 


\section{NURSING STUDENT ANXIETY IN SIMULATION SETTINGS}

of the simulation room prior to starting." One student appreciated "a brief tour specific to our scenario in the morning... so we could iron out little details and logistical questions beforehand.” Another stated “I feel the best when we get a chance to practice skills before going in to simulation.” Seven students commented on the clinical situation, or simulation scenario in which they were involved, as being helpful to their learning. The fidelity, or reality, of the situation was important to one student who wrote: “The situation is very real and walking away from the situation gives you great insight into real life situations.” Another commented on how the simulation learning could translate into practice: "It also gives me a 'what if' opportunity that is a good learning experience that allows me to reflect on how I would respond to similar situations when they arise in patient care.” The element of surprise in simulation was mentioned as helpful to learning by one student who stated "I truly enjoy preparing for the various case scenarios and the 'unknownness' that surrounds the experience.”

Seven respondents identified their peers as helping them feel comfortable in simulation. The comments referred to watching peers and sharing feelings with them. One student finds it helpful to know her team members prior to the simulation, stating “The more I know I will work well with my team, the more confident I am. The less I know my team members, or the more I expect them to work differently than I do, the less confident I feel. Knowing I can trust a team member greatly increases my confidence.” Another alluded to the importance of observing others in simulation prior to participating in a case, and stated "Not being the first to go helps with the anxiety. I see that everyone else feels the same way.” Another concurred that the observation of others in simulation 


\section{NURSING STUDENT ANXIETY IN SIMULATION SETTINGS}

is a learning experience and said, "I love watching other people in simulation. I absorb a lot from their interactions, deciding what I like about their decisions and what I would do differently. I value watching others a much as I value my own time interacting with sim.”

Several comments addressed other topics, including experience and allowing learning to happen. One student commented, "I think the more clinical experience I gain, the more confident I feel going into simulation.” Another stated "I think the experience has become less anxiety-inducing later in my program as I have had more of a base of knowledge and experiences to be able to apply when I am in simulation.” Since the transfer of learning in simulation to practice is the goal, it is hopeful that these students also can apply what they have learned in simulation to their clinical patients.

One student commented: "I feel like I have been able to relax and go with the flow pretty well. Once I get in the room I just take what comes to me and realize it's a learning experience, and I slowly gain more confidence throughout my time in the sim room.” This ability to relax implies a personal quality that seems to facilitate learning for this student.

The most detailed response to "what has helped you feel confident in your learning” came from a student who mentioned several themes. This student replied:

I think simulation provides a good opportunity for me to step out of my comfort zone in a safe way. I can face challenging situations and learn to think clearly in such situations without the added stress and fear of causing patient harm, while the cameras and eyes documenting my performance helps me take it very seriously and helps my faculty and peers supplement the learning experience with feedback, etc. Also, simulation can provide specific and difficult situational experiences that I may never (or rarely) see in real clinical settings, which I think gives me an advantage when similar situations actually do happen in real life. Moreover, if serious situations (such as in simulation) were to happen in the 


\section{NURSING STUDENT ANXIETY IN SIMULATION SETTINGS}

clinical setting, I would most likely seek the assistance of my preceptor or RN assigned to the patient, whereas in simulation I get the opportunity to fully face the challenge myself or with my peers.

This response indicates that the student understands the rationale for simulation and is able to benefit from the learning that is intended. This is not always the case, as identified by one student who answered the question with "Has not helped my learning in clinical." This student provided no further details; therefore it is difficult to infer what specifically about simulation could be changed to improve the student's learning. The same number of students, 46, also provided written responses to the question "Please describe anything else about simulation that has caused anxiety for you.” These responses also ranged from brief phrases to full paragraphs. The responses were analyzed and coded in the same manner as the responses regarding confidence. Five distinct themes were identified in these responses, and are listed below along with the number of students mentioning them. Table 4.9: Themes for Anxiety-Related Elements and Respondents Mentioning

\begin{tabular}{|l|l|}
\hline Theme & $\begin{array}{l}\text { Number of } \\
\text { Respondents }\end{array}$ \\
\hline Clinical Situation & 18 \\
\hline Environment/Equipment & 13 \\
\hline Observed/Cameras & 12 \\
\hline Time/Preparation & 9 \\
\hline Peers & 7 \\
\hline
\end{tabular}

The clinical situation with which students were faced in simulation was mentioned more than any other theme as causing anxiety for them. Conversely, in the 


\section{NURSING STUDENT ANXIETY IN SIMULATION SETTINGS}

previous question about what has helped students feel confident, several students mentioned the clinical situation as helpful. Some aspects of the clinical situation implicated as anxiety-inducing were "the scenarios were testing too much of a skill level," “if I know the situation is not being handled very well,” and "not knowing what to expect.”

Students in most courses are given four different patients to study prior to their simulation session. They are informed 30 to 60 minutes before the session which patient scenario they will be assigned. This amount of time is not sufficient for one student, who said "The small amount of time between learning our patient assignments and preparing does not feel like enough time to become fully aware of the things that need to be done for the patient. For example, orders of when to give the patient oxygen when their SpO2 is low." One student expressed frustration that "We should actually be able to resolve an issue, or a component of an issue, during our time in sim. Does there always have to be another added complication?” The time frame of a simulation scenario, usually 15 to 25 minutes, was problematic for a student who stated "During the first few simulation experiences I had the feeling that I had to get everything accomplished in the given time period which caused a feeling of being rushed.”

In simulation, as in real clinical practice, unexpected patient situations or events sometimes occur. One student related anxiety with “Getting orders over the phone for drugs I haven’t prepared for when we are taught never to give a drug that we do not know or understand or have looked up.” The attempt to help students learn to understand and respond to new information in a patient case elicited this response from one student: 


\section{NURSING STUDENT ANXIETY IN SIMULATION SETTINGS}

"Knowing that the actual scenario and patient needs will likely vary from my initial perception contributes to my anxiety and feeling of lack of preparation.”

Several students mentioned the clinical situation as causing anxiety, but also included comments indicating that they had come to terms with that anxiety, or adapted to it as part of the learning experiences. One student called the unanticipated event a “curveball” and explained that "originally it was getting hit with a curveball...but I’ve learned to manage that anxiety as I've become more experienced. I know that I may not always do the right thing, but it's a safe place to make a mistake.” Another had a similar comment: "Not knowing exactly what will happen, but it makes simulation interesting and close to real life. Surprises are good.” One student identified how simulation helps manage anxiety in real situations:

The elements of simulation that help to provide advanced learning experiences are the same elements that create anxiety, and I think this is unavoidable. It is simply uncomfortable and nerve-racking to face highpressure, challenging clinical situations that I haven't faced before. But the only way to reduce such anxiety is to gain experiences that boost confidence, which is exactly what simulation does (in my opinion). Even in simulation scenarios that I didn't perform well, it still served to boost my confidence because the experience taught me what not to do and through feedback I learned what to do.

The second theme mentioned by the students was equipment and environment. Students spend more time on their clinical units than they do in simulation, and some report being more comfortable on the clinical units than in simulation because of this. One response about what caused anxiety was "not knowing how the room is set up." As one student explained “After spending a few days on a hospital floor, I can generally find almost anything. When I go into simulation, however, I feel like I have to look for things 


\section{NURSING STUDENT ANXIETY IN SIMULATION SETTINGS}

all the time. This had a detrimental effect on my confidence in the room, and I can imagine a real patient getting worried if their nurse spent most of the time wandering around the room looking for gauze.”

Several comments expressed frustration with the equipment in simulation. There was dissatisfaction with "Equipment not working properly during simulations, medications missing, etc.,” and “Not familiar enough with the equipment either - where to find it, how to use it - and that contributes to a feeling of frustration.” Uncertainty about the operation and capabilities of the mannequin were also related to anxiety. One commented "Having sim with the sim man makes me anxious because I am not sure if we are seeing what we're actually supposed to be seeing or if something is a technical malfunction.” Another expressed anxiety related to "assessing the mannequin and getting the assessment wrong because of the flaws. For example on code day I was told going into the simulation that I could feel all pulses, but in reality pulses could only be felt on the left side."

Being on camera was rated very highly on the survey as causing anxiety, with a mean score of 3.95. Being observed and being on camera were also mentioned frequently in the open-ended questions, with 12 students mentioning this theme. Students replied to "what else has caused anxiety" with "People are watching you," "Being watched in every move," "I do not enjoy being on display for other students and faculty," and "being on camera is always nerve racking no matter what the situation is.” One student explained that being observed affected performance: "Being on camera, being recorded, being 


\section{NURSING STUDENT ANXIETY IN SIMULATION SETTINGS}

observed by peers and faculty all causes me anxiety. I feel pressured and uncomfortable being watched and don’t feel that I perform nearly as well as I do in natural settings.”

While students are participating in a simulation case, peers and faculty are not only watching, but may also be discussing the case as it is happening. This was problematic for a student who explained:

At times the conversations occurring in the room where we are watching other simulations, make it more anxious for me when I go to do my simulation, because I think that the same conversations are probably occurring then too. There is rarely anything derogatory said, but it's just the under-the-breath comments about what they think someone should do or that they're missing this or that piece of data, if it comes more often from faculty that are present than from students.

Being an observer increased anxiety for one student who stated "When I make mistakes on camera in front of faculty and peers, it makes me feel inadequate...but I know it is a part of the learning process. Watching my peers struggle is anxiety provoking.”

Preparation for simulation, although being mentioned as aiding the learning by nine students in the first open-ended question, was also mentioned as anxiety provoking by nine students. In response to things that have caused anxiety, students responded "too much time to think about it before hand and try to speculate how the scenario will unfold,” "prioritizing during preparation,” and “the prep articles and resources don’t seem to help much once you're in the sim situation.” One student specifically identified that the amount of time required preparing for simulation was problematic: "The amount of prep work required for sim is a great source of anxiety for me. In an intense accelerated program with our plates over-flowing with work, many of us feel like we are 


\section{NURSING STUDENT ANXIETY IN SIMULATION SETTINGS}

barely keeping our heads above water with the course work and clinical aspects

alone...the work load causes me great anxiety.”

Seven students identified peers as helping them feel confident, and the same number of students mentioned peers as causing anxiety for them. Specific responses to what causes anxiety included "peer feedback," "having too many people in the sim lab at one time,” and “watching my peers struggle.” One student commented, "When watching other students I hear other students in the audience make noises/comments that suggest they are critical of what they are watching. This makes me anxious about what they might be saying about me.” Another student referred to the practice of taking care of simulated patients in teams, suggesting "the need to participate and demonstrate our ability while also giving team members a chance to participate” caused anxiety.

Although not identified as a major theme, two students made comments about wanting more specific feedback on their performance. One stated "When nobody says anything about my performance, good or 'bad,' I feel increased anxiety.” Another commented "During the debrief I do feel as though more specific feedback could be given to each student that participated rather than generalities.”

\section{Focus Group}

Two focus groups were planned after the survey was completed; one with the accelerated program students, and one with the traditional three-year program students. Several email invitations to the students resulted in nine student volunteers, who were organized into a single focus group. The focus group’s guiding questions were similar to those on the survey, including the open-ended questions. The repetition of content in the 


\section{NURSING STUDENT ANXIETY IN SIMULATION SETTINGS}

focus group supported triangulation of the data obtained in the study. Additional data was sought from the participants who volunteered for the group, including a description of how it feels to be anxious and what recommendations they might suggest to improve learning in simulation.

\section{Setting}

The students and facilitator met in a room in the Simulation and Clinical Learning Center during an evening when no classes were in session. The room was the same one in which students observe and debrief simulation activities in their clinical courses. The location for the focus group was deliberate, with the intention of bringing students into the environment where they experienced their simulation observations and debriefings. Because the students were from different cohorts and did not necessarily know one another prior to the focus group, the facilitator spent approximately 45 minutes with the participants prior to starting the audio-recorded dialogue. Snacks and beverages were provided to help increase participant comfort and familiarity with one another.

\section{"Draw yourself in simulation” Activity}

To begin the session, the participants were provided with paper, pens, and colored markers, and were asked to “draw yourself in simulation.” The “draw yourself in simulation” activity was based on the "Draw-a-Scientist" test (DAST) that was first used in 1983 to examine children's views of scientists, particularly related to stereotypes such as gender. Most studies using the DAST were done with elementary-aged students, though Thomas (2006) examined images of scientists drawn by undergraduate students 


\section{NURSING STUDENT ANXIETY IN SIMULATION SETTINGS}

and found them similar to drawings by young children. There were no studies found that used a tool like the DAST with nurses or nursing students.

Each of the nine focus group participants drew a picture, which was submitted after the focus group. Although this activity was done primarily as an icebreaker and to get participants in the mindset of the focus group topic, themes similar to those identified in the survey could be found in the pictures. The idea of "being observed" was present in three of the pictures. One showed observers behind the one-way observation window as students cared for a patient. One picture showed a very large overhead camera, not drawn to scale, which was shown as much larger than the nursing student. A third student drew a trembling, sweating, tearful person who was under a spotlight. There was a very large pair of eyes looking down on this student as well as two cameras pointed at her. Other drawings seemed to imply a reaction to the clinical situation itself. One student drew herself assessing the mannequin, declaring, “I can hear a heartbeat!” Another was giving an injection to a mannequin who was saying, "I am from planet sim.” Confusion about what do to was indicated in two drawings. One detailed picture showed a perplexed nurse in a room with a patient with multiple things going wrong: IV pump beeping, monitor alarming, foley catheter bag leaking, and a supply cart with a note saying "Stuff you need but don’t know is here.” Another showed a nurse dropping a stack of papers, stating, “Starting to think I don’t need all these papers.” She was holding a "Nursing toolbox" and saying “maybe just this box of nursing skills,” perhaps indicating that the preparation documents were not as necessary as being able to perform, or do the skills required. One student drew a person who looked happy and was labeled "Not shaky, not sweaty, During 


\section{NURSING STUDENT ANXIETY IN SIMULATION SETTINGS}

sim," and frowning with the label "Shaky, sweaty, after sim.” When the participants were done with the pictures, the facilitator reminded them that the group interview was being recorded, and the digital tape recorder was placed in the center of the large rectangular table around which they were sitting.

\section{Guided Focus Group Questions}

The facilitator was a trained social worker who had graduated from the same accelerated nursing program about one year before the study, and was currently enrolled in a graduate nursing program. She was familiar with facilitating group discussions as required in her previous role as a social worker. She had also participated in simulation in her social worker role at a previous place of employment, and as a nursing student in this program. The facilitator directed the discussion with the use of probing questions and reflections. The 63-minute session was audio-recorded by a digital recorder, which sat in the middle of the table. The interview was transcribed, and the transcribed manuscript was examined for common themes related to each of the major questions, which were:

- What does it feel like in simulation, and what causes those feelings?

- How is your anxiety manifested?

- What helps your anxiety, or makes you feel more comfortable?

- What else would help you?

- What recommendations do you have to improve learning in simulation?

What does it feel like in simulation? Two main categories of feelings were discussed, and these were consistent with the descriptions of feelings addressed on the survey. Feelings were defined as either “anxiety” or “calm/relaxed/confident.” The table lists the terminology used by students to describe their feelings, and lists the number of times the feelings were mentioned during the focus group. 


\section{NURSING STUDENT ANXIETY IN SIMULATION SETTINGS}

This question was analyzed in consideration of the student responses to the 19 elements on the survey, where students were asked to rate the items according to their feelings, with options ranging from highest score (5) to lowest score (1). The numbers correspond to the following responses: 5. Very Anxious, 4. Slightly anxious, 3. Neutral, 2. Moderately confident and 1 . Very confident. During their discussions, students described two main categories of feelings, and these could be defined as either "anxiety" or "calm/relaxed/confident," aligned with either the high or low end of the score range. The table lists the number of times the feelings were mentioned during the focus group. Table 4.10: Frequency of Feelings Identified by Participants

\begin{tabular}{|c|c|c|}
\hline & \multicolumn{2}{|c|}{ Feeling identified by focus group participants } \\
\hline & Anxious & Calm/Relaxed/Confident \\
\hline Terminology used & $\begin{array}{l}\text { "anxiety” } \\
\text { “freaked out” } \\
\text { "basket case” } \\
\text { "super anxious” } \\
\text { "mildly horrifying” } \\
\text { "frustrating” } \\
\text { "wound up like a clock” } \\
\text { "upset” } \\
\text { "paralyzed” } \\
\text { "I can’t breathe” } \\
\text { "losing it” } \\
\text { "worry” } \\
\text { "nerve wracking” }\end{array}$ & $\begin{array}{l}\text { "low key and relaxed” } \\
\text { "confident” } \\
\text { "feel calm” } \\
\text { "kept it together” }\end{array}$ \\
\hline Number of times mentioned & 36 & 12 \\
\hline
\end{tabular}

From this table, it is clear that anxiety was a frequent topic of discussion, being mentioned 36 times, or three times more than calm, relaxed, confident feelings. Table 


\section{NURSING STUDENT ANXIETY IN SIMULATION SETTINGS}

4.11 lists the specific aspects of simulation to which students related their anxious feelings.

Table 4.11: Causes of Anxiety and Times Mentioned

\begin{tabular}{|l|l|}
\hline \multicolumn{2}{|c|}{ Anxiety } \\
\hline Aspect of simulation & $\begin{array}{l}\text { Number of } \\
\text { times } \\
\text { mentioned }\end{array}$ \\
\hline Clinical situation & 14 \\
\hline Environment/equipment & 7 \\
\hline Cameras/being observed & 7 \\
\hline $\begin{array}{l}\text { Peers/observing them or } \\
\text { receiving feedback from them }\end{array}$ & 5 \\
\hline $\begin{array}{l}\text { Being first or last in } \\
\text { simulation }\end{array}$ & 2 \\
\hline $\begin{array}{l}\text { Personal experience with } \\
\text { topic of simulation }\end{array}$ & 1 \\
\hline
\end{tabular}

The aspect of simulation causing anxiety that was mentioned most often was the clinical situation being represented. This was similar to the responses to the open-ended questions on the survey. Other themes identified on the survey were also discussed in the group, including environment and equipment, cameras and being observed, and peers. Additional anxiety-provoking aspects identified in the focus group were being first or last in simulation and personal experience with the topic represented in the simulation. One student relayed concern about caring for a simulated patient with cancer after recently dealing with cancer in people she knew personally.

Table 4.12: Causes of Calm/Relaxed/Confident Feeling and Times Mentioned

\begin{tabular}{|l|l|}
\hline \multicolumn{2}{|c|}{ Calm/relaxed/confident } \\
\hline Aspect of simulation & $\begin{array}{l}\text { Number of } \\
\text { times } \\
\text { mentioned }\end{array}$ \\
\hline
\end{tabular}




\section{NURSING STUDENT ANXIETY IN SIMULATION SETTINGS}

\begin{tabular}{|l|l|}
\hline Clinical situation & 2 \\
\hline Safe environment & 1 \\
\hline Preparation & 1 \\
\hline Peers & 1 \\
\hline
\end{tabular}

The participants discussed being calm, relaxed, or confident infrequently. They had many more concerns and ideas related to the anxiety they experienced. The clinical situation, also a cause of anxiety, was mentioned twice. Safe environment, simulation preparation, and peers were each mentioned one time as contributing to confidence.

How is anxiety manifested? Participants were able to describe in a fairly detailed manner how their anxiety was manifested in simulation. They described physiological, cognitive, and emotional responses. Physiological responses to simulation anxiety included comments about sweating, such as: "I would get sweaty, especially because I’m usually heavily caffeinated," “I'm sweaty and I'm wiping my sweat on my scrubs and it's a nightmare and I just want to get out of there," and "I sweat profusely. It’s a very Godzilla sympathetic nervous system response.” One student reported being “fidgety and shaky.” Another related having a prior issue, saying, "I have an anxiety disorder too so I'm anxious about-I don't get anxious about sim but if I'm anxious about something else, I get paralyzed. It’s not about sim but it’s-I can’t breathe.”

Cognitive problems due to simulation anxiety were also described. One student explained: “Then they give you a new drug and you're like oh crap! Where’s the drug guide? But I just can’t even focus on the drug." Some report memory problems, such as "You forget the alphabet” and "When I feel like I'm prepared and there are those twists 


\section{NURSING STUDENT ANXIETY IN SIMULATION SETTINGS}

and turns, and it just-I just kinda blank out on a lot of it, I think.” Their comments indicated concern that their reactions could potentially impact patient care. One refers to receiving new information in simulation and reports a problem focusing: "focus for me I can't see the numbers, can't read them. I get stuff and have no idea what it means.” Interpreting information becomes a problem for a student who feels: "I know there’s something wrong here. You know I just have no idea what it is at this moment and just trying to kind of like synthesize all the things that you should be synthesizing based on what I've read and happened and putting it all together, I just like - I can't do that very effectively while I’m in there.” Another student agreed and said, “Yeah, I kinda lose whatever I’ve prepared for; I can’t think about it anymore. I-my mind kinda goes blank and my heart starts beating really fast. And then I know I'm not doing a good job.”

The emotional responses for one student were related to being observed: “I feel everybody's judging. That's where my anxiety comes in. I'm like oh my God, I don’t want to talk about it.” Occasionally participants become tearful in simulation, as the following student explained: “And then this last experience I, like a baby, cried as soon as I stepped - got off the threshold. I just let it go because I kept it together...As soon as I got out the door, I just let it go. And that's kinda how I feel like just a rush of - oh my God! That was horrible. It's over now.” One student said the situation in simulation was "like a mildly horrifying feeling; just like oh, I have to relive this.” Simulation created “contrived pressure" for one student, who explained "the anxiety is maybe different than the anxiety that I would feel in a clinical situation, it still creates this pressure that you have to operate under somehow.” 


\section{NURSING STUDENT ANXIETY IN SIMULATION SETTINGS}

The willingness to discuss issues such as anxiety disorders and becoming tearful after a simulation seem to indicate that students were open and willing to be honest with their focus group responses. Several of the comments related anxiety to the loss of ability to think, focus, remember, or make sense of what is going on, all of which could be dangerous in a clinical situation where a nurse needs to make a critical decision. Only one comment had a positive response to the anxiety, stating "It gives me a heightened awareness of how I performed. And I think that will translate later, or at least I hope, being optimistic.” This translation of the learning to the clinical environment is the ultimate goal of simulation.

What helps your anxiety or makes you feel more confident? After the discussion of what causes anxiety, the facilitator asked "what helps? What makes you feel more confident when you are in there or in here about to go in there?” Participant responses were similar to those obtained in the survey results, falling into similar categories. The responses reflect that students were in different cohorts and different places in the program, had experienced a variety of simulation cases, and had responded to them differently. Responses included not only what has helped students in the past, but their recommendations for what might help future learning. The following table lists the themes of the responses to "what helps your anxiety, or makes you feel more comfortable” and the number of responses in each theme.

Table 4.13: Themes: Helps Anxiety or Increases Confidence

\begin{tabular}{|l|l|}
\hline Theme & Number of comments \\
\hline
\end{tabular}


NURSING STUDENT ANXIETY IN SIMULATION SETTINGS

\begin{tabular}{|l|l|}
\hline Peers & 22 \\
\hline Orientation/Preparation & 16 \\
\hline Feedback/Debriefing & 9 \\
\hline Challenges/Prepares for real life & 9 \\
\hline
\end{tabular}

Peers were one of the themes mentioned as helping increase confidence in both the open-ended questions on the survey and in the focus group. During the focus group, students expressed appreciation for their peers' support. In a comment that indicates appreciation for peers and feedback, one student stated "I feel like our groups have been pretty good at giving constructive criticism and positive feedback. And I feel like a mix of that is healthy and good; not tearing them to shreds as that one guy suggested. But yeah, like suggesting a few things that you can work on is good.”

Another student commented on the ability to learn while observing others in simulation, stating:

I feel more when you are watching the groups going and they're doing what you would imagine yourself doing. Like I think that's what's most helpful about SIM for me. It isn't necessarily when I'm in the room, but like you have three other experiences where you're in a much more confident space. You're sitting in your seat and you're like she should probably go do this. And then she goes and does it. And you're like yes! We have the same learning! 


\section{NURSING STUDENT ANXIETY IN SIMULATION SETTINGS}

Because the simulation implementation model experienced by the students includes being an active observer for a portion of every simulation session, being in the observer role is an important opportunity for learning.

It is valuable for some students to be familiar with others in the simulation group, as noted in comments such as "I think that I find it more and more comfortable as I know who's in the group...I would get a lot of love and moral support like even though I did something ridiculous and terrible. Like that's really comforting to me.” Most simulation scenarios involve more than one student, usually two or three, providing care for the simulated patient. This was discussed as problematic for learning for several of the students. One student stated that "the three nurses or whatever” was "really awkward.” Another agreed, stating, “it’s frustrating to have too many people to do too little in terms of like simulating a real situation.” Identifying the importance of participation in the scenario, a comment was made about the need for involvement by all students: "usually the shyest person doesn't get to do as much as they would do if they were by themselves."

An appreciation for being part of a team of nurses was described by one student who discussed the roles assumed by each nurse during the scenario. This student said, I liked one time when we had, there were three of us. And it was the first time we all had specific roles. And one person was the med nurse, one person was the lead nurse and one person was the assessment nurse... we just really stuck to those roles and in that particular situation it worked out really well.

Both survey responses and focus group comments described an appreciation for orientation and preparation prior to a simulation session. Comments included "if I do a 


\section{NURSING STUDENT ANXIETY IN SIMULATION SETTINGS}

lot of prep, I feel pretty, not totally confident, but I feel better” and, “with the prep ahead of time...Whether it ends up doing any good or not, I feel I’ve done all I can do. I've read the articles. I've looked at the diseases. I've looked at the medications...that's all I can do.” Another commented "preparation is definitely the key to at least coming into it, feeling good about it regardless of how it goes beyond that.” Students also discussed coming to a simulation session early and doing further preparation when they arrived. One said “coming early is so key.” Others appreciated "going into the room and like checking out stuff,” and "getting a chance to explore it before the pressure’s on.”

Debriefing is an important aspect of simulation and was the most commonly cited theme in the open-ended survey question regarding elements that help students feel confident in their learning. Dialogue in the focus group echoed the positive attitudes towards debriefing. One student likes "having the opportunity to talk about it afterwards especially related to some of the frustrations," and another is "definitely glad we have the debriefing or I would just go home probably hating myself for the rest of the day.” Other comments include: "I can come in and be like this was on my mind but and kind of explain it or walk through it and say that how that affected the other things. I really like the after part.”

In a simulation that didn’t go well, one student explained what was helpful in debriefing:

the flow of it didn't go well. And they came in and were just like 'that was terrible, that was really awful.' And it was hard to watch because you could see, like you knew what was happening; that they had prepared a certain way, it got switched on them. And it was all very confusing. And what I thought was really great was that the staff kinda went through and said what went wrong? They 


\section{NURSING STUDENT ANXIETY IN SIMULATION SETTINGS}

asked the people who did it. Like what do you think went wrong? And they wrote on the list and they said now what went well...it was nice, they really broke it down really well...I liked the reflection part.

Also consistent with the survey was the fact that students in the focus group discussed the way that their learning is facilitated by the fact that simulation challenges them and prepares them for real life. Comments included: "I find it easier to reflect back on those experiences in a kind of powerful way that might affect my ability to do those skills later on...I remember doing that in SIMs and I remember exactly how I messed up because I was sweating bullets. I know how to do it right now. And I can maybe operate better than I did then.”

What would help you? Recommendations? The last question asked by the facilitator requested students to give their recommendations for improving future learning in simulation. Students were specific in their recommendations and the following table lists them along with numbers of comments made about each recommendation.

Table 4.14: Recommendations to Improve Learning in Simulation

\begin{tabular}{|l|l|}
\hline Recommendation & $\begin{array}{l}\text { Number of } \\
\text { Comments }\end{array}$ \\
\hline "Practice" or “mini" simulations & 18 \\
\hline Specific skills review prior to simulation & 14 \\
\hline Watching video of self after simulation & 14 \\
\hline $\begin{array}{l}\text { Eliminating criticism by faculty and peers during } \\
\text { simulation }\end{array}$ & 12 \\
\hline $\begin{array}{l}\text { Observation and feedback by clinical faculty } \\
\text { More specific individual feedback in debrief or } \\
\text { afterwards }\end{array}$ & 7 \\
\hline
\end{tabular}




\section{NURSING STUDENT ANXIETY IN SIMULATION SETTINGS}

\begin{tabular}{|l|l|}
\hline Being able to call peers for help & 6 \\
\hline
\end{tabular}

“Practice” or “mini” simulations. One student suggested, "it would be nice if say maybe in the first term or something there were shorter periods of time that you were in the SIM environment and tiny scenarios and kind of like just to get - I don't know, just to get familiar with working in that.” Students elaborated further and described “just mini little situations where you just are going in to do a patient interaction... a few more of those.” Students believe these “mini” simulations could take place “during a skills lab...so you had the practice of you're gonna go in on camera. Everyone else is gonna be watching you; you know that. You have that ten minutes or you have five minutes to just work through your case scenario.” The mini simulation "gives people who are getting anxious about being on camera etc, some exposure to that and practice.” Since most practice of physical assessment early in the program is done on fellow students, the group recommended having actors assist in the mini simulations. "One stranger in our first term could have helped...in the SIM lab.”

Specific skills review prior to simulation. Although ideally skills are not integrated into simulation until students have learned them in a practice lab setting, some students feel the lab does not provide enough opportunity for them to practice and develop competence in specific areas. Students requested “a really quick mini skills review right before because just the nature of the accbacc program...you don’t get any clinical experience with it.” Focusing on psychomotor skills can detract from the learning objective as one student described: “I don’t know how to get this machine to stop beeping 


\section{NURSING STUDENT ANXIETY IN SIMULATION SETTINGS}

and so then you're whole focus turns to the alaris pump and you forget that there's a person dying over here and you're just like how do I do this because I've only kind of done it once in skills lab?”

During the discussion about skills, a need to focus on higher level learning in simulation was described. A particularly perceptive comment relates to critical thinking: okay, you don't have to reveal anything about the patients, but hanging IV fluids. Let's run through it. Or even pulling up meds; let's run through that...So just reducing the number of distracters that could be in there because for me, I want to practice my critical thinking...You can practice those (skills) over and over but it's like having the patient there, having to put it together, synthesizing the information that you're getting and being able to work with that. I don't want to synthesize the pump.” One student suggested posting an online link to skills videos as preparation for simulation so that, during simulation, "you can focus on more critical things.

Watching video of self after simulation. Students are aware that the simulation sessions are videotaped and saved in the simulation center after the session. All students sign a consent for this before their first simulation session and yearly thereafter. These videos are available for students to watch although they seldom request to do so. During the focus group, a conversation about the videos transpired and students discussed the potential value in viewing their own scenarios. Comments included: "I liked the idea posed earlier of being able to watch yourself afterward. I am not necessarily sure I'd want to do it, but for people who feel really self critical during the thing, I think it would be helpful to see what their classmates are talking about when they give them praise because you can learn a lot from that." One student suggested "hosting it somewhere where it's optional. I think is a really great idea because I know some people have-are really anxious about watching themselves.” 


\section{NURSING STUDENT ANXIETY IN SIMULATION SETTINGS}

Eliminating criticism by faculty and peers during simulation. During a

simulation session, students are observed by simulation faculty who are running the scenario in a control room as well as by their peers. Sometimes, a clinical faculty person who is not part of the simulation faculty is also present in the observation/debriefing room with students during the scenarios. Many students appreciate the presence of clinical faculty, however, it also causes anxiety for some. One request was for "less external dialogue in this room while things are going on. Because that's one of the things for me is just knowing that people are thinking about what I'm doing and thinking I should be doing something else... one time the faculty member was the one kind of saying...too much commentary.” Another student reported "We’ve had clinical instructors sometimes and they don't pay attention at all. They'll check their cell phones or be out of the room and sometimes I kinda appreciate it because I'm like not too much pressure. But in terms of having feedback, not a help.”

Observation and feedback by clinical faculty. During each clinical course, students are supervised in the clinical setting by a faculty person who is able to assess and monitor their progress throughout a ten-week academic quarter. This clinical faculty person is responsible for assigning a grade for each student. Students value this relationship and the feedback they receive from clinical faculty. Due to other teaching commitments or personal preference, clinical faculty do not always accompany their students to simulation and the students in the focus group identified this as a problem.

One student commented "I think one thing that might help with faculty is if your clinical instructor is here, if you could just talk...Because I’ve always wondered okay, 


\section{NURSING STUDENT ANXIETY IN SIMULATION SETTINGS}

what do they - like how did I do in there? What did I do wrong? And I think if it was the clinical instructor, just five minutes.” Another student described a time when that happened and said "that was fantastic! Our clinical instructor was in here and she was like 'hey, my group: Let's go chat for a second.' And we were able to kind of go over the skills that maybe didn’t go right or more importantly go over what happened, what we did, maybe what we should think twice about doing if the situation should happen again.” The student described this as "almost like a debrief," and felt that "it's nice to have that more time in so specific to you and what you're doing and just that smaller group and that was really helpful.” Although simulation faculty attempt to discuss the entire simulation case and provide feedback about each action and decision, time limits prevent a thorough discussion of every aspect of every case, and clearly students appreciate additional time to sort through all the events of a simulation. One student reflected a need to further explore the events of a simulation session and said "one issue I had is my clinical instructors don't come and I want to talk to them but they don’t come so they don’t see what happens.”

More specific individual feedback in debrief or afterwards. In addition to wanting feedback from their clinical faculty, students discussed needing individual feedback based on their own performance in simulation. Some students specifically mentioned wanting more feedback about what they might have done "wrong." One commented "I really want to - I would love to go detail step by step. Like okay, what should I have done? Where did I mess up? Because I never really feel like I know what went wrong after.” Another stated, “I think I end up maybe more self critical after having 


\section{NURSING STUDENT ANXIETY IN SIMULATION SETTINGS}

post traumatic thing because maybe you don’t get enough feedback. Like constructive criticism like this is kinda what you did wrong and here's how it could have maybe been done better. I feel like there's lots of accolades to the things you do right in there.” This student continued with "I know 100 percent sure that there are things I'm not doing right in there. And I do want to hear about those things when I come out. And I would probably be less caught up in my own head being self-critical if somebody would just be 'this is what you could have done better specifically."'

Being able to call peers for help. Although some students commented that there were too many students participating in a simulation scenario, there were also comments made about the helpfulness of calling in more peers to help. Students felt that at times, there were skills they were not comfortable with, and spending time on them detracted from their overall learning experience. An example was given in a discussion of foley (urinary) catheters. "If we get in there and they need one, can I call for any of you guys to come in here, place a foley and because I'm just not comfortable with that yet...if you need to put one in and you don't want to take away from the rest of your learning, you could say, hey, I need (another student) in here... and they'll come running in.” Some students had used this resource, calling it "sort of phone a friend" and relayed that "having that extra set of hands and knowing that I can just call someone in is really nice."

\section{Integrated Results}

Both a survey and a focus group were used in this study for several reasons. Johnson and Christensen (2012) list five rationales for using mixed design in research. Two of these possible rationales, triangulation and complementarity, support the use of 


\section{NURSING STUDENT ANXIETY IN SIMULATION SETTINGS}

mixing qualitative and quantitative data in this simulation study,. Triangulation relates to use of "convergence and corroboration of results from different methods studying the same phenomenon” (p. 439). The intent was to use survey and focus group results to increase the credibility of the results. The second rationale is complementarity, in which "the investigator seeks elaboration, enhancement, illustration, and clarification of the results from one method with results from the other method” (p. 439). The data obtained from the focus group helped increase understanding of the data obtained from the survey by asking students to elaborate on their ideas.

When examining the combined data from all parts of the study, several ideas are consistently evident. The predominant feeling reported in relationship to simulation learning activities was anxiety as opposed to calmness or confidence. This was evident in the focus group in the number of mentions of "anxious" (36 mentions) over "calm, relaxed, or confident” (12 mentions). The survey results also substantiated the impact of anxiety on student responses to simulation. The most highly rated simulation elements were: possibility of making a mistake, being on camera, performing in front of faculty and peers, and distinguishing between what is real and what is simulated. Each of these five elements received a mean score above 3.5 with 3.0 being neutral. The lowest-rated elements, or those most closely associated with confidence were: receiving feedback from faculty and peers, observing others, and working with a team. Only these four items received mean scores below 2.8. Students in the focus group were fairly descriptive in their explanation of how anxiety was manifested. They described physiological (sweating 


\section{NURSING STUDENT ANXIETY IN SIMULATION SETTINGS}

and shaking,) cognitive (memory loss and decreased ability to focus,) and emotional (horrifying and pressured) reactions in simulation.

Three distinct data sources could be examined in a search for common themes: the scaled survey items, the open-ended survey questions, and the focus group discussion. Each of these sources provided information on what causes anxiety for students and what helps them feel confident. The themes (and sub-themes for clinical situation/patient scenario) are summarized below:

- Clinical Situation/Patient Scenario

o Possibility of mistake/Decision-making

0 Distinguishing what is real

o Calling provider

- Camera/Being observed

- Feedback from faculty and peers

- Orientation/Preparation

- Peers/Colleagues

- Safe environment

- Challenges/Prepares for real life.

Although the students were not specifically asked on the survey about recommendations that might help them learn more readily in simulation, some of their survey comments concurred with the ideas that were later discussed in the focus group. The main topics mentioned were: use of “mini-sims” to practice before a simulation session, a specific review of nursing skills that may be required in a simulation, watching a video of one’s own performance after a simulation session, and more specific individual feedback about performance.

A final result relates to differences in student responses based on their grouping by demographic data. This could not be elaborated upon during the focus group, because 


\section{NURSING STUDENT ANXIETY IN SIMULATION SETTINGS}

focus group participants were not identified in the transcription. There were several statistically significant differences in anxiety-related elements, however, and these will be discussed in Chapter 5.

\section{Summary}

This chapter summarized the results of both the online survey and the focus group interviews. The quantitative data obtained by the survey included numerical responses to nineteen different elements of the simulation experience, which were analyzed and ranked in order of their relationship to anxiety. Demographic data was collected and examined for relationship to survey responses. The survey included two open-ended questions about what caused anxiety in simulation, and what helped students feel confident. These responses were examined for themes, which were explained in the results.

A graduate student who was experienced with simulation and the nursing program then facilitated a focus group of volunteer students. The focus group was audiorecorded and then transcribed by a professional transcription company. The transcription was analyzed for themes and each theme was explored and examples of student comments were given. The next chapter will further explore the findings of the survey and the focus group. Implications for faculty practice and improving learning will be identified and examined. 


\section{NURSING STUDENT ANXIETY IN SIMULATION SETTINGS}

\section{Chapter 5 - Summary, Conclusions, Implications}

The purpose of this study was to examine nursing student perspectives about learning in simulation, particularly perspectives related to anxiety and its impact on learning. Technology is allowing nurse educators an opportunity to provide realistic clinical experiences without the risk of patient harm using mannequins or actors in a simulated clinical environment. Observation of students by fellow learners and faculty is inherent in this teaching methodology. The equipment and methodology support learning, but may cause stress and anxiety for some students, which may in turn impact their ability to learn. This study explored how student anxiety during simulation affects learning and provides ideas about how to address it.

This study began with a survey in which students were asked to rate a list of potential stressors present in the simulation environment. Survey items included technical aspects of the simulation, such as video equipment and mannequins, and human factors such as being observed by faculty and student colleagues. Participants had an opportunity to respond to two open-ended questions and list other self-identified stressors and confidence-building elements of the simulation experience. A focus group was held after the results of the surveys had been reviewed. Participants first drew a picture of themselves in simulation. They were then asked about their feelings in simulation, what specifically increased their confidence or caused anxiety for them, and what helped them manage their anxiety. The facilitator then elicited student suggestions for interventions to help them manage their anxiety and learn more readily. 


\section{NURSING STUDENT ANXIETY IN SIMULATION SETTINGS}

In the following summary and analysis, the feelings of students related to simulation will be described and the impact of those feelings on learning will be examined. Survey and focus group results will be discussed in terms of the themes that were identified. Each theme will be discussed in terms of how it affects student learning, whether in a supportive or detrimental manner. Survey results that revealed differences between groups will be delineated, and relationships between study results and the literature reviewed in chapter two will be examined. Suggestions for improving student learning in simulation, particularly those recommended by students themselves, will be defined, along with suggestions for further research.

\section{Themes Derived From Data: Sources of Anxiety and Confidence}

As adult learners, nursing students are capable and willing to share their thoughts and ideas about their coursework and required learning activities. The students who participated in this study were thoughtful and open in their comments on the survey and their focus group conversation. Their comments were carefully analyzed and sorted into themes, which proved helpful in understanding their point of view. The table below demonstrates how the themes were perceived by the participants both on the survey and the focus group. The left-hand column contains the elements of simulation most related to anxiety, the right-hand column lists elements most related to confidence, and the center column lists elements to which students had mixed reactions. The table is discussed below. 
NURSING STUDENT ANXIETY IN SIMULATION SETTINGS

Table 5.1: Themes-Sources of Anxiety and Confidence

\begin{tabular}{|c|c|c|}
\hline Anxiety-related & $\begin{array}{l}\text { Mixed reactions } \\
\text { (related to both } \\
\text { confidence and } \\
\text { anxiety) }\end{array}$ & Confidence-related \\
\hline $\begin{array}{l}\text { Clinical Situation/Patient Scenario: } \\
\text { Possibility of mistake/decision- } \\
\text { making } \\
\text { Distinguishing what is real } \\
\text { Calling provider }\end{array}$ & Peers/colleagues & Safe environment \\
\hline Orientation/Preparation & $\begin{array}{l}\text { Challenges/Prepares } \\
\text { for real life }\end{array}$ & $\begin{array}{l}\text { Feedback from } \\
\text { faculty/peers }\end{array}$ \\
\hline
\end{tabular}

\section{Clinical Situation/Patient Scenario}

As a clinical learning tool, simulation is built around a clinical situation or patient scenario. During this realistic situation, learners practice specific cognitive, psychosocial, and technical skills. The purpose for using simulation in nursing education is "to replicate some or nearly all of the essential aspects of a clinical situation so that the situation may be more readily understood and managed when it occurs for real in clinical practice” (Morton, 1995, p. 76). The clinical situation, often termed the "scenario," is the element of simulation that is central to the learning. For purposes of this analysis, the clinical situation includes the patient, represented by an actor or mannequin, and the space in which the situation takes place. The clinical situation may include additional participants such as family members or friends of the patient, other health care providers such as nurses and physicians, and the equipment and supplies necessary to provide care for the 


\section{NURSING STUDENT ANXIETY IN SIMULATION SETTINGS}

patient during the scenario. In other words, the clinical situation includes everything required to create a realistic simulation scenario. The clinical situation was recognized by students as relevant to their learning in the survey and focus group.

The simulated patient, represented by a mannequin, actor, or standardized patient, is central to the clinical situation. Working with the mannequin (mean score 2.95) and working with an actor or standardized patient (mean score 2.87) received fairly neutral scores on the survey. Students may view them as an accepted or vital piece of the clinical situation. Technical malfunctions are understandably frustrating, however, and one student wrote that the mannequin caused anxiety because "I'm not sure if we are seeing what we're actually supposed to be seeing or if something is a technical malfunction.” A conversation in the focus group revealed, “it helps... when I realize it’s a real person. Or there's at least one person in there; a family member.” This student said, "something with just a mannequin, those have been the sims that I've had the most trouble with.” Another agreed that it helps “if there's a real person for me to communicate in there with, aside from the other nursing student.” Although the National Council of State Boards of Nursing (NCSBN) study discussed in Chapter 1 includes both mannequins and actors or standardized patients in its definition of simulation, most studies in the literature use either mannequins or actors as patients, and no studies could be found identifying different learner responses based on the type of simulated patient used.

Three sub-themes of the clinical situation were identified in the data. They are (a) possibility of making a mistake/decision-making, (b) distinguishing what is real, and (c) calling provider. 


\section{NURSING STUDENT ANXIETY IN SIMULATION SETTINGS}

Possibility of mistake/Decision-making. The possibility of making a mistake in

the clinical situation was ranked highest in provoking anxiety for the survey respondents. Understandably, knowing that others were watching them as they made a "wrong” decision or carried out the "wrong” intervention with their patient causes anxiety. The anxiety regarding mistakes may also be related to the students' realization of how easy it is to make an error that could potentially impact a real patient's well being. Students discussed both interpretations in the open-ended questions and the focus group.

One student related mistakes or "failure” to anxiety and stated, “my anxiety builds when team work and communication begin to fall apart or simply fail, or if I know that the situation is not being handled well." Others fear "making a mistake due to nerves" or “doing something ‘wrong' or ‘stupid’ while on camera.” These feelings are similar to those reported by Lasater (2007), whose focus group participants reported, “you could really mess up” or “feel[...] like an idiot” in simulation (p. 273). Clapper (2010) explained that learning could be an emotional experience for students, who may fear being "unveiled as a fraud” (p. e12). Faculty running simulations need to stress that mistakes are made at all levels, even by experienced nurses, and that simulated experiences provide an opportunity to learn how to understand and manage mistakes. Faculty can emphasize this point by carefully guiding debriefing discussions in an open discussion in which a mistake is “figured out” without using blame or judgment.

Conversely, one student in the focus group commented that mistakes did not have an impact on anxiety and suggested that mistakes made in simulation were irrelevant. This student remarked, “I feel like it's fake so you can try whatever you want. And if you 


\section{NURSING STUDENT ANXIETY IN SIMULATION SETTINGS}

mess up, who cares...you're not gonna kill anyone.” As a simulation instructor in the program, I have never felt that students took the clinical situation lightly or that mistakes were made deliberately. This may be, however, a different way of learning for a particular individual and may be a way of coping with anxiety.

The healthcare industry has been emphasizing the importance of providing safe care since the 1999 Institute of Medicine (IOM) Report, “To Err is Human: Building a Safer Health System” (Kohn, Corrigan, \& Donaldson, Eds). Recognizing that a large number of Americans (between 44,000 and 98,000, depending on methods used to estimate numbers) die every year due to medical errors, healthcare organizations are following the recommendations resulting from the IOM Report. These recommendations include increasing efforts to identify and report adverse events leading to patient deaths, and creating systems whereby healthcare workers are involved in implementing safe practices at the care delivery level. Simulation is an ideal environment in which to stress the importance of safe delivery of healthcare. Students can be taught that errors are events that are bound to happen in a complex system and that they can be managed and limited in number when handled with honesty in an environment with systems in place for proper reporting and follow-up. Supporting students when they make an error in simulation by guiding a discussion on what happened and what could be done to prevent a recurrence, can lead not only to better learning, but also to decreased anxiety and improved safety when students go on to practice in the real world.

Although decision-making would seem to be related to the possibility of making a mistake, students did not seem to see it as such. On the survey, making decisions for a 


\section{NURSING STUDENT ANXIETY IN SIMULATION SETTINGS}

patient or about a patient received scores of 3.14 and 3.13. Respondents seemed fairly comfortable with these aspects of simulation. It appears that it is making the wrong decision that causes anxiety.

Distinguishing what is real. Distinguishing between what is real and what is simulated was also rated fairly high on the anxiety scale, with a mean score of 3.55. Faculty attempt to create a "high-fidelity" or realistic clinical environment in simulation in order to elicit real interactions and real responses from students. The simulated environment, however, often leaves much to be desired in terms of approximation to reality. A mannequin, although somewhat realistic in terms of assessment data such as heart and lung sounds, and ability to reply to questions via faculty voice through a microphone, will never replace interactions with a real human patient who may cry, grimace, or physically resist a procedure. Equipment such as IV pumps, nasogastric tubes, and medications may be similar to those used in the hospital. But the IV is inserted into a plastic vein; the mannequin has no human response to an uncomfortable procedure, and is not able to physically swallow a medication. There are, therefore, certain elements that must be simulated. Students may be asked, for instance, to "pretend” to give a patient a pill without actually having the pill placed in the mannequin's mouth.

On the other hand, in an attempt to provide students with repetitive practice of certain nursing skills, students are expected to do certain tasks in a realistic manner. They are told to wear gloves when contacting simulated body fluids, to follow sterile technique when performing procedures that require it, and to administer the correct dose of the 


\section{NURSING STUDENT ANXIETY IN SIMULATION SETTINGS}

correct medications into the correct IV port on their simulated patient. It is understandable these practices can confuse them or causes them to be anxious.

Dieckmann, Gaba, and Rall (2007) discussed in depth the relationship between a simulated event and a real one, and the importance of fidelity, or approximation of reality. They argue against the "widespread belief that simulation experiences (and effectiveness) improve proportionately as the precision of the replication of the real world improves” (p. 183). Instead of focusing on fidelity as critical to effective simulations, Dieckmann, Gaba and Rall prefer to focus on the value of simulation as "social practice," which they define as "a contextual event in space and time, conducted for one or more purposes, in which people interact in a goal-oriented fashion with each other, with technical artifacts (the simulator), and with the environment (including relevant devices” (p. 184). For students to benefit from this "social practice," they need to accept the fact that the simulated event may lack certain aspects of a real situation. One student in the study commented that “what helps me is to view the situation as real, if I don’t do that then I feel like a fool playing with medical equipment.” This supports Dieckmann, Gaba and Rall's contention that “if a simulation 'works,' then participants experience the simulation scenario relevant to the goal of the session and they are able to make semantical sense of the scenario despite its physical differences from the clinical situation" (p. 185). In order for students to "buy in" to the effectiveness of simulation as a learning activity, they may not need to focus on distinguishing between what is real and what is simulated. Instead, it may be helpful to encourage them to engage in the case and the learning “as if” it were real and accept the differences from reality as unchangeable 


\section{NURSING STUDENT ANXIETY IN SIMULATION SETTINGS}

aspects of simulation. In other words, for effective learning in simulation, "participants should either willingly accept this 'as-if' character and where necessary suspend disbelief, taking on as real patient care what they know is not; or they can acknowledge and accept the artificial character of simulation and the differences from the clinical setting while still seeing the relevance of the exercise for its stated pedagogical goal” (p. 189). Helping students understand this may be an important objective of orientation to simulation and defining the expectations of learners.

Calling provider. A mean score of 3.29 was received for "calling a physician or provider.” Though not related to being “very anxious,” there were students who felt that communicating with a physician caused some anxiety. There were no other studies found in which communicating with a physician or any other healthcare providers was reported as causing anxiety in simulation. Although occasionally, in the study participants’ nursing program, a physician may participate in the simulation sessions, the physician role is primarily portrayed by simulation faculty. Professional, respectful communication is modeled by faculty and encouraged by students in all stages of simulation, including the debriefing. The student scope of practice does not include taking orders verbally from a physician, however, so when encountered in simulation, the experience is new for the student. Miscommunication among healthcare providers in all roles is blamed for many, often life-threatening errors in hospitals and healthcare settings. Faulty communication is one of the human factors identified in the IOM report as contributing to an unsafe healthcare system, and, because of this, there is significant emphasis placed on safe, effective communication in nursing and medical education programs. The responsibility 


\section{NURSING STUDENT ANXIETY IN SIMULATION SETTINGS}

of relaying accurate information at the proper time to the right person often lies in the hands of the registered nurse. Learning to do this properly, although it may cause students to be anxious, is a critical aspect of their nursing program.

\section{Being on Camera/Observed}

Being on camera, being observed by faculty, and being observed by peers were rated highly for anxiety. Students specifically identified that being observed in simulation was different and more intense than being observed on a clinical unit. Parker and Myrick (2012) found similar results in a grounded theory study that explored the socialpsychological aspect of simulation. One of the main themes derived from their analysis was termed "performing in the fishbowl” (p. 368). Parker and Myrick found that being observed by others caused students feelings of fear, anxiety, and stage fright during their simulations. They felt, however, that the feedback in debriefing helped them tolerate this performance anxiety. Beischel (2013) addressed being observed as well and explained that simulation is perceived similarly to testing and added that "during a simulation, the student's performance is inevitably critiqued, independent of a subsequent grade” (p. 228). The students in this study are not graded on their performance in simulation and yet, as identified by Beischel, "when a student performs in front of others, erroneous answers and faulty execution of nursing interventions are apparent to all” (p. 228). Therefore, even knowing that a simulation is not a high-stakes testing event may not reduce student anxiety.

Two students provided positive feedback regarding being observed: "the cameras and eyes documenting my performance helps me take it very seriously” and “just 


\section{NURSING STUDENT ANXIETY IN SIMULATION SETTINGS}

knowing that I am being watched causes some anxiety, but this is an unavoidable (and important) part of SIM, so I wouldn’t want it to change.” Most comments about being observed, however, related to negative aspects of anxiety. "Knowing I'm being watched causes anxiety" and "being on camera is always nerve-wracking” were more typical remarks on the survey.

During the focus group, the cameras were a major topic of discussion, being mentioned seven times in relationship to anxiety. In response to "what causes anxiety," one student stated “the audience” and another replied, “it’s the cameras and everybody sitting here watching on the screen.” One called it "the performance piece” of simulation.

The “draw yourself in simulation” pictures revealed that cameras and eyes watching were on students’ minds. Though no specific directions were provided other than to draw a picture of oneself in simulation, several of the students incorporated an observation aspect to the drawing, including people (presumably faculty, since that is how simulation is implemented for the students) watching from behind a one-way mirror, and large eyes and cameras watching over the student. One student drew a nurse holding a syringe near a patient bed over which there was a very large microscope-like object aimed directly at the nurse. This was consistent with students' written comments and conversations.

The cameras were, however, viewed in a positive manner by several students who suggested during the focus group that they would learn from being able to view their video after a simulation. One person thought watching the video afterwards might help “people who feel really self critical during the thing” and one said, “I wouldn’t love 


\section{NURSING STUDENT ANXIETY IN SIMULATION SETTINGS}

watching me but I think I'd get a lot out of that.” Watching one’s own video may trigger self-reflection, as described by a student who believed "if you can watch it, you can kind of critique yourself, which may not - people may not be really willing to do that. I mean I know I don’t want to tell people they sucked.” When Elfrink, Nininger, Rohig, and Lee (2009) asked nursing students what they would like to change about simulation, their response was to eliminate the watching of students' videotaped scenarios during the debriefing, as they preferred to spend time in debriefing discussing the case and not watching it again. Offering students an opportunity to watch their own simulation video in privacy after the debriefing may allow for more critical self-reflection without a need to feel defensive about one's actions.

\section{Feedback/Faculty and Peers}

Receiving feedback from faculty (mean score 2.78) and receiving feedback from peers (mean score 2.61) were also addressed by respondents in the open-ended questions and in the focus group. Feedback and debriefing were, in fact, the most commonly cited confidence-building aspects of simulation in the replies to the open-ended survey questions, and a predominant theme in the focus group. Students expressed a need to hear positive feedback (“there’s so much support in the room that I’m like oh, okay. I'm not that bad”), specific, individual feedback (“during the debrief I do feel as though more specific feedback could be given to each student”), and critical feedback (“pointing out mistakes and telling me how it should have been done instead so that I can use it in my future practice”). 


\section{NURSING STUDENT ANXIETY IN SIMULATION SETTINGS}

The literature on debriefing supports the contention that it is a critically important component of simulation. Fanning \& Gaba (2007) explain that the reflection after an event is critical to experiential learning. They state that "the attempt to bridge this natural gap between experiencing an event and making sense of it led to the evolution of the concept of the 'postexperience analysis' or debriefing," and that, “as such, debriefing represents facilitated or guided reflection in the cycle of experiential learning” (p. 116).

Several articles cited described the impact of debriefing on learning. Clapper (2010) suggests that learning in simulation may evoke negative emotions such as anxiety among learners, but that discussing those emotions is a critical aspect of debriefing. Cordeau (2010) asked students to describe their emotions during simulation and identified anxiety as present throughout the experience, including the debriefing. Although related to anxiety, the students in Cordeau's study valued debriefing for the opportunity to discuss their learning and analyze their own thoughts and actions. Participants in Lasater’s study expressed “a strong desire for more direct feedback from the simulation facilitator” (Lasater, 2007, p. 273), and wanted the feedback to be straightforward, "including the severity of the patient outcomes if the judgments they exercised had been followed in reality” (p. 274). The study participants' discussions of the importance of specific and individual feedback are supported in the simulation literature. Students clearly value input from their faculty and peers.

\section{Orientation/Preparation}

The orientation to simulation and the preparation beforehand (mean score 2.94) were identified as fairly neutral in terms of feelings experienced by students. 


\section{NURSING STUDENT ANXIETY IN SIMULATION SETTINGS}

Interestingly, preparation for simulation was mentioned frequently in the open-ended questions as well as in the focus group. Respondents were divided between viewing the preparation as anxiety provoking and confidence building, which is consistent with the item receiving a neutral mean score on the survey.

The students in this study are provided with two orientation videos on Sakai, their online course management system. The orientation videos are included in each clinical course with a simulation component, and consist of a video tour of the simulation room and an explanation of how to prepare for each simulated patient as well as expectations in simulation. Most students are instructed to watch the videos each term, but one student had obviously not received that information and stated that "watching the orientation video (which I just happened to find the night before my first sim) was extremely helpful. There were multiple aspects of the Sim environment that made more sense and came to me intuitively during my scenario because I watched the video.” Simulation faculty and staff are usually available before each simulation session to review where items are in the simulation room, how equipment works, and general skills that may be needed. One student appreciated this, stating, "having the opportunity to go in the room and explore the equipment before going in helps me feel more comfortable.”

Students are also given patient-specific information to read about the three or four simulation cases that will be implemented during their simulation session. This general information is provided weeks in advance of their simulation. The preparation material is designed with the input of course faculty and for the purpose of complementing course content, therefore each student is required to prepare for all of the patients, regardless of 


\section{NURSING STUDENT ANXIETY IN SIMULATION SETTINGS}

which one they will be assigned in simulation. For most courses, students learn which team they will be on and which patient they will have 30 to 60 minutes prior to the session. This is not enough for one student who felt "the amount of time between learning our patient assignments and preparing does not feel like enough.” Another student felt that the preparation was too much, and was "a great source of anxiety" related to "an intense accelerated program with our plates over-flowing with work.” “Assigned readings for simulation create anxiety in the form of me trying to anticipate what is likely to happen," was a complaint of one student, although this anticipation of patient risk factors is one reason why preparatory readings are assigned. During the focus group one student identified an appreciation of this preparation, stating, "I think it’s good to anticipate what could go wrong...I find that (it helps) when I have a set list of expectations.”

Data from this study indicate that students have mixed feelings about whether preparation for simulation fosters their confidence or increases their anxiety. In a study of undergraduate nursing students, Gantt (2013) studied the effect of preparation, using the Spielberger State-Trait Anxiety Inventory (STAI) to investigate whether an additional preparatory activity affected nursing student performance or anxiety during summative simulations. Results indicated no difference in student performance on the summative simulation evaluation, as measured by a grading rubric. The additional preparation, which consisted of an additional supervised simulation practice with focused debriefing for the experimental group, did not have an impact on student scores.

The study did find, however, that students who had an increase in anxiety in simulation had lower scores on the evaluation as well. There was an inverse relationship 


\section{NURSING STUDENT ANXIETY IN SIMULATION SETTINGS}

noted between anxiety and performance; when anxiety increased, scores decreased. Students reported "the extra simulation practice time made them feel better, even though their scores were not affected” (p. e31). Students provided recommendations for specific preparation practices that would help decrease their anxiety. These focused on skills reviews prior to simulation such as “hanging IV fluids. Let’s run through it. Or pulling up meds, let's run through that.” They also discussed including a "link” in their online course management system to skills videos they could review prior to their simulation session.

\section{Peers/Colleagues}

Peers are integral to the learning in a simulation environment. The literature review examined learning theories that support the use of simulation in nursing programs, and constructivism was defined as a theory supportive of simulation. Simulation is usually a clinical learning activity done in groups over the course of a curriculum, thus it involves building upon a learner’s prior knowledge and incorporating multiple perspectives. These constructivist principles are important in the implementation of simulation. Hmelo-Silver, Duncan, and Chin (2007) describe the importance of collaboration with other learners and reflection in the constructivist approach; both of these are basic elements of simulation.

Aside from the anxiety caused by being observed, students in this study counted peers among the most helpful elements of simulation. The theme of peers overlaps some with the theme of feedback, but there were other elements of peer involvement that students noted as well. Peers were identified in the focus group more times than any other 


\section{NURSING STUDENT ANXIETY IN SIMULATION SETTINGS}

element as an aspect of simulation that helps students feel confident. Students discussed how helpful it was to know their peers prior to the simulation, and how they valued peer support in debriefing.

Watching others in a scenario reinforced learning even when students weren't actively involved in a scenario. This was described by one student who stated, "watching people do things that you're thinking 'oh they should go do this' is validating.” Another related a feeling of having the "same learning” while watching and thinking about what they would be doing. Another concurred that the observation of others in simulation is a learning experience and said, "I love watching other people in simulation. I absorb a lot from their interactions, deciding what I like about their decisions and what I would do differently. I value watching others as much as I value my own time interacting with sim.”

On the other hand, "watching peers struggle” reportedly caused anxiety for some, along with having "too many people to do too little” in a scenario. Students also discussed the fact that individual personality characteristics may impact learning; specifically, the "assertive person” may be most involved in the case, which is "detrimental for the shy person, because they could do it especially if they were forced to by being the only one in there.”

Two other studies specifically mentioned the effect peers had on the learning of others. In Walton, Chute, and Ball's (2011) grounded theory study, they asked students how simulation helped them learn, and how faculty could facilitate learning. Students reported a high level of anxiety in simulation, but this actually decreased as they gained 


\section{NURSING STUDENT ANXIETY IN SIMULATION SETTINGS}

experience, and their experience helped them comfort and support other students. This decrease in anxiety with experience was not a finding in the current study. Parker and Myrick (2012) identified peers as integral to the learning process, asking, "what is the social-psychological process involved in using HPS (human patient simulation) as a teaching-learning modality to educate undergraduate nursing students” (p. 368). Their contention was that “undergraduate nursing students' participation in an HPS-based clinical scenario is a social endeavor that conforms to millennial learners’ preference for immersive, reality-based, and collaborative construction of knowledge” (p. 365). They concluded that the "trust and accountability of peers" was needed "when students engage in the social discourse of peer observation and critique that are inherent in the highfidelity simulated clinical scenario experience” (p. 369).

\section{Safe Environment}

In their response to the open-ended questions on the survey, safe environment was listed as a factor related to confidence as opposed to anxiety. Students described a safe environment as “knowing you can’t cause patient harm.” They reported preferring that mistakes "are committed when practicing on a dummy rather than a real patient," and that they preferred doing something for the first time in simulation rather than at a critical moment with a real patient. Others described safety in terms of being "comfortable being myself and I know that if I make a mistake, it is a safe space to do so.” One student deemed simulation a "safe space" in which one could be "supportively corrected by faculty and peers.” Also, several mentioned the confidentiality of the simulation center as being necessary for their emotional safety. 


\section{NURSING STUDENT ANXIETY IN SIMULATION SETTINGS}

Students in the focus group discussed one issue that contributed to an unsafe environment in simulation; the discussions that occur in the observation room (which is also where debriefing occurs) when students are watching peers involved in a scenario. They felt it would be helpful if there were "less external dialog in this room while things are going on,” and expressed trepidation about what people, especially clinical faculty, were saying about them when they were the ones being watched. Mention of this specific aspect of observation was not found in other studies. In his discussion of learning theories pertinent to simulation, Clapper (2010) writes that "for good learning to occur, the environment must be one that allows for experimentation and failure in the learning process without the risk of some sort of professional backlash” (p. e12). When students hear clinical faculty questioning or criticizing the performance or the decisions made by other students during scenario observation, they may feel threatened and insecure going into their own scenario. This could jeopardize their ability to "learn from those opportunities without fear and intimidation looming over them” (Clapper, p. e11). In Knowles’s (2005) description of optimal learning environments, he mentions the importance of "physical comfort, mutual trust and respect, mutual helpfulness, freedom of expression, and acceptance of differences” (p. 93). Knowles also believes the teacher accepts “each student as a person of worth and respects his feelings and ideas,” and "seeks to build relationships of mutual trust and helpfulness among the students by encouraging cooperative activities and refraining from inducing competitiveness and judgmentalness” (p. 93). Comments from the focus group indicate students in this study would agree. 


\section{NURSING STUDENT ANXIETY IN SIMULATION SETTINGS}

The safe learning environment associated with simulation was also explored by Ganley and Linnard-Palmer (2010), who used a survey design to examine student and faculty perceptions of academic safety in simulation. They reported student anxiety, described as nervousness, humiliation, and intimidation, and explored what is needed to provide an academically safe learning environment in which anxiety was manageable. Students described the preferred environment as one free of ridicule and embarrassment, which was echoed in my focus group. Students in Ganley and Linnard-Palmer’s study invited challenges as long as they could ask questions of supportive faculty. They wanted an opportunity "to increase confidence, to experience healthy anxiety, and to excel in a positive environment” (p. e4).

\section{Challenges/Prepares for Real Life}

The fact that simulation both challenges students and prepares them for real life was discussed as a confidence-building aspect. Students were able to explain how simulation learning could transfer to patient care in comments like: "I like that I can receive immediate feedback and constructive criticism, so I know what to do when I'm on the floor" and "the situation is very real and walking away from the situation gives you great insight into real life situations.” One student mentioned being able to "fully face the challenge myself or with my peers" in simulation as potentially helpful when there are no faculty or preceptors around. Others mentioned that unexpected events in simulation caused anxiety, "but it makes simulation interesting and close to real life.” Students also appreciated talking through the pathophysiology of what was happening in the scenario and how this could impact a patient. 


\section{NURSING STUDENT ANXIETY IN SIMULATION SETTINGS}

The focus group discussion about the challenges faced in simulation revolved around anxiety, although students frequently commented that this anxiety was helpful. In some instances, managing anxiety in simulation was seen as practice for managing anxiety in real life, because "in real life, we're gonna be nervous in some situations and gonna feel anxiety, but if you can keep it together for the patient's and family's sake...that’s your job.” One student acknowledged that reflecting back on simulation “might affect my ability to do those skills later on.” This student "remembered...exactly how I messed up because I was sweating bullets,” but believed “I know how to do it right now. And I can maybe operate better than I did then.” Some also mentioned times in clinical when they thought back to a simulation and it helped them figure out what to do on the unit.

Literature supports the idea that simulation prepares students to practice in real life, though specific reports of transferability of knowledge from simulation to clinical units are difficult to design. Along with learning in simulation, students are learning in other areas as well, and attributing their increased knowledge to any one learning activity is difficult.

\section{Group Differences in Anxiety}

Among the nineteen elements of simulation listed on the survey, only five comparisons yielded statistically significant differences between accelerated and threeyear students or students early versus late in program. These were identified in Chapter 4, Table 4.7. Other differences were related to gender or amount of time the student had been in the nursing program. 


\section{NURSING STUDENT ANXIETY IN SIMULATION SETTINGS}

\section{Working with Medical Equipment-Gender}

Using an alpha level of .05, there was a statistically significant difference in the element related to working with medical equipment based on gender, with a p-value of .000. The mean score for males was 2.28, and the mean score for females was 3.56. The male students appear to be more confident in working with medical equipment, which might include items such as cardio-respiratory monitors, IV pumps and tubing, and oxygen delivery devices. There were no other studies found investigating the topic of gender and anxiety, and, because of anonymity, no differences noted in comments in the focus group.

\section{The Preparation Beforehand - Late in Program Versus Early in Program}

The mean score for students late in the program (therefore with more time and clinical experience) was 3.15, and for those early in the program, 2.67. The p-value was .046. This indicates that as students move closer to graduation, regardless of which program they were in, the preparation for simulation is related to an increase in anxiety, and the difference is statistically significant. In the responses to the open-ended question regarding what helps students feel confident, orientation or preparation was listed among the items that help, with nine students mentioning that prep increases their confidence. This topic deserves more investigation since student comments indicate that preparation is helpful. Why preparation increases anxiety for those nearer to graduation is unexplained. Although they did not study preparation for simulation specifically, Walton, Chute, and Ball (2011) examined students’ self-reported levels of anxiety related to 


\section{NURSING STUDENT ANXIETY IN SIMULATION SETTINGS}

simulation. They reported high levels of anxiety with all simulations that decreased as students had continued practice.

\section{Working with Medical Equipment - Accelerated Versus 3-year Program}

Using an alpha level of .05 , the difference between students in the accelerated

program versus those in the 3-year program was statistically significant, with a p-value of .015. The mean score for those in the accelerated program was 3.75, and for those in the 3-year program, 3.03. The students in the accelerated program were more anxious working with medical equipment. The length of their program, fifteen months (or five quarters), is significantly shorter than the three years (or nine quarters, with breaks in the summers) spent in the traditional baccalaureate program. Therefore, they have fewer hours of clinical experience (both simulated and "real”) working with equipment than the three-year students, which may account for their increased anxiety, or lack of confidence in this area. In a literature review of clinical experiences of undergraduate nursing students, McNiesh, Benner, and Chesla (2010) noted a relationship between student confidence and competence with skills. They found that "a lack of confidence in skills tended to cause preoccupation with performance and the possibility of making an error, whereas proficiency and competence in performing skills freed the student to focus on the patient” (p. 52). Working with medical equipment is likely a skill in which the students need more time and experience to increase their confidence and provide safe care.

\section{Working with Mannequin - Accelerated Versus 3-year Program}




\section{NURSING STUDENT ANXIETY IN SIMULATION SETTINGS}

Using an alpha-level of .05, the difference between the anxiety of the accelerated students and the students in the 3-year program related to working with a mannequin is statistically significant. The mean score for the accelerated program students is 3.33, compared to 2.56 for those in the 3-year program. The p-value is .026. As noted above in the "working with medical equipment" responses, the students in the accelerated program have less time in simulation as well as on clinical units in which to gain comfort with medical and simulation equipment. With regards to equipment and mannequins, the students in the focus group did have a conversation about what would help them in simulation. They suggested more time spent prior to simulation reviewing and becoming comfortable with the equipment. Because of the anonymity of the focus group data, it is not known which students specifically wanted more time with the equipment prior to simulation, but offering additional practice time to any student who is interested may be beneficial to learning.

\section{Administering Medications - Accelerated Versus 3-year Program}

The mean score for accelerated program students was 3.56, and for 3-year program students, 2.36. This is statistically significant, with a p-value of .017. With the greater time spent in their program, the 3-year students have more clinical hours and more experience with medications, both in simulated and hospitalized patients, giving them more opportunities to become comfortable with this skill. Administering medications may be seen as similar to working with medical equipment and working with the mannequin; the students do not have as many clinical hours in simulation or working with patients and therefore they experience greater anxiety related to these skills. 


\section{NURSING STUDENT ANXIETY IN SIMULATION SETTINGS}

\section{Differences in Accelerated Versus 3-year Program Students}

Most of the significant differences noted in scores on the survey were between students in the accelerated baccalaureate (AB) and three-year programs. The accelerated program, which is five consecutive terms, or 15 months long, delivers a curriculum that is similar, albeit condensed, to the more traditional, three-year (nine terms) baccalaureate program. The AB students had higher anxiety related to working with medical equipment, working with mannequins, and administering medications. This data may support the offering of a different type of support for students in the accelerated program. Potentially, they could benefit from additional orientation or practice time with medical equipment, simulation mannequins, and medication administration. The challenge in implementing this support is the students' full schedules with coursework and clinicals, providing little free time in which to incorporate further practice.

Accelerated nursing programs are relatively new and were initiated with the intention of supplying more registered nurses because demand for nurses outstrips supply. The first such program in the United States was a second-degree program, one year in length that began in 1971 (Cangelosi \& Whitt, 2005). The number of accelerated programs has grown and the American Association of Colleges of Nursing (AACN) identified 230 accelerated baccalaureate nursing programs in January 2013. Characteristics of students in accelerated programs include being motivated, older, more diverse, and goal-directed (Oermann, Alvarez, O’Sullivan, \& Foster, 2010).

An examination of the literature on accelerated programs reveals differences between $\mathrm{AB}$ nursing students and traditional nursing students in several areas. A study 


\section{NURSING STUDENT ANXIETY IN SIMULATION SETTINGS}

done by Youssef and Goodrich compared stress, critical thinking ability, and performance of accelerated and traditional nursing students. They report "these (accelerated) students are exposed to tension and stress because of increased demand on their time, energy, and financial resources” (Youssef \& Goodrich, 1996, p. 77). The authors used the State-Trait Anxiety Inventory (STAI) to measure stress levels twice during a semester and the accelerated students "showed consistently higher stress levels at the beginning of the semester and before final exams” (Youssef \& Goodrich, p. 79), though the difference was significant only at the beginning of the semester. To address the higher stress levels, recommendations were made to offer "relaxation techniques," “support groups,” and “seminars in time management” (Youssef \& Goodrich, p. 81).

Noting the paucity of literature describing stressors or coping strategies of accelerated nursing students, Hegge and Larson (2008), used a survey to examine this topic. They distributed 280 surveys to students in 6 different programs, and 137 surveys were returned. "Extensive to extreme stress” during their programs was reported by nearly two thirds of the respondents, which the students attributed mainly to "the amount of material to be mastered in a short time frame” (p. 28). The authors recommend that nursing faculty in accelerated programs help students by increasing their awareness of coping strategies including connecting them with "peer or professional mentors,” suggesting appropriate channels to deal with issues, and encouraging "students to seek help from their faith traditions” (p. 30).

In a review of literature related to accelerated nursing programs, Cangelosi and Whitt (2005) identified three primary areas of research: student demographics, 


\section{NURSING STUDENT ANXIETY IN SIMULATION SETTINGS}

descriptions of programs and curricula, and teaching/learning strategies. In a summary of teaching/learning strategies, they found "accelerated students fit the definition of adult learners in many ways," and recommended "state of the art methods such as simulations, interactive technologies, contemporary topics, clinical concept mapping, and case-based problem solving” (p. 115). There was no mention of studies specifically related to stress or anxiety.

\section{Research Aims: Anxiety and Learning}

This study examined the feelings experienced by nursing students in simulation, and explored ways to improve their learning. The study and analysis led to increased understanding in the following areas:

- The specific aspects of simulation that increase students' comfort and learning, and the aspects that cause anxiety for them

- The student perspectives of what facilitates their learning in simulation, and their recommendations for further improvement of learning

- The awareness of differences in responses to simulation based on students' specific program (accelerated vs. traditional) and the impact on learning

- The potential utility of a model (“Comfort-Stretch-Panic”) in facilitating learning in simulation, which will be discussed below

\section{Implementing the Findings - A Broad Perspective}

While stress may facilitate learning, we need to understand how much stress is helpful, when it becomes detrimental, and how to create an environment that is optimal for student well being and learning. Through the survey and focus group, students provided thoughtful feedback on the topics above. Their ideas are compatible with a “Comfort-Stretch-Panic” (CSP) model. In their own variant of this model, Palethorpe and Wilson (2011) explained that learners respond to challenging tasks in different ways, as 


\section{NURSING STUDENT ANXIETY IN SIMULATION SETTINGS}

was certainly evident with nursing students in the survey and focus group. Learning in groups is inherent in simulation implementation, and as Palethorpe and Wilson state, "finding the optimum level of challenge is not easy at an individual level, and this is further complicated when a group of people are involved” (p. 421). As nursing faculty and simulation facilitators, it is imperative that we address how we can use simulation to teach groups of students, helping each individual member of the group to determine what support they need to maximize their learning.

Student comments about their simulation experiences could be categorized into comfort zone, stretch zone, and panic zone responses. Their comments on how simulation impacts their learning could also be categorized into these zones. The following table defines comfort, stretch, and panic zones and lists examples of student responses that exemplify the zones.

Table 5.2: Comfort-Stretch-Panic Model in Simulation

\begin{tabular}{|c|c|c|}
\hline Comfort Zone & Stretch Zone & Panic Zone \\
\hline $\begin{array}{l}\text {-Little challenge present } \\
\text {-Involvement is minimal } \\
\text {-Any learning is mainly } \\
\text { considered to be by chance } \\
\text { (Palethorpe and Wilson, } \\
\text { 2011) }\end{array}$ & $\begin{array}{l}\text {-Learners presented with some } \\
\text { stress } \\
\text {-Motivated to optimal } \\
\text { performance } \\
\text {-Challenging conditions } \\
\text { (Palethorpe and Wilson, 2011) }\end{array}$ & $\begin{array}{l}\text {-Challenge or stress becomes too } \\
\text { great } \\
\text {-Learning is severely impaired } \\
\text {-Decrease in efficiency } \\
\text { (Palethorpe and Wilson, 2011) }\end{array}$ \\
\hline Student Responses & Student Responses & Student Responses \\
\hline $\begin{array}{l}\text {-I feel like it's fake so } \\
\text { you can try whatever } \\
\text { you want. And if you } \\
\text { mess up, who cares? }\end{array}$ & $\begin{array}{l}\text {-Appreciate the aspects of } \\
\text { the unknown } \\
\text {-It's good preparation for } \\
\text { learning how to deal with } \\
\text { feelings } \\
\text {-If I do a lot of prep, I feel } \\
\text { not totally confident, but } \\
\text { better } \\
\text {-I think it's good to } \\
\text { anticipate what could go }\end{array}$ & $\begin{array}{l}\text {-I went to go call somebody } \\
\text { with the phone and I could not } \\
\text { see the phone number, and it's } \\
\text { right on the phone } \\
\text {-I'm sweaty } \\
\text {-A very Godzilla sympathetic } \\
\text { nervous system response } \\
\text {-I cried } \\
\text {-I can't handle this, think I'm } \\
\text { going to have a seizure }\end{array}$ \\
\hline
\end{tabular}


NURSING STUDENT ANXIETY IN SIMULATION SETTINGS

\begin{tabular}{|c|c|c|}
\hline & wrong & $\begin{array}{l}\text {-I’m freaking out. I don't } \\
\text { know what these drugs are }\end{array}$ \\
\hline Impact on Learning & Impact on Learning & Impact on Learning \\
\hline $\begin{array}{l}\text {-Has not helped my } \\
\text { learning in clinical }\end{array}$ & $\begin{array}{l}\text {-Learn from other people's } \\
\text { mistakes...I'm not going to } \\
\text { let my pride get in the way of } \\
\text { patient safety } \\
\text {-I can explain what was on } \\
\text { my mind, walk through it. I } \\
\text { like the 'after' part. } \\
\text {-Have to operate under } \\
\text { pressure, I find it easier to } \\
\text { reflect back on those } \\
\text { experiences in a kind of } \\
\text { powerful way that might } \\
\text { affect my ability to do those } \\
\text { skills later on } \\
\text {-Our groups have been pretty } \\
\text { good at giving constructive } \\
\text { criticism and positive } \\
\text { feedback } \\
\text {-The staff went through the } \\
\text { case and said, what do you } \\
\text { think went wrong, what went } \\
\text { well? They really broke it } \\
\text { down, I liked that reflection }\end{array}$ & $\begin{array}{l}\text {-I lose what I've prepared for } \\
\text {-My mind goes blank and my } \\
\text { heart starts beating really fast } \\
\text {-I can't see the numbers, can't } \\
\text { read them } \\
\text {-We did vitals and forgot } \\
\text { them, did a call a minute later } \\
\text { and couldn't remember what } \\
\text { the respirations were } \\
\text {-I didn't know the protocol. I } \\
\text { was about to kill that person. } \\
\text { And for me, that doesn't } \\
\text { foster my learning }\end{array}$ \\
\hline
\end{tabular}

There were few statements made by students suggesting that they were in the comfort zone during simulation. The comments above, however, provide evidence that not all students are engaged and benefitting from simulation activities, and some may not take it seriously as clinical practice. Obtaining more information from students in this zone will increase faculty knowledge and provide answers to improving student learning for those students who are not engaged in the process. Students in the stretch zone are likely obtaining the maximum benefit from simulation. Their comments indicate that they are being challenged and that they are able to relate what they are learning in simulation 


\section{NURSING STUDENT ANXIETY IN SIMULATION SETTINGS}

to the real world of patient care. They are not free of anxiety, but are motivated to learn from the experience. For these students, simulation seems to be "working” as a complement to clinical practice in patient care settings.

Students in the panic zone are beyond being able to learn in a simulated environment, as evidenced by their comments that their distress is impacting their cognitive ability. Although they did not identify them as such, the recommendations of the focus group to improve learning could possibly take students from the panic zone to the stretch zone, where learning is maximized. Palethorpe and Wilson (2011) identified approaches by which this could be accomplished, including several that echo focus group recommendations. These include extra skills coaching and encouraging the group to support each other. The CSP Model has definitely proven helpful in interpreting and synthesizing study data. It may be helpful to share the model with nursing students as they are oriented to the simulation environment. Introducing the "comfort, stretch, panic" terminology and helping students access resources and support to bring them to the stretch zone may be useful teaching interventions.

\section{Implementing the Findings - Student Suggestions}

The question "what would help decrease your anxiety or facilitate your learning in simulation" was asked within the anonymity of the focus group, therefore it is not known whether the suggestions were initiated by students in the accelerated or traditional baccalaureate program. Since the group consisted of only nine students, it is also unknown whether this sample was representative of the needs of the other students in the 


\section{NURSING STUDENT ANXIETY IN SIMULATION SETTINGS}

undergraduate nursing programs. Their responses, however, do provide a starting point for further investigation of support needed by students to improve learning in simulation.

“Mini-sims.” The most frequently discussed suggestion was for "practice sims" or "mini-sims" to help students adapt to the simulation environment. As one student described, "it would be kind of nice if say maybe in the first term or something there were shorter periods of time that you were in the sim environment and tiny scenarios...to get familiar with working in that." One student requested "mini little situations where you just are going in to do a patient interaction.” Students mentioned that “practice sims” might help them become accustomed to being observed and suggested coming in to practice “during a skills lab,” and going in "with a partner...while the people just watched you - so you had the practice of you're gonna go in on camera. Everyone else is gonna be watching you; you know that.” Others agreed that this might be beneficial, and explained that this need not require significant staff or faculty assistance: “you don’t have to get the extra staff. It gives people who are getting anxious about being on camera some exposure to that and practice.” Another referred to this as “desensitization” to the cameras.

As part of the "practice sim,” several students felt it would be helpful to have real people rather than mannequins on which to practice. They commented that most of their practice assessments in lab were done on their classmates “who you're mostly comfortable with, who are all fairly healthy and normal.” Although mannequins are used of necessity in simulation when invasive skills are required, there are times when the simulated patient is an actor they have never met (just as their "real” patients are people 


\section{NURSING STUDENT ANXIETY IN SIMULATION SETTINGS}

they have never met.) They discussed how it would have been helpful to have "just one stranger” in lab, “not one of the people that you've already been doing the assessment on over and over again.” One student even suggested using students from another cohort to do this: "our class could do it for the fall accbaccs (accelerated students).” In terms of anxiety when confronted with a new patient in simulation, this idea may help students when they enter the simulation room and are faced with a new patient and an unfamiliar situation.

Skills Review. Review of specific skills prior to simulation was also recommended. Students specifically mentioned nursing procedures like nasogastric tube and urinary catheter insertions, IV pump management, and preparing intravenous medications. These skills are demonstrated in lab sessions, which are separate from simulation sessions. Students sometimes have opportunities to practice these skills, but they clearly felt the practice time was not sufficient for them to feel confident. One student described practice in lab with an IV pump, which was not enough, because "you don’t get any clinical experience with it because it just never came up in clinical. And then you're thrown into sim and that's just supposed to be one of the things to take care of.” Students do have access to a resource that includes descriptions and videos of nursing procedures. One student asked for a "link” to the necessary skills videos for a simulation session, so that during a simulation the procedure would be expected and manageable. This student would feel "okay, I watched that last night. I think I know how to get through it. I’ll do my best.” 


\section{NURSING STUDENT ANXIETY IN SIMULATION SETTINGS}

Reviewing Video After Session. In many educational programs, having students watch the video and do a self-evaluation or reflection of their own performance is a common practice. Students in the focus group were not in agreement about whether this would be helpful, or that they would take advantage of an opportunity to view their own videotape. One student said, “I wouldn’t love watching me, but I think I’d get a lot out of that." One felt that it might decrease anxiety, commenting "it would probably help me not actually feel nervous because if I didn’t look nervous, awesome!” Another agreed, stating, "I don’t look like I’m falling apart so I can not worry about that.”

Although the simulation videos are saved for a period of time after the simulation sessions, there has been no deliberate attempt to make them available for viewing after the sessions. There have been occasions when faculty or students have requested to view videos, and those requests were met. It would be possible to make videos more widely available to students, and this would require a plan to allow access while maintaining confidentiality for the students involved. It would be important to keep records of how often videos were accessed and to assess the impact of reviewing them on students' anxiety and performance.

\section{Eliminating Criticism by Faculty and Peers During Simulation. Several} focus group members expressed concern over the dialogue that occurs between students and sometimes faculty who are observing a simulation. While students appreciated feedback after their case in the debriefing, they were uncomfortable with comments being made about students who were actively engaged in a scenario, and therefore unable to be part of the conversation. As one student explained, it "is just knowing that people are 


\section{NURSING STUDENT ANXIETY IN SIMULATION SETTINGS}

thinking about what I’m doing and thinking I should be doing something else.” That student observed, “when those people come back in, it was a completely different (conversation),” and the same feedback was not provided to the participants when they re-joined the group.

As with the other student recommendations, this was a conversation among a small group of nine volunteer students, who obviously chose to participate in the focus group because they had opinions about simulation which they hoped would be heard. Regarding the conversation during a case, it may be improved simply by addressing the value of feedback and professional communication in student orientation to simulation expectations. The issue of faculty comments is important as well, as noted by a student who commented, “it’s especially important feedback if it’s faculty because that's obvious for role modeling at the very least.” The faculty members who teach in the simulation lab are considered part of the undergraduate nursing faculty, but are focused on teaching in simulation and have expertise in implementing and debriefing simulations. It may be beneficial to provide faculty development to clinical instructors on the impact of simulation learning on students and how they could contribute to creating a safe learning environment when observing with their students.

Providing Feedback. Students requested both feedback “from clinical instructors" and "more specific individual feedback" on their performance in simulation. The importance of feedback is discussed frequently in the literature on adult learning. Bransford, Brown, and Cocking (2000) discussed feedback as important in their review of research on learning. They conclude that "in order for learners to gain insight into their 


\section{NURSING STUDENT ANXIETY IN SIMULATION SETTINGS}

learning and their understanding, frequent feedback is critical: students need to monitor their learning and actively evaluate their strategies and their current levels of understanding” (p. 78). Many of the simulation-based studies discussed in Chapter 2 mention the importance of feedback or debriefing for student learning (Crider \& McNiesh, 2011; Kaddoura, 2010; Elfrink, Nininger, Rohig, \& Lee, 2009; Lasater, 2007). Lasater's (2007) study reported that students especially want feedback on what they could have done better; that was mentioned in my focus group as well.

Currently, the time allotted in simulation for debriefing is approximately thirty minutes, or about twice as long as the scenario itself. This is consistent with recommendations in the simulation literature (Dreifurst \& Decker, 2012). As Dreifurst and Decker explain, “the objectives of the simulation, the level of the learner or participant, the behaviors, decisions and outcomes of the clinical experience, and the time constraints inherent in the schedule all impact debriefing time” (p. 111). The time constraints are a critical factor in how long debriefing lasts and therefore in how much individual feedback students receive. Participants in the focus group appreciated the input from their clinical instructors that they sometimes received after a simulation session. Because this is not always possible due to clinical faculty schedules and responsibilities, coming up with an alternative way to provide this individual feedback would be ideal. An online post-simulation reflection form was recently initiated in this program, in which students respond to questions about how they feel they prepared and contributed to the simulation session. They are also asked about their "aha moment” or "take-away” learning from simulation, as well as what they are confused or have questions about. 


\section{NURSING STUDENT ANXIETY IN SIMULATION SETTINGS}

Students submit this information via Sakai, their online course management system.

Their reflections are read by simulation faculty, who then provide them with individual written feedback specific to their participation in the simulation session. This online reflection form will need to be evaluated by students for their perceptions of its effectiveness.

Being Able to Call Peers for Help. In their focus group conversations, students discussed wanting to call for help during a simulation. This is a practice that has been implemented in simulation, as described by one student who commented "they kind of made it a thing where you can just kind of like stick your head out the door and 'hey, we need an extra hand.”' The option to call for help when needed is actually stressed by simulation faculty in the pre-briefing that occurs immediately prior to a simulation, though often students do not take advantage of this assistance. They sometimes relate wanting to try things on their own in a safe environment rather than calling for help, or even forgetting that they have that option when they feel stressed. The challenge in implementing the "calling for help” option is that it may provide students an "out” when they don’t want to try a new skill in simulation, where it would be safe to do so. The advantage is that students learn to admit when they are not capable of making a decision or not able to manage an event safely, and understand whom to call and how to describe specifically what is happening and what they need —a skill that will be valuable in the work world. Whether students are encouraged to call for outside assistance during a simulation will need to be considered by faculty and students in each simulation session, since learning needs vary among cohorts and clinical courses. 


\section{NURSING STUDENT ANXIETY IN SIMULATION SETTINGS}

\section{Limitations of the Study}

One limitation of the study was the small sample size. Only 178 students were eligible, and they were all students at the same university. The fact that the researcher is a faculty member may also have had an effect on who chose to participate, how they answered the survey questions, and what they discussed in the focus group. The students were told that the focus group moderator would not be one of the simulation faculty members.

Regarding consent for the focus group, Howatson-Jones (2007) explains, “a balance needs to be found between the paternalism of the researcher in seeking to protect participants, and the autonomy of individuals to make their own decisions. Thus, representation of the study needs to avoid coercion, but provide sufficient information about potential benefits and liabilities to capture interest” (p. 10). It was possible that students who have extreme anxiety and those who are less likely to have a positive attitude towards simulation would volunteer for the focus group, affecting the dialogue and the results. Another limitation was the fact that students from both programs - the accelerated and the traditional 3-year program-were included in one focus group. Although the intention was to separate students by program, there were insufficient volunteers to hold two groups. Participants may have been less willing to divulge personal information about their responses in simulation with focus group members they did not know. The dialogue in the group, however, seemed very candid and sincere. 


\section{NURSING STUDENT ANXIETY IN SIMULATION SETTINGS}

Combining the students from different programs in one focus group may actually have had a positive impact in this case, and members may have been more willing to convey their thoughts and feelings.

\section{Reflection on Recommendations}

The review of learning theories included a discussion of Vygotsky's theory of social constructivism. The important concepts in this theory include the More Knowledgeable Other (MKO) and The Zone of Proximal Development (ZPD). The MKO is one who has more knowledge about a topic than the learner and may be a teacher or more knowledgeable peer. The ZPD is a point in a learner's development where a task can be accomplished with help from the MKO, and lies between being unable to perform a task even with help, and being able to perform the task unassisted. In simulation, faculty attempt to present students with clinical situations they will at some time be expected to perform unassisted in their nursing role. During their educational programs, it is reasonable to expect that students are in the $\mathrm{ZPD}$, and that they require assistance in learning to become competent. Students are often anxious during this stage, and conscientious teachers must be understanding, supportive, and provide the assistance or scaffolding that students need. The recommendations described above by the focus group participants may be seen as the student perspective about ways to provide scaffolding for their learning.

As methods of scaffolding, the student recommendations for decreasing anxiety and improving learning ought to be considered. The validity of each of them was discussed by members of the focus group, and each one is possible, given the necessary 


\section{NURSING STUDENT ANXIETY IN SIMULATION SETTINGS}

space, time, staff, and faculty. Two recommendations have, in fact, already been implemented in this program: the provision of specific individual feedback postsimulation via a written, online form, and a link to skills videos in preparatory materials for students to review prior to their simulation session. A third recommendation, being able to call on peers for help, has been used by some groups of students in certain courses, but may need to be encouraged for all groups. Continued dialogue with students about facilitating their learning in simulation would be beneficial. A student/faculty simulation advisory group might be a venue in which this could be accomplished.

As identified in the NCSBN study, a large majority of nursing programs (87\%) in the United States are using simulation experiences in their courses for teaching and assessment of procedures and skills, communication, decision-making, and team training. Nursing students benefit from simulation to varying degrees, and optimizing the learning for them is a faculty responsibility. This small-scale study investigated student perspectives regarding their learning in simulation and how that could be maximized. The student recommendations to decrease anxiety and improve learning were specific and thoughtfully discussed, and as such, are especially valuable.

Since simulation is implemented in different ways across the country, the results from this sample may not be applicable to a broad range of programs. The group model of simulation implementation, curricular integration, faculty expertise and perspectives, and student characteristics are some of the variables that differ from program to program. The quantitative data obtained in this study were valuable in identifying the student responses to various elements of the simulation experience, as implemented in this 


\section{NURSING STUDENT ANXIETY IN SIMULATION SETTINGS}

particular program. The qualitative data obtained in the open-ended survey questions and during the focus group were valuable as well. Although the recommendations for mechanisms to decrease anxiety and improve learning apply specifically to the program where the study took place, they are ideas that could potentially be applicable to students in other programs, and could certainly be examined elsewhere. Myers (2000), defended the use of small samples as well as qualitative research, particularly related to research in nursing education and practice, explaining that, "a small sample size may be more useful in examining a situation in depth from various perspectives, whereas a large sample would be inconsequential” (n.p.) Rather than being used to make generalizations, this study explored how a particular group of learners experiences and makes sense of their learning. The study, then, or at least the topic of the study, may be useful for faculty desiring to improve learning in their own program, specifically related to student anxiety.

\section{Suggestions for Additional Research}

Though many nurse educators value the integration of simulation in curricula, the nature of the simulation environment also makes it an ideal place for research. Variables can be controlled in simulation that cannot be controlled on a clinical unit. As Foronda, Liu, and Bauman (2013) explain, the simulation center should "be seen as a powerful research laboratory, overflowing with possibilities to provide important evidence to guide educators” (p. e6). Multiple possibilities exist for further research. Using the simulation lab as a setting, stress, anxiety, and learning in simulation need to be studied, along with ideas for how to keep anxiety, and therefore student learning, at an optimum level. 


\section{NURSING STUDENT ANXIETY IN SIMULATION SETTINGS}

\section{Measuring Anxiety}

Though no measurement of anxiety was used in this study, other researchers have used the Spielberger State Trait Anxiety Inventory (STAI) in identifying anxiety in simulation. Megel et al (2011), Gore, Hunt, Parker, and Raines (2011), and Szpak \& Kamek (2011), for instance, reported that when students participated in simulation prior to a clinical experience they had lower state anxiety scores when caring for real patients in clinical. Beischel (2011), however, found that anxiety, as measured on the STAI, did not affect cognitive learning outcomes. Had an anxiety measurement tool been used in this study, different data may have been discovered related to individual traits and impact on learning.

With further understanding of student responses, individualized interventions could be designed and implemented. As Palethorpe and Wilson (2011) explain, “anxiety is an idiosyncratic phenomenon," and "strategies that may help one individual may be counterproductive with another” (p. 435). Specific studies examining how often students are in the panic zone and which students are most at risk could be valuable, since there is evidence that learning ceases when students are experiencing panic. Studies in which interventions to move students out of the panic zones are tried and evaluated would be helpful. It may be interesting to study those students in the comfort zone as well, since they may not be taking the simulation experience seriously. Perhaps these students need an increased challenge or further orientation and preparation for simulation.

\section{Evaluating Interventions}




\section{NURSING STUDENT ANXIETY IN SIMULATION SETTINGS}

Additionally, any measures implemented to decrease anxiety or improve learning need to be studied for their impact and validity. Recommendations by students, although extremely valuable, are insufficient alone in determining the value of the measures, as most will require faculty and staff time, space, equipment and supplies, as well as other resources. Implementing mini-simulations, for instance, would necessitate creating scenarios in which a skill was embedded and finding the time in skills lab or clinical areas in which to allow students to engage in the practice, along with faculty and staff to set up and facilitate the session. Studies to measure student learning and performance based on the mini-simulations would be recommended. While we owe it to our students to provide the support they need to learn, we must justify the expense by demonstrating effectiveness or return on investment. The same would be true for an intervention such as video viewing by students after their simulation. Once a method was determined to provide this resource to students, their use of the video and potential improvements in skill or performance would need to be measured. This will involve an evaluation of student learning and performance, particularly as they relate to use of resources.

\section{Comparing Programs}

Some differences did emerge between students in different programs. Although the accelerated program and the more traditional three-year program present essentially the same baccalaureate nursing curriculum, there are differences in the way that curriculum is implemented. Student responses indicated that certain aspects of simulation (administering medications, working with medical equipment, and working with mannequins) cause more anxiety for students in the accelerated program. Specific studies 


\section{NURSING STUDENT ANXIETY IN SIMULATION SETTINGS}

investigating increased practice with medications and equipment and its effect on anxiety and performance would be helpful. It would be useful to discover whether this impacted students' performance as they moved into their nursing practice.

Since many students expressed concern about the time and requirements of the accelerated program, further studies on the accelerated program in general would be beneficial to faculty. A faculty “Accelerated Baccalaureate Curriculum committee” is currently examining pertinent issues. It is possible that simulation could be useful in different ways to help this group of students and studies could be designed to investigate this issue. Studying the student perspective on issues is particularly valuable, as adult learners have definite ideas on what they need in a learning environment.

\section{Faculty Development}

The study data revealed that faculty support and feedback are important to students in the simulation environment. The comments and suggestions made by clinical faculty and simulation faculty are valued and taken seriously by students. Study results need to be shared with clinical faculty and considered as simulation sessions are implemented in each course. Involvement of clinical faculty during scenario observations and sharing of feedback specific to each student could be reinforced, and the impact on student anxiety and learning could then be examined.

\section{Conclusion}

The findings of this study provide valuable insight on student learning in simulation. Because students often discuss their anxiety in the simulation setting, it was thought that they would provide important information for faculty wishing to improve the 


\section{NURSING STUDENT ANXIETY IN SIMULATION SETTINGS}

learning experience for them. This proved to be true, both in the survey and the focus group. The sincerity and straightforwardness which students demonstrated in their responses was appreciated and, in fact, necessary for the conclusions of this study.

While it is conceivable that the students with higher anxiety levels were more likely to participate in the study, their responses are valuable and their recommendations may help others who are struggling or who could benefit from further interventions. The general feeling of anxiety may be correlated with other personal qualities that were not measured in this study, or it may simply be a function of an individual's personality or preferred learning style. To individualize learning, it may be helpful to offer a "menu” of strategies to improve student learning; for example, offering skills reviews or practice simulations as optional activities. Because of the small size of the focus group, it may be helpful to provide more students with an opportunity to bring their thoughts and ideas to faculty, via, for instance, a student advisory board for simulation. The use of any support activities could be tallied, providing an indication of student preference. Further studies of differences between students in accelerated programs and those in traditional programs may also help identify the student support necessary to ensure success.

With the provision of safe patient care by expert nurses as the ultimate goal, nursing education research needs to focus on student learning and how that learning transfers to practice. This mixed methods study provided data that supports the use of simulation, and explains student anxiety as related to learning. Determining methods to implement and evaluate student suggestions will be the next step in advancing teaching through the use of simulation. 


\section{NURSING STUDENT ANXIETY IN SIMULATION SETTINGS}

\section{References}

Adamson, K. \& Prion, S. (2013). Reliability: Measuring internal consistency using Cronbach’s alpha. Clinical Simulation in Nursing, 9(5), e179-e180 http://dx.doi.org/10.1016/j.ecns.2012.12.001

Alinier, G., Hunt, B., Gordon, R., \& Harwood, C. (2006). Effectiveness of intermediate fidelity simulation training technology in undergraduate nursing education. Journal of Advanced Nursing, 54 (3), 359-369.

Anderson, J. M. \& Warren, J. B. (2011). Using simulation to enhance the acquisition and retention of clinical skills in neonatology. Seminars in Perinatology, 35, 5967. doi:10.1053/j.semperi.2011.01.004

Askham, P. (2008). Context and identity: exploring adult learners' experiences of higher education. Journal of Further and Higher Education, 32(1), 85-97.

Beischel, K. P. (2013). Variables affecting learning in a simulation experience: A mixed methods study. Western Journal of Nursing Research, 35(2), 226-247. doi: $10.1177 / 0193945911408444$

Blum, C. A., Borglund, S., \& Parcells, D. (2010). High-fidelity nursing simulation: Impact on student self-confidence and clinical competence. International Journal Of Nursing Education Scholarship, 7(1), Article 18 doi: 10:2202/1548-923X.2035

Brandon, A. \& All, A. Constructivism theory analysis and application to curricula. Nursing Education Perspectives, 31(2), 89-92.

Bransford, J. D., Brown, A. I., \& Cocking, R. R. (2000). How people learn: Brain, mind, experience, and school. Washington DC: National Academy Press. 


\section{NURSING STUDENT ANXIETY IN SIMULATION SETTINGS}

Bransford, J. D., \& Schwartz, D., L. (1999). Rethinking transfer: A simple proposal with multiple implications. Review of Research in Education, 24, 61-100. Published by: American Educational Research Association Stable URL: http://www.jstor.org/stable/1167267 Accessed: 19/04/2012 21:53

Brewer, E. P. (n.d.). Successful techniques for using human patient simulation in nursing education. Journal of Nursing Scholarship, 43(3), 311-317. doi: 10.1111/j.15475069.2011.01405.x

Cazzell, M., \& Rodriguez, A. (2011). Qualitative analysis of student beliefs and attitudes after an objective structured clinical evaluation: Implications for affective domain learning in undergraduate nursing education. Journal of Nursing Education, 50(12), 711-714.

Chappy, S., Jambunathan, J., \& Marnoch, S. (2010). Evidence-based curricular strategies to enhance BSN graduates’ transition into practice, Nurse Educator, 35(1) 20-24.

Clapper, T. C. (2010). Beyond Knowles: What those conducting simulation need to know about adult learning theory. Clinical Simulation in Nursing, 6(1), e7-e14. doi:10.1016/j.ecns.2009.07.003

Cordeau, M. A. (2010). The lived experience of clinical simulation of novice nursing students. International Journal for Human Caring, 14(2), 9-15.

Creswell, J. W. (2013). Qualitative inquiry \& research design: Choosing among five approaches. Thousand Oaks CA: Sage. 


\section{NURSING STUDENT ANXIETY IN SIMULATION SETTINGS}

Crider, M. C., \& McNiesh, S. C. (2011). Integrating a professional apprenticeship model with psychiatric clinical simulation. Journal of Psychosocial Nursing, 49(5), 4249. doi:doi:10.3928/02793695-20110329-01

Curtis, E. A., \& Redmond, R. (2007). Focus groups in nursing research. Nurse Researcher, 14(2), 25-37.

Dieckmann, P., Gaba, D., \& Rall, M. (2007). Deepening the theoretical foundations of patient simulation as social practice. Simulation in Healthcare, 2(3). 183-193. DOI: 10.1097/SIH.0b013e3180f637f5

Dillard, N., Sideras, S., Ryan, M., Carlton, K.H., Lasater, K., \& Sidtberg, L. (2009). A collaborative project to apply and evaluate the clinical judgment model through simulation. Nursing Education Perspectives, 30(2), 99-104.

Eggenberger, T., Keller, K., \& Locsin, R. Z. (2010). Valuing caring behaviors within simulated emergent nursing situations. International Journal for Human Caring, 14(2), 23-29.

Elfrink, V. L., Kirkpatrick, B., Nininger, J., \& Schubert, C. (2010). Using learning outcomes to inform teaching practices in human patient simulation. Nursing Education Perspectives, 31(2), 97-100.

Elfrink, V. L., Nininger, J., Rohig, L., \& Lee, J. (2009). The case for group planning in human patient simulation. Nursing Education Perspectives, 30(2), 83-86.

Eysenck, M. W., Derekshan, N., Santos, R., \& Calvo, M. G. (2007). Anxiety and cognitive performance: Attentional control theory. Emotion, 7(2), 336-353. DOI: $10.1037 / 1528-3542.7 .2 .336$ 


\section{NURSING STUDENT ANXIETY IN SIMULATION SETTINGS}

Fanning, R., \& Gaba, D. (2007). The role of debriefing in simulation-based learning. Simulation in Healthcare, 2(2), 115-125. DOI: 10.1097/SIH.0b013e3180315539

Foronda, C., Lie, S., \& Baumann, E. (2013). Evaluation of simulation in undergraduate nurse education: An integrative review. Clinical Simulation in Nursing. January 2013. http://dx.doi.org/10.1016/j.ecns.2012.11.003

Galloway, C. M. (2001). Vygotsky’s constructivism. M. Orey (Ed.), Emerging perspectives on learning, teaching, and technology. Retrieved from http://projects.coe.uga.edu/epltt/

Ganley, B. J., \& Linnard-Palmer, L. (2010). Academic safety during nursing simulation: Perceptions of nursing students and faculty. Clinical Simulation in Nursing, 8(2), e49-e57. doi:10.1016/j.ecns.2010.06.004

Gantt, L. (2013). The effect of preparation on anxiety and performance in summative simulations. Clinical Simulation in Nursing, 9, e25-e33. doi:10.1016/jecns.2011.07.004

Gonzales, R., Pietsch, T. T., Kozub, K., Cole, P., Nifras, R., Russell-Headley, K., Durhams, T., et al. (2010). Caring: Looking beyond simulations. International Journal for Human Caring, 14(2), 16-22.

Gore, T., Hunt, C. W., Parker, F., \& Raines, K. H. (2011). The effects of simulated clinical experiences on anxiety: Nursing students’ perspectives. Clinical Simulation in Nursing, 7, e175-e180.

Gropelli, T. M. (2010). Using active simulation to enhance learning of nursing ethics. Journal of Continuing Education in Nursing, 41(3), 104-105. 


\section{NURSING STUDENT ANXIETY IN SIMULATION SETTINGS}

Haas, B., Seckman, C., \& Rea, G. (2010). Incorporating cultural diversity and caring through simulation in a baccalaureate nursing program. International Journal for Human Caring, 14(2), 51-52.

Hamilton, C. (2010). The simulation imperative of end-of-life education. Clinical Simulation in Nursing. 6(4), e131-e138. Doi:10.1016/j.ecns.2009.08.002

Hayden J. (2010). Use of simulation in nursing education: National survey results. Journal of Nursing Regulation, 1(3), 52-57.

Hmelo-Silver, C. E., Duncan, R. G., \& Chinn, C. A. (2007). Scaffolding and achievement in problem-based and inquiry learning: A response to Kirschner, Sweller, and Clark. Educational Psychologist, 42(2), 99-107.

Howatson-Jones, I. L. (2007). Dilemmas of focus group recruitment and implementation: A pilot perspective. Nurse Researcher, 14(2), 7-17.

Hovanscek, M. (2007). Using Simulation in Nursing Education, in Jeffries, P.R. (Ed.) (2007). Simulation in nursing education: From conceptualization to evaluation. New York, NY: National League for Nursing.

Hsieh, H., \& Shannon, S. (2005). Three approaches to qualitative content analysis. Qualitative Health Research. 15: 1277 DOI: 10.1177/1049732305276687

Joëls, M., Pu, Z., Wieger, O., Oitzl, M. S., \& Krugers, H. (2006). Learning under stress: How does it work? TRENDS in Cognitive Sciences, 10(4), 152-158.

Johnson, B., \& Christensen, L. (2012). Educational research Quantitative, qualitative, and mixed approaches. Thousand Oaks CA: Sage Publications. 


\section{NURSING STUDENT ANXIETY IN SIMULATION SETTINGS}

Johnson, R. B., \& Onwuegbuzie, A. J. (2004). Mixed methods research: A research paradigm whose time has come. Educational Researcher, 33(7), 14-26.

DOI: 10.3102/0013189X033007014

Jonnasen, D. H. (1994). Thinking technology: Toward a constructivist design model. Educational Technology, 34(4), 34-37.

Kaakinen, J., \& Arwood, E. (2009). Systematic review of nursing simulation literature for use of learning theory. International Journal of Nursing Education Scholarship, 6(1). doi:DOI: 10.2202/1548-923X.168

Kaddoura, M. A. (2010). New nurses’ perceptions of the effects of clinical simulation on their critical thinking, learning, and confidence. Journal of Continuing Education in Nursing, 41(11), 506-516.

Kameg, K., Mitchell, A. M., Clochesy, J., Howard, V. M., \& Suresky, J. (2009).

Communication and human patient simulation in psychiatric nursing. Issues in Mental Health Nursing, 30, 503-508. DOI: 10.1080/01612840802601366

Kirschner, P. A., Sweller, J., \& Clark, R. E. (2006). Why minimal guidance during instruction does not work: An analysis of the failure of constructivist, discovery, problem-based, experiential, and inquiry-based teaching. Educational Psychologist, 41(2), 75-86.

Knowles, M. S., Holton, E. F., \& Swanson, R. S. (2005). The adult learner. (6th ed.). Burlington MA: Elsevier.

Kohn, L., Corrigan, J., \& Donaldson, N., Eds. (2000). Committee on Quality of Health Care in America, Institute of Medicine, National Academies Press, ISBN: 0-309- 


\section{NURSING STUDENT ANXIETY IN SIMULATION SETTINGS}

51563-7. Retrieved from

http://www.iom.edu/ /media/Files/Report\%20Files/1999/To-Err-is-

Human/To\%20Err\%20is\%20Human\%201999\%20\%20report\%20brief.pdf

Lasater, K. (2007). High-Fidelity Simulation and the development of clinical judgment: students' experiences. Journal of Nursing Education, 46(6), 269-276.

Levine, G. (2008). A Foucaultian approach to academic anxiety. Educational Studies, 44, $62-76$.

Lutz, S., \& Huitt, W. (2004). Connecting cognitive development and constructivism: Implications from theory for instruction and assessment. Constructivism in the Human Sciences, 9(1), 67-90.

Marshall, C., \& Rossman, G. B. (2011). Designing qualitative research. Thousand Oaks CA: Sage.

Megel, M. E., Black, J., Clark, L., Carstens, P., Jenkins, L., Promes, J., Snelling, M., et al. (2011). Effect of high-fidelity simulation on pediatric nursing students’ anxiety. Clinical Simulation in Nursing, 8(9), e419-e428 doi:10.1016/j.ecns.2011.03.00

Meyer, M. N., Connors, H., Hou, Q., \& Gajewski, B. (2011) The effect of simulation on clinical performance, Simulation in Healthcare, 6(5), 269-277. doi:10.1097/SIH.0b013e318223a048

Morgan, D., L. (1997). Focus groups as qualitative research. Thousand Oaks CA: Sage. Morton, P.G.(1995). Creating a laboratory that simulates the critical care environment. Critical care Nurse, 16(6), 76-81. 


\section{NURSING STUDENT ANXIETY IN SIMULATION SETTINGS}

Muller, M. P., Hansel, M., Fichtner, A., Hardt, F., Weber, S., Kirschbaum, C., Ruder, S., et al. (2009). Excellence in performance and stress reduction during two different full scale simulator training courses: A pilot study. Resuscitation, 80, 919-924. doi:10.1016/j.resuscitation.2009.04.027

Myers, M. (2000). Qualitative research and the generalizability question: standing firm with Proteus. Qualitative Reports 2000: 4(3/4) n.p. http://www.nova.edu/ssss/QR/QR4-3/myers.html.n.p. Published March 2000. Accessed March 3, 2013.

Nehring, W. M., \& Lashley, F. R. (2009). Nursing simulation: A review of the past 40 years. Simulation \& Gaming, 40(4), 528-552. DOI: 10.1177/1046878109332282

Nehring, W. M., \& Lashley, F. R. (2010). High-Fidelity Patient Simulation in Nursing Education. Sudbury, MA: Jones and Bartlett.

Nestel, D., Groom, J., Eikeland-Husebo, S., \& O'Donnell, J. (2011). Simulation for learning and teaching procedural skills: The state of the science. Simulation in Healthcare, 6(7), S10-S13. DOI: 10.1097/SIH.0b013e318227ce

Orb, A., Eisenhauer, L., \& Wynaden, D. (2000). Ethics in qualitative research. Journal of Nursing Scholarship, 33(1), 93-96.

Palethorpe, R. J., \& Wilson, J. P. (2011). Learning in the Panic Zone: Strategies for managing learner anxiety. Journal of European Industrial Training, 35(5), 420438. DOI 10.1108/03090591111138008 


\section{NURSING STUDENT ANXIETY IN SIMULATION SETTINGS}

Parker, B., \& Myrick, F. (2012). The pedagogical ebb and flow of human patient simulation: Empowering through a process of fading support. Journal of Nursing Education, 51(7), 365-372. doi:10.3928/01484834-20120509-01

Reed, C. C., Lancaster, R. R., \& Musser, D. B., (2009). Nursing leadership and management simulation creating complexity. Clinical Simulation in Nursing, 5(1), e17-e21.

Reising, D. L., Carr, D. E., Shea, R. A., \& King, J. M. (2011). Comparison of communication outcomes in traditional versus simulation strategies in nursing and medical students. Nursing Education Perspectives, 32(5), 323-327.

Rieber, L. P. (1992). Computer-based microworlds: A bridge between constructivism and direct instruction. Educational Technology Research \& Development, 40(1), 93106. doi: 10:10.1007/BF02296709

Sappington, T. E. (1984). Creating learning environments conducive to change: The role of fear/safety in the learning process. Innovative Higher Education, 9(1), 19-29.

Schiavenato, M. (2009). Reevaluating simulation in nursing education: Beyond the human patient simulator. Journal of Nursing Education, 48(7), 388-394. doi:10.3928/01484834-20090615-06

Schoening, A. M., Sittner, B. J., \& Todd, M. J. (2006). Simulated clinical experience nursing students’ perceptions and the educators’ role. Nurse Educator, 31(6), 253258. 


\section{NURSING STUDENT ANXIETY IN SIMULATION SETTINGS}

Sears, K., Goldsworthy, S., \& Goodman, W. M. (2010). The relationship between simulation in nursing education and medication safety. Journal of Nursing Education, 49(1), 52-55.

Selye, H. (1950). The Stress of Life. New York, NY: McGraw-Hill.

Serrant-Green, L. (2007). The challenges and opportunities offered by focus groups. Nurse Researcher, 14(2), 3.

Sim, J. (1998). Collecting and analysing qualitative data: Issues raised by the focus group. Journal of Advanced Nursing, 28(2), 345-352.

Sinclair, B., \& Ferguson, K. (2009). Integrating simulated teaching/learning strategies in undergraduate nursing education. International Journal of Nursing Education Scholarship, 6(1). DOI: 10.2202/1548-923X.167

Smith-Stoner, M. (2009). Using high-fidelity simulation to educate nursing students about end-of-life care. Nursing Education Perspectives, 30(2), 115-120.

Sogunro, O. A. (1998). Impact of evaluation anxiety on adult learning. Journal of Research and Development in Education, 31(2), 109-120.

Stefanski, R. R., \& Rossler, K. L. (2009). Preparing the novice critical care nurse: A community-wide collaboration using the benefits of simulation. Journal of Continuing Education in Nursing, 40(10), 443-451.

Storr, G. B., (2010). Learning how to effectively connect with patients through low-tech simulation scenarios. International Journal for Human Caring, 14(2), 36-40. 


\section{NURSING STUDENT ANXIETY IN SIMULATION SETTINGS}

Szpak, J. L., \& Kameg, K. M. (2011). Simulation decreases nursing student anxiety prior to communication with mentally ill patients. Clinical Simulation in Nursing, e1e7, .doi:10.1016/j.ecns.2011.07.003

Thomas, M. M., (2006). The draw a scientist test: A different population and a somewhat different story. College Student Journal, 40(1), 140-148.

Wagner, D., Bear, M., \& Sander, J. (2009). Turning simulation into reality: Increasing student competence and confidence, Journal of Nursing Education, 48(8), 465467. doi:10.3928/01484834-20090518-07

Walton, J., Chute, E., \& Ball, L. (2011). Negotiation the role of the professional nurse: The pedagogy of simulation: a grounded theory study. Journal of Professional Nursing, 27(5), 299-310. doi:doi:10.1016/j.profnurs.2011.04.005

Weaver, A. (2011). High-fidelity patient simulation in nursing education: An integrative review. Nursing Education Perspectives, 32(1), 37-40.

Zoladz, P., \& Diamond, D. (2009). Linear and non-linear dose-response functions reveal a hormetic relationship between stress and learning, Dose-Response, 7,132-148, DOI: 10.2203/dose-response.08-015.Zoladz 


\section{NURSING STUDENT ANXIETY IN SIMULATION SETTINGS}

Appendix A: Informed Consent for Research Study, Survey

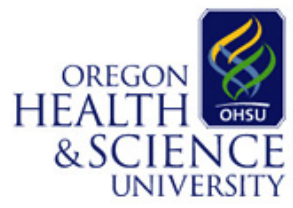

\section{P Portland State}

Informed Consent for Research Study: Survey

"Understanding Nursing Student Anxiety in Simulation Settings"

Researcher: Mary L. Cato

You are invited to participate in a research study conducted by Mary L. Cato, doctoral student at Portland State University, Graduate School of Education. The researcher hopes to learn more about the anxiety students experience in simulation, and how it affects their learning. This study is being conducted in partial fulfillment of the requirements for a doctoral degree in Higher Education Leadership at Portland State University, and is under the supervision of Dr. Candyce Reynolds, faculty at Portland State University. You were selected as a possible participant in this study because you are currently enrolled in a nursing program at Oregon Health \& Science University, and you have participated in simulation as part of your nursing coursework.

If you decide to participate, you will be asked to take a survey that will be administered online, and that will ask you to rate a number of items that may cause anxiety in simulation. While participating in this study, it is possible that you will be reminded of experiences that were uncomfortable for you or your colleagues in simulation. You will not be asked to provide your name or any other details identifying your personal experiences in simulation. There are no other risks to your participation in the survey, which should take less than 20 minutes to complete. You may not receive any direct benefit from taking part in this study, but the study may help increase knowledge to help others in the future. After the survey results have been tabulated, you may be asked to participate in voluntary focus groups designed to obtain further information about simulation and anxiety.

Any information that is obtained in connection with the survey portion of this study and that can be linked to you will be kept confidential. This information will be kept confidential by being stored on a password protected computer. Survey responses will be stored electronically and kept in a secure data base for a minimum of three years.

Your participation is voluntary. You do not have to take part in this study, and it will not affect your course grades at Oregon Health \& Science University. You may also 


\section{NURSING STUDENT ANXIETY IN SIMULATION SETTINGS}

withdraw from this study at any time without affecting your standing with Oregon Health \& Science University.

If you have questions or concerns about your participation in this study, contact Mary L. Cato, Assistant Professor, at Oregon Health \& Science University Simulation and Clinical Learning Center, 2525 SW $1^{\text {st }}$ Avenue, Portland OR. If you have concerns about your rights as a research subject, please contact Research and Strategic Partnerships, Market Center Building $6^{\text {th }}$ floor, Portland State University, (503) 725-4288.

Your signature indicates that you have read and understand the above information and agree to take part in this study. The researcher should provide you with a copy of this form for your own records.

Signature Date

Print name 


\title{
NURSING STUDENT ANXIETY IN SIMULATION SETTINGS
}

\author{
Appendix B: Survey
}

\section{Simulation Survey : Mary Cato}

Simulation is often a powerful learning experience, and some students report that the clinical simulation in their nursing program causes a variety of emotional responses. These responses may affect the learning that occurs in simulation. The items on this survey describe various aspects or elements of simulation. Think about how each of these items affects your feelings while you are engaged in simulation learning activities. You may be engaged in several of these activities at once, but consider the effect of each single item and how it contributes to your feelings. Mark the response that most closely explains your reaction to each item.

RESPONSES: Very confident, Moderately confident, Neutral, Slightly anxious, Very anxious

GENERAL DIRECTIONS (EACH PAGE): Think about how each of these aspects of simulation affects your feelings while you are engaged in simulation activities. Mark the response that most closely explains your reaction.

\section{ITEMS:}

\section{Before Simulation}

1. The preparation before simulation contributes to my feeling_: (Select response)

\section{During Simulation}

2. Caring for a patient in the simulation room environment contributes to my feeling :

3. Working with the medical equipment in the simulation room contributes to my feeling__:

4. Distinguishing between what is real and what is simulated (like patient assessment data or operation of equipment) contributes to my feeling _ :

5. When working with the mannequin I feel__:

6. When working with a live actor or standardized patient I feel__:

7. Being "on camera” contributes to my feeling__:

8. Caring for a patient with my team contributes to my feeling_ :

9. When I call a physician or other provider on the phone I feel__:

10. When making a decision about the patient I feel_:

11. When administering medications I feel__:

12. Performing in front of my peers contributes to my feeling_: 


\section{NURSING STUDENT ANXIETY IN SIMULATION SETTINGS}

13. Performing in front of faculty contributes to my feeling_:

14. The possibility of making a mistake contributes to my feeling_:

15. When making decisions for the patient I feel__:

16. When observing other students in the simulation room I feel__:

\section{During Debriefing}

17. When I receive feedback from my peers I feel__:

18. When I receive feedback from faculty I feel__:

\section{Summary}

19. My general feeling during the entire simulation experience is__:

Please describe anything else about simulation that has helped you feel confident.

Please describe anything else about simulation that has caused anxiety for you.

Now, to complete the survey, please answer a few questions about yourself.

\section{Program and term in which you are currently enrolled}

D1. Accelerated Baccalaureate Program

$$
2^{\text {nd }} \text { quarter } \quad 5^{\text {th }} \text { quarter }
$$

3-Year Program

Junior Senior

D2. I have a previous degree (prior to entering my nursing program): (Check all that apply) 


\section{NURSING STUDENT ANXIETY IN SIMULATION SETTINGS}

No previous degree

Associate’s degree

Bachelor's degree

Master’s degree

Other advanced degree

\section{D3. I have previous work experience: (Check all that apply)}

In healthcare

In social services

In public speaking or performing

Interacting with the public

Other experience

\section{D4. Gender}

Male

Female

Other

D5. Age

$20-29 \quad 30-39 \quad 40-49 \quad 50-59 \quad 60-69$

D6. How long did it take you to complete this survey?

Thank you for participating in this survey. 


\section{NURSING STUDENT ANXIETY IN SIMULATION SETTINGS}

Appendix C: Informed Consent for Research Study, Focus Group
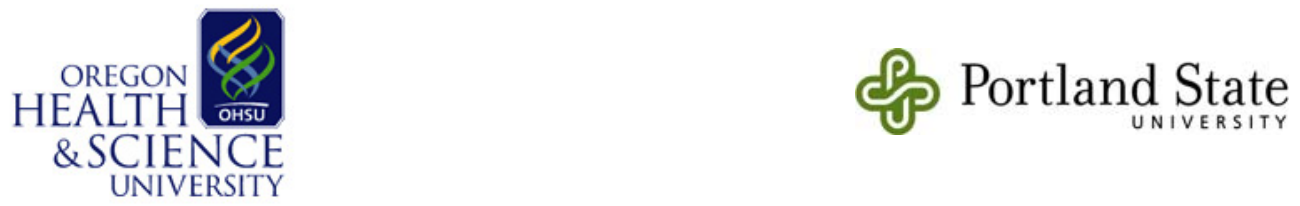

Informed Consent for Research Study: Focus Group

"Understanding Nursing Student Anxiety in Simulation Settings”

Researcher: Mary L. Cato

You are invited to participate in a research study conducted by Mary L. Cato, doctoral student at Portland State University, Graduate School of Education. The researcher hopes to learn more about the anxiety students experience in simulation, and how it affects their learning. This study is being conducted in partial fulfillment of the requirements for a doctoral degree in Higher Education Leadership at Portland State University, and is under the supervision of Dr. Candyce Reynolds, faculty at Portland State University. You were selected as a possible participant in this study because you are currently enrolled in a nursing program at Oregon Health \& Science University, and you have participated in simulation as part of your nursing coursework.

If you decide to participate, you will be asked to take part in one focus group with other Oregon Health \& Science University nursing students. The focus group will be facilitated by a moderator who is not a nursing faculty member at Oregon Health \& Science University. The topics of discussion for the focus group will be anxiety and learning in simulation. The focus group will be audio recorded, and the recording will be evaluated by the researcher. Students will not be asked to use their names in the focus groups, and will not be identified by name in any information related to the study. The recorded discussion of the focus group will be transcribed and analyzed for content and themes.

While participating in this study, it is possible that you will be reminded of experiences that were uncomfortable for you or your colleagues in simulation. You will not be asked to provide your name or any other details identifying your personal experiences in simulation. There are no other risks to your participation in the focus groups, which will take approximately 90 minutes. You may not receive any direct benefit from taking part in this study, but the study may help increase knowledge about anxiety and learning in simulation that may help others in the future. There will be no compensation for participation in the focus group, but participants will receive a gift card from a local coffee shop in appreciation for their participation.

Any information that is obtained in connection with the focus group and that can be 


\section{NURSING STUDENT ANXIETY IN SIMULATION SETTINGS}

linked to you or identify you will be kept confidential by the researcher. Confidentiality among the focus group members themselves, however, cannot be guaranteed, as the researcher has no control over the information that may be discussed by participants after the focus group has concluded. Participants will be asked to respect each other's privacy by not discussing the conversation of those who attended the group.

Your participation is voluntary. You do not have to take part in this study, and it will not affect your course grades at Oregon Health \& Science University. You may also withdraw from this study at any time without affecting your grades or your standing with Oregon Health \& Science University.

If you have questions or concerns about your participation in this study, contact Mary L. Cato, Assistant Professor, at Oregon Health \& Science University Simulation and Clinical Learning Center, 2525 SW $1^{\text {st }}$ Avenue, Portland OR, phone number 503-4949497, email catom@ohsu.edu. If you have concerns about your rights as a research subject, please contact Research and Strategic Partnerships, Market Center Building $6^{\text {th }}$ floor, Portland State University, (503) 725-4288.

Your signature indicates that you have read and understand the above information and agree to take part in this study. This means that you are agreeing to be audio recorded in the focus group, and to potentially have your anonymous direct quotes included in the reporting of the focus groups. The researcher should provide you with a copy of this form for your own records.

\section{Signature Date}

\section{Print name}

